SYSTEMS ENGINGEERING ANALYSIS AND DIGITAL COMMUNICATION BUS DESIGN FOR THE CAL POLY SUPER PROJECT

\author{
A Thesis \\ Presented to the Faculty of \\ California Polytechnic State University, \\ San Luis Obispo
}

\author{
In Partial Fulfillment \\ of the Requirements for the Degree of \\ Master of Science in Electrical Engineering
}

by

Matt Marcus Camack

June 2010 
(C) 2010

Matt Marcus Camack

ALL RIGHTS RESERVED 


\section{Committee Membership}

Title:

Author:

Date Submitted:

Committee Chair:

Committee Member:

Committee Member:
Systems Engineering Analysis and Digital Communication Bus

Design for the Cal Poly SuPER Project

Matt Marcus Camack

June 2010
Dr. Ali Shaban, Professor, Electrical Engineering

Dr. Daniel Waldorf, Professor, Industrial and Manufacturing

Engineering 


\title{
Abstract \\ Systems Engineering Analysis and Digital Communication Bus Design for the Cal Poly SuPER Project
}

\author{
Matt Marcus Camack
}

With an expected lifetime of 20 years and an expected cost of $\$ 500$, the Cal Poly Sustainable Power for Electrical Resources (SuPER) project needed a strong central design. This thesis looks at the work completed by students over the previous 5 years, with an eye on the future, to create the phase 2 design. Part of this new structure focuses on a distributed communication bus for monitoring system health and status. Instead of complex and costly computer or FPGA systems, the new system will run solely with microcontrollers. This reduces costs and will hopefully still be used within 5,10 , and 20 years as the number of embedded devices continues to grow globally. The new system design was created using many systems engineering tools and benchmarks, including: requirements breakdown, hardware interfacing, software interfacing, safety, reliability, maintainability, and cost. Major components have been broken down into subsystems with well-defined requirements for implementation. These smaller projects can be completed by future team members as senior projects, independent work, or even Master's theses. Upon test and integration, these subsystems will come together into a fieldready model to help bring power to the two billion people on Earth lacking it. 


\section{Table of Contents}

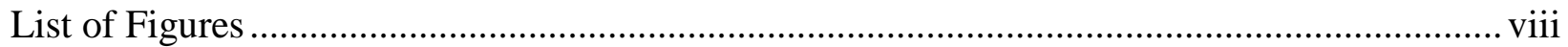

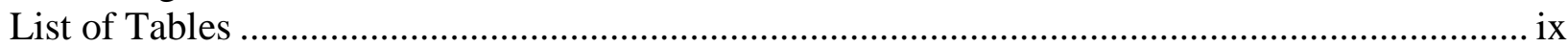

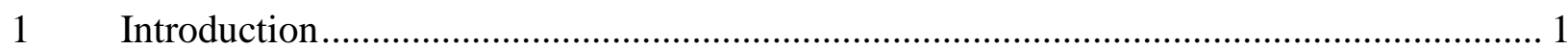

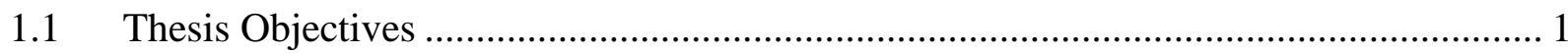

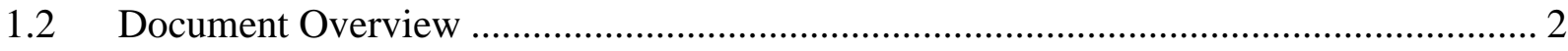

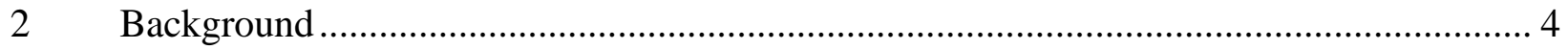

2.1 The Case for the SuPER System ...................................................................... 4

2.2 Solar and Wind Energy Availability .............................................................. 5

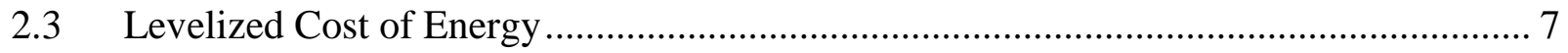

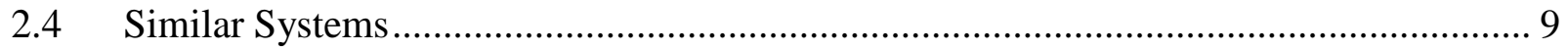

2.4.1 Comparable Projects in Academia ............................................................. 9

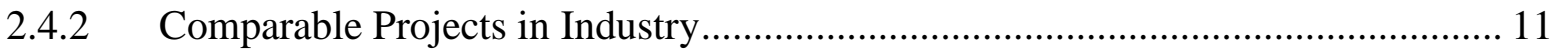

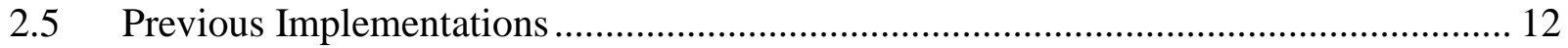

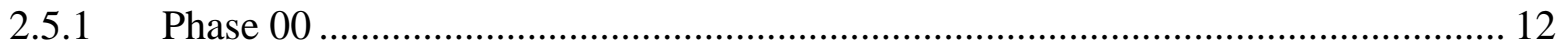

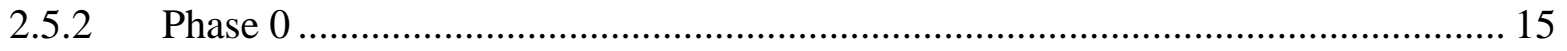

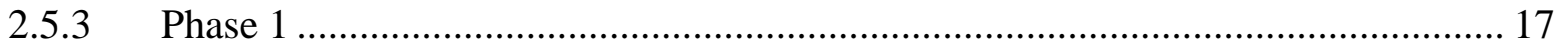

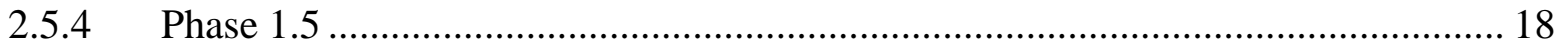

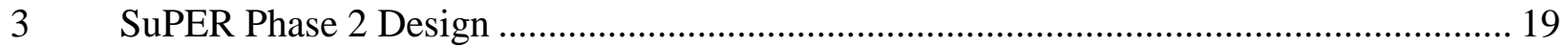

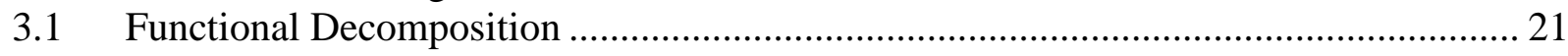

3.2 Operating System and FPGA Disadvantages ..................................................... 23

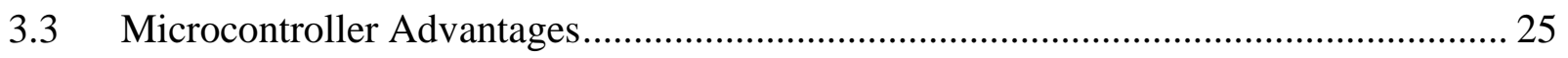

3.4 Digital Communication Bus Selection.................................................................. 26

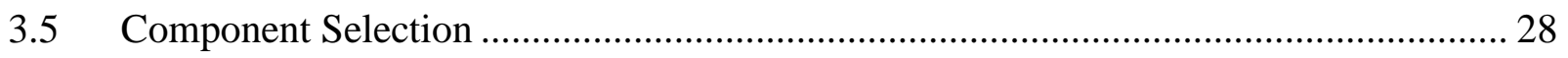

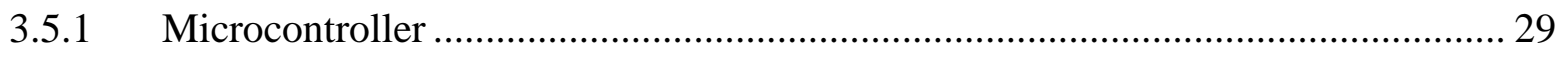

3.5.2 Control Switches ................................................................................ 31

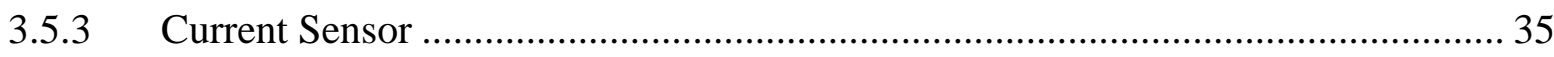

3.5.4 Voltage Scaling ....................................................................................... 36

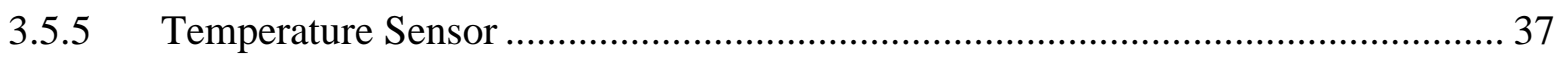

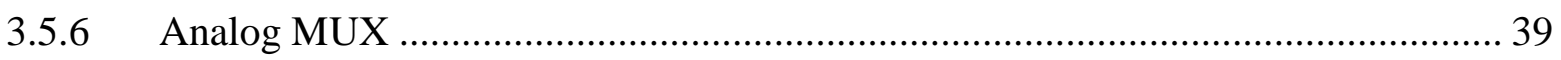

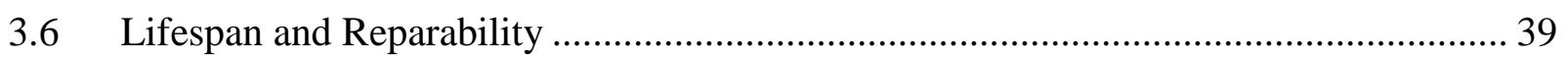

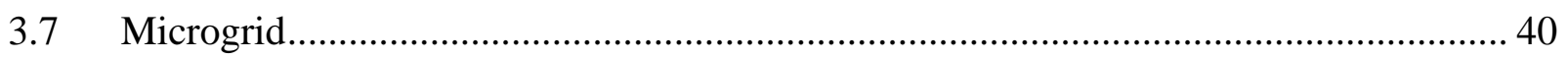

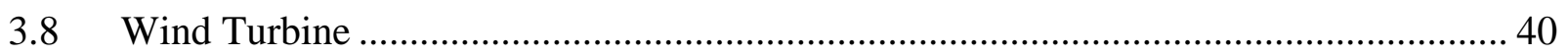

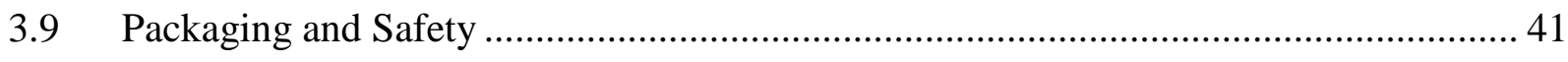

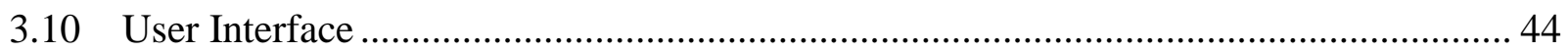




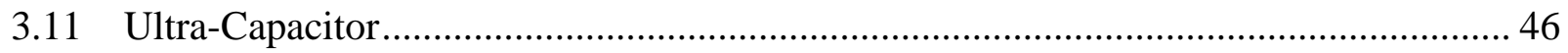

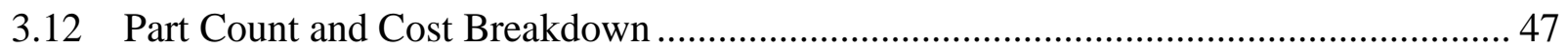

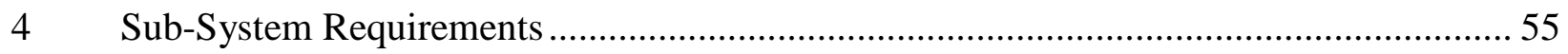

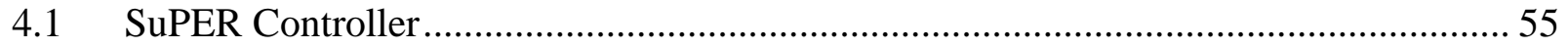

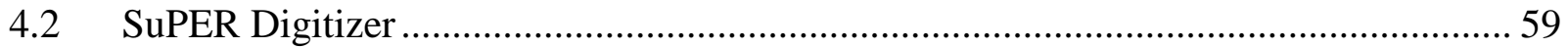

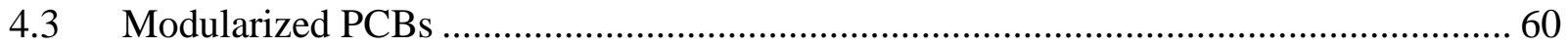

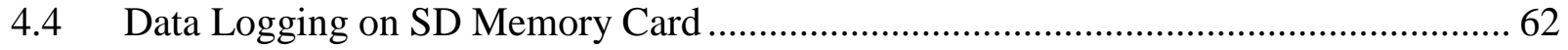

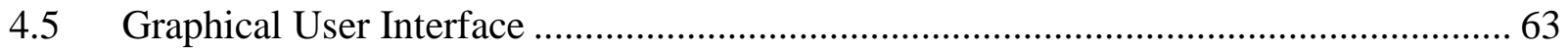

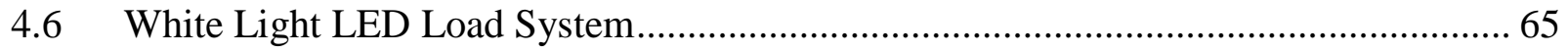

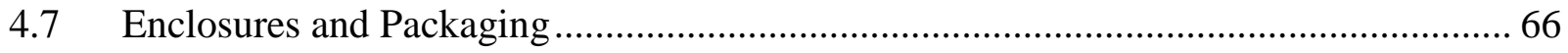

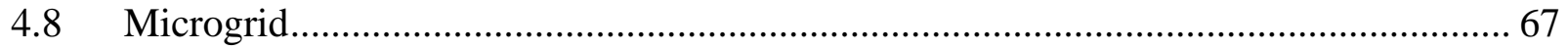

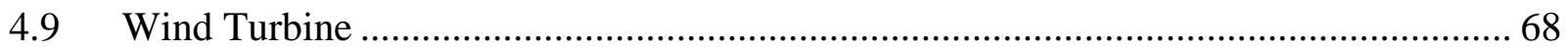

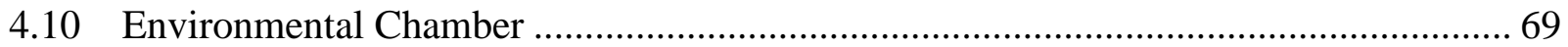

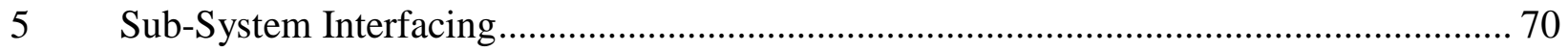

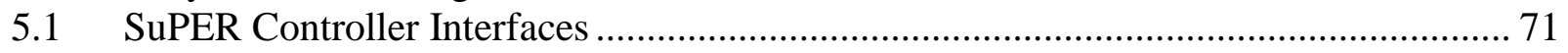

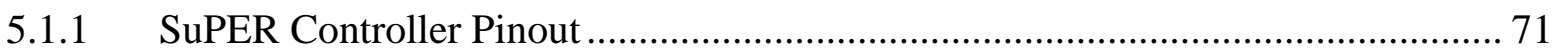

5.1.2 SuPER Controller-to-SuPER Digitizer Description ............................................. 72

5.1.3 SuPER Controller-to-DC-DC Converter Description ........................................... 73

5.1.4 SuPER Controller-to-SD Memory Card Description ............................................. 74

5.1.5 SuPER Controller-to-Laptop Description ………….......................................... 75

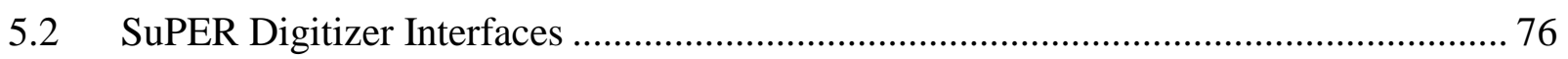

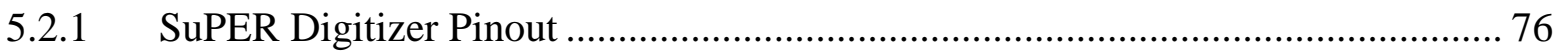

5.2.2 SuPER Digitizer -to- SuPER Controller Description ................................................. 80

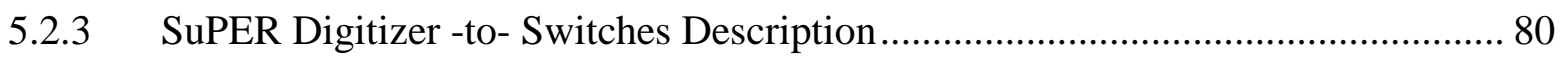

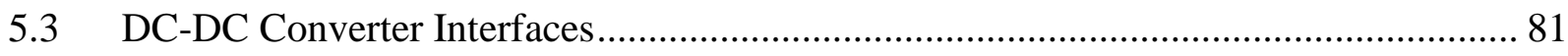

5.3.1 DC-DC Converter -to- SuPER Controller Description ......................................... 81

5.3.2 DC-DC Converter -to- PV Panel Description ......................................................... 81

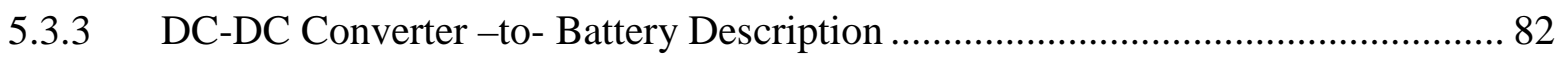

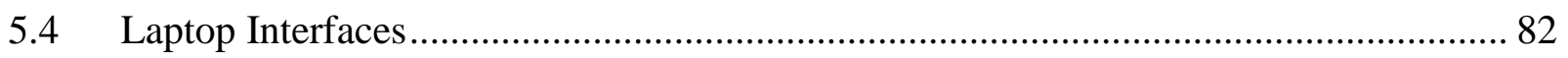

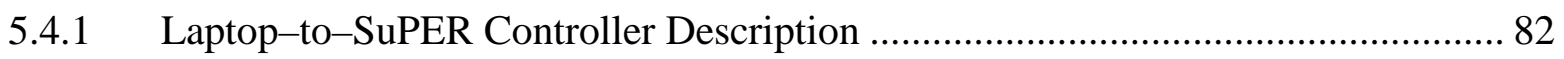

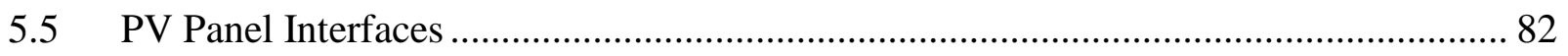

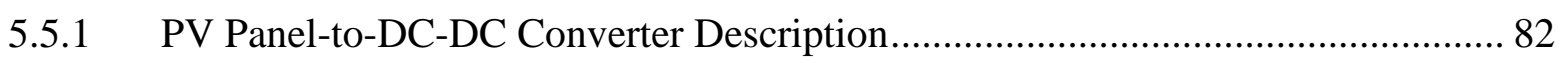

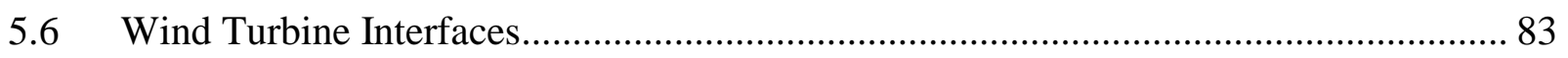

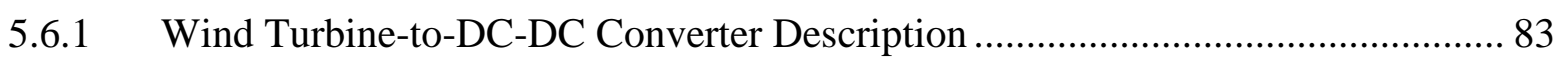

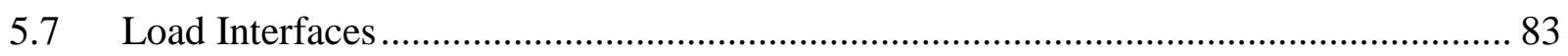




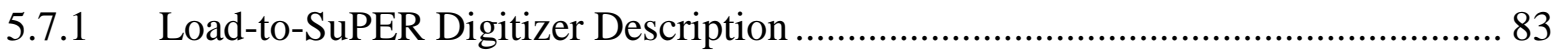

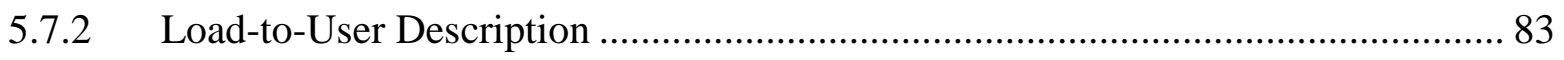

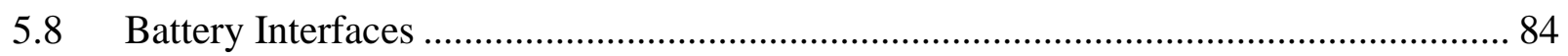

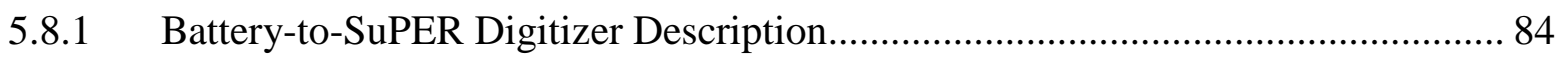

5.8.2 Battery-to-Ultra Capacitor Description.............................................................. 84

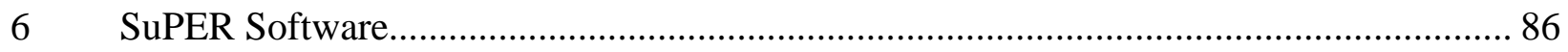

6.1 Charge Controller and Simulation Software Description ……..................................... 86

6.2 SuPER Controller Software Description.................................................................... 87

6.2.1 SuPER Controller-to-DC-DC Converter API ........................................................ 90

6.2.2 SuPER Controller-to-SD Memory Card API.......................................................... 91

6.2.3 SuPER Controller-to-Laptop API ..................................................................... 91

6.2.4 SuPER Controller-to-SuPER Digitizer API......................................................... 92

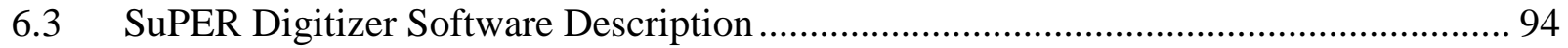

6.3.1 SuPER Digitizer-to-SuPER Controller API......................................................... 95

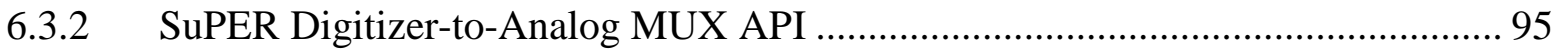

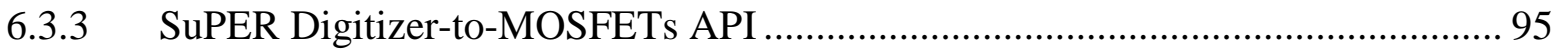

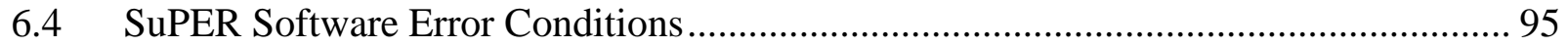

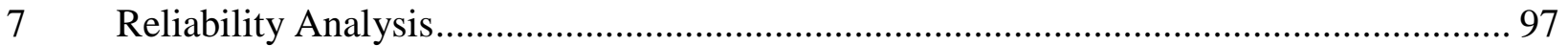

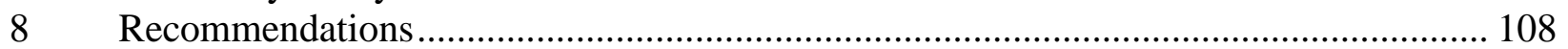

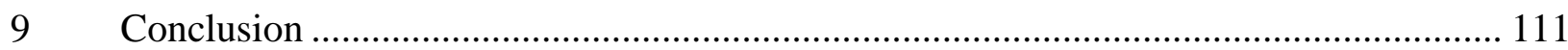

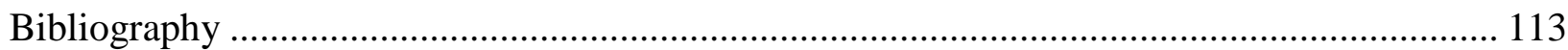

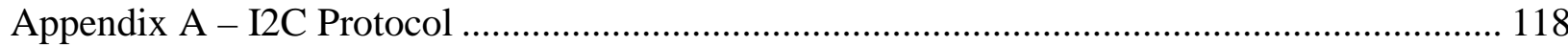

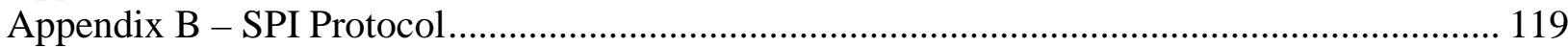

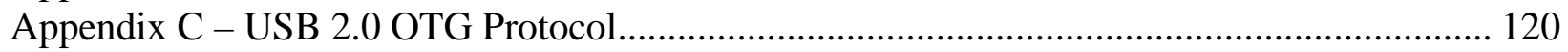

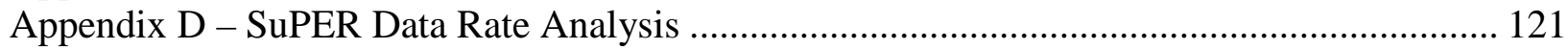

Appendix E - Charge Controller 'C' Code.......................................................................... 125

Appendix F - Student Project Descriptions...................................................................... 127

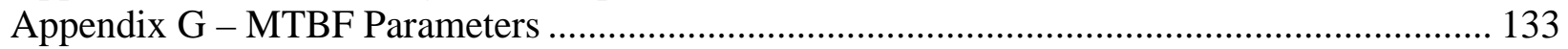

Appendix H - Getting Started with the SuPER Project............................................................... 137

Appendix I - Analysis of Senior Project Design ........................................................................ 138 


\section{List of Figures}

Figure 2-1 - Solar Energy Zones Based on Latitude [30] .................................................... 5

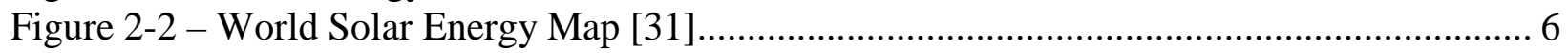

Figure 2-3 - Solar Cell Efficiencies [42] ...................................................................... 7

Figure 2-4 - Levelized Cost of Energy for Various Energy Production Methods [35]................. 8

Figure 2-5 - SuPER Phase 00 System Diagram ........................................................... 14

Figure 2-6 - SuPER Phase 0 System Diagram ................................................................ 16

Figure 2-7 - SuPER Phase 1 System Diagram .................................................................. 17

Figure 3-1 - SuPER Phase 2 System Diagram .............................................................. 20

Figure 3-2 - SuPER Functional Decomposition........................................................... 22

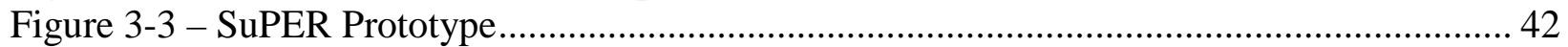

Figure 3-4 - Circuit breaker on SuPER phase 1.5 ......................................................... 43

Figure 3-5 - Power flow through manual breaker box ....................................................... 44

Figure 3-6 - User Interface software flowchart ............................................................. 45

Figure 3-7 - Battery Terminal Voltage at DC Motor In-Rush ............................................ 46

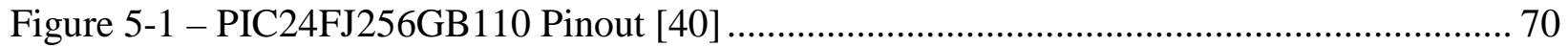

Figure 5-2 - Secure Digital Card with Pin Numbers [24] ................................................... 74

Figure 5-3 - Analog MUX IC Pinout [43].................................................................... 79

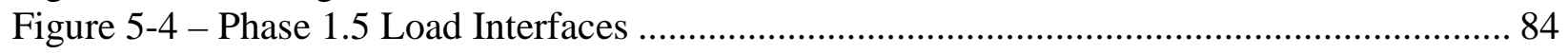

Figure 5-5 - Switch Locations for Controlling Power Flow ................................................. 85

Figure 6-1 - Communication Schemes between the SuPER Subsystems ................................ 88

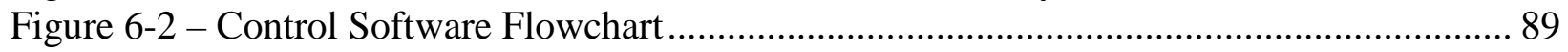

Figure 6-3 - Controller USB 2.0 OTG Software Flowchart ................................................. 90

Figure 6-4 - Controller to DC-DC Converter Example Software Description .......................... 90

Figure 6-5 - Controller to SD Memory Card Example Software Description .......................... 91

Figure 6-6 - Controller to Laptop Example Software Description............................................ 92

Figure 6-7 - Controller to Digitizer Example Software Description....................................... 93

Figure 6-8 - Digitizer Software Flowchart .................................................................... 94

Figure 7-1 (a,b,c) - Risk Priority Number Rating Scales [27] ........................................... 102

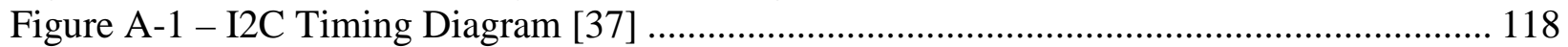

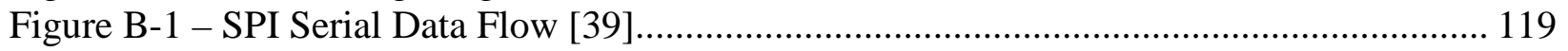

Figure B-2 - SPI Timing Diagram [38] .................................................................... 119 


\section{List of Tables}

Table 3-1 - Digital Communication Bus Selection ...................................................... 28

Table 3-2 - Microcontroller Selection ............................................................................ 31

Table 3-3 - Control Switch Selection ............................................................................. 33

Table 3-4 - Previous MOSFETs Used on SuPER ................................................................. 35

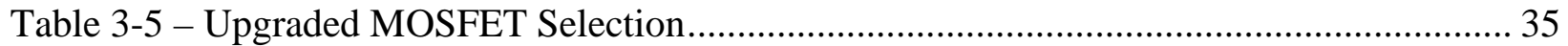

Table 3-6 - Current Sensor Selection .............................................................................. 36

Table 3-7 - Temperature Probe Selection ............................................................................ 38

Table 3-8 - SuPER Parts List and Cost Breakdown for Phase 1.5 ......................................... 49

Table 3-9 - SuPER Parts List and Cost Breakdown for Phase 2 ............................................. 53

Table 5-1 - Printed Circuit Assembly Microcontroller Pinout for Controller.............................. 72

Table 5-2 - Secure Digital Pinout [25] ........................................................................ 74

Table 5-3 - Printed Circuit Assembly Microcontroller Pinout for Digitizer.............................. 77

Table 5-4 - SuPER Digitizer Board MOSFET Pinouts .................................................... 78

Table 5-5 - Analog MUX Pinout on Digitizer Board .......................................................... 79

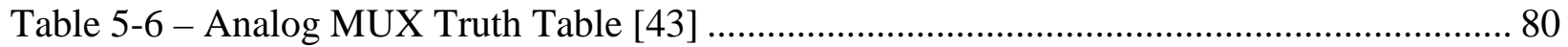

Table 5-7 - Switch Control for Ultra-capacitor Modes...................................................... 85

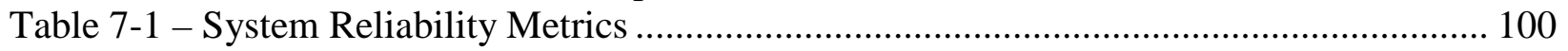

Table 7-2 - Failure Modes and Effects Analysis (FMEA) ................................................. 103

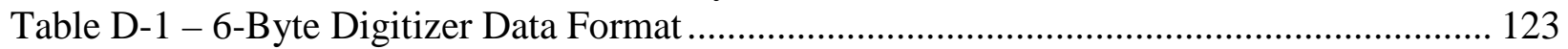

Table G-1 - System Reliability Parameters and Sources .................................................... 133 


\section{Introduction}

\subsection{Thesis Objectives}

The main goal of my thesis is to provide a redesigned SuPER system that can be easily maintained over the 20 year life expectancy. In the past, projects have been added to the system at-will without clear regards to any final system design. Many issues arise in a situation like this when the projects aren't formerly defined, the interfaces aren't congruent, and things are poorly documented. For a smaller system, it may be possible to get away with this, but as SuPER becomes more complex it yearns for a cohesive model to be built from. My thesis will modularize these sub-systems so they can be completed by any students at any time, but still have a central organization to work towards for implementation.

My goals on the SuPER project have been to gain experience as a systems engineer and to push SuPER towards a finished product that could help the 2 billion people in the world without electricity. As a future systems engineer in the aerospace/defense sector, I wanted to learn as much as possible about the processes needed to succeed on a complex project. Anybody can learn the theoretical side, but real project based learning is the best of all. Working on SuPER would allow me to use my prior computer engineering undergraduate work and electrical engineering graduate knowledge to make systems level decisions on a project with many complex devices I had never worked with before. This project based learning would in turn push the SuPER project closer to a final design that could be field tested at the Cal Poly Organic Farm before deployment in developing nations.

This thesis uses many systems engineering tools to perform a complete system analysis. A functional decomposition was completed to find out what was actually needed and then 
requirements were developed for the sub-systems that would accomplish these functions. Interfaces were defined so projects could be modularized, but eventually fit together when they are all completed. Reliability and risk analyses were done to find where failures could occur during the 20 year lifespan. Testing and integration plans have been developed for the subsystems to ensure they successfully meet the system requirements.

Another large part of this thesis is a digital communications bus which will be used to send data and commands throughout the system. This will allow for more error free operation and maintenance of the system. Recommendations are given for how future students working on SuPER will be able to implement or improve its design. Overall, my goals were to redesign system elements to be more reliable and easily maintainable over the lifetime of the system.

\subsection{Document Overview}

Chapter 2 contains a background on why the SuPER system is a worthy cause, including a discussion of similar systems that have been attempted and the previous phases of the SuPER prototype. Chapter 3 contains most of the design decisions used to create the phase 2 design. This includes reasons why previous phase design choices were good or bad, the selection criteria used to pick new components, and some systems level choices such as packaging, cost, and part count. Chapter 4 details the requirements for each of the subsystems developed. Chapter 5 contains the interface control documentation needed between all the subsystems. Chapter 6 contains a description of the software needed for controlling and monitoring the subsystems. Chapter 7 has a reliability analysis for the new phase 2 design and sheds some light on which areas of the system are most prone to failure. Chapter 8 includes recommendations for the next student who takes on the role of systems engineer for the integration of all of the subsystems. Chapter 9 rounds out the body of the paper with a conclusion, followed by a bibliography. 
Various appendices are included as supplemental knowledge that will help understand various topics throughout the paper. Appendices A, B, and C contain the general protocol information for working with the I2C, SPI, and USB 2.0 OTG busses. Appendix D has a data rate analysis which helps determine exactly how information can be passed around the system's communication bus. Appendix E contains the $\mathrm{C}$ code written by Matthew McFarland for the charge controller. Appendix F contains descriptions of the various projects that will be available for future SuPER team members to work on. This includes senior projects and masters theses. Appendix G shows which datasheets MTBF numbers came from or the parameters used for MIL-STD-217F to generate MTBF figures. Appendix $\mathrm{H}$ is a general strategy for a new student to come up to speed with the SuPER project and how to get started on one of the various subsystems. 


\section{Background}

\subsection{The Case for the SuPER System}

As the world's population continues to grow beyond 6 billion inhabitants, technological sophistication is only outpaced by the number of people without access to it. The SuPER project was envisioned by Dr. Harris [1] in 2005 to bring the benefits of electricity to the over 2 billion people lacking it. This newfound electrical power is a safe alternative to kerosene lamps used in many developing countries for lighting. It can also be used to power refrigeration units, irrigation equipment, televisions, and other appliances that have the potential to drastically increase the quality of life for billions of people.

Advanced civilizations have developed robust methods of generating, storing, and transmitting electricity, but under-developed nations lack this infrastructure. The start up costs for getting a remote village on a power grid are enormous. The SuPER system hopes to offer a much cheaper and quicker way to bring electricity into these areas.

Photovoltaic panels and wind turbines are growing in numbers as many people have decided to make a switch to more sustainable energy practices. Carbon dioxide emitting technologies like gasoline and coal have many processing steps that take time, money, and energy to refine before the power is available. However, solar and wind energies are abundant and virtually available 24 hours a day anywhere on Earth. The next section will explain more about the benefits or solar and wind energy. 


\subsection{Solar and Wind Energy Availability}

Figure 2-1 displays how abundant solar energy is on Earth. The most favorable and moderately favorable zones for solar power encompass most of the world's population, including almost all of Africa. Figure 2-2 shows the actual amounts of solar energy in $\mathrm{kWh} / \mathrm{m}^{2}$ for the entire Earth. Again, most of Africa receives greater than $1500 \mathrm{~W}$ of energy per square meter.

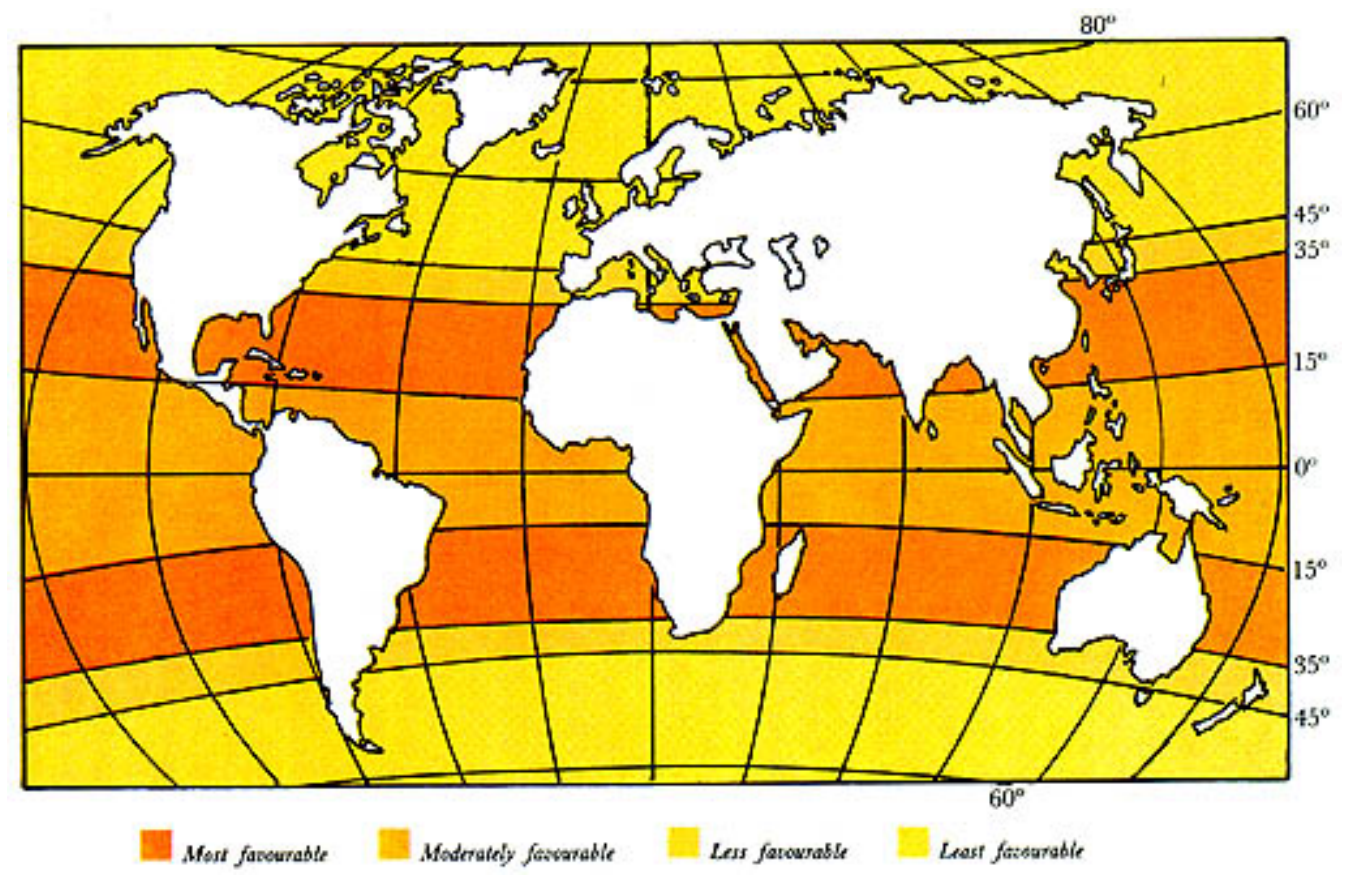

Figure 2-1 - Solar Energy Zones Based on Latitude [30] 


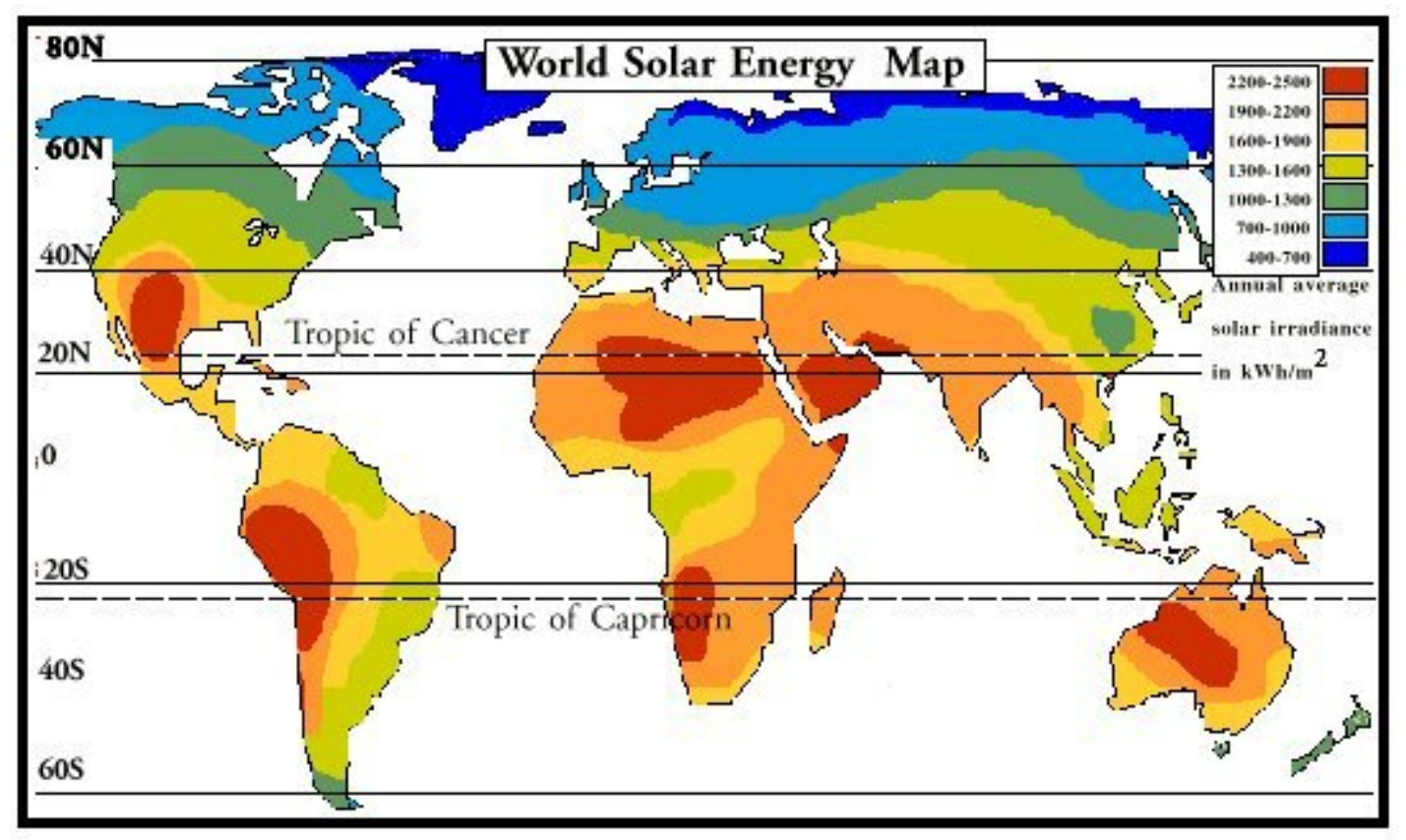

Figure 2-2 - World Solar Energy Map [31]

Solar systems are far from being $100 \%$ efficient, but they can provide a great deal of energy to a small area. Most household solar energy systems convert $20 \%$ of the solar irradiance into electrical power at best. This number is constantly increasing, however, as research in this field continues. There are more efficient solar cells being developed that can reach nearly $40 \%$ in efficiency. As this field expands, higher efficiency solar panels will be available on the market for cheaper prices. Future implementations of the SuPER system will benefit from this research, either providing more power to the user or reducing the overall system size (which is currently dominated by the photovoltaics). Figure 2-3 displays solar cell efficiencies through the year 2010. 


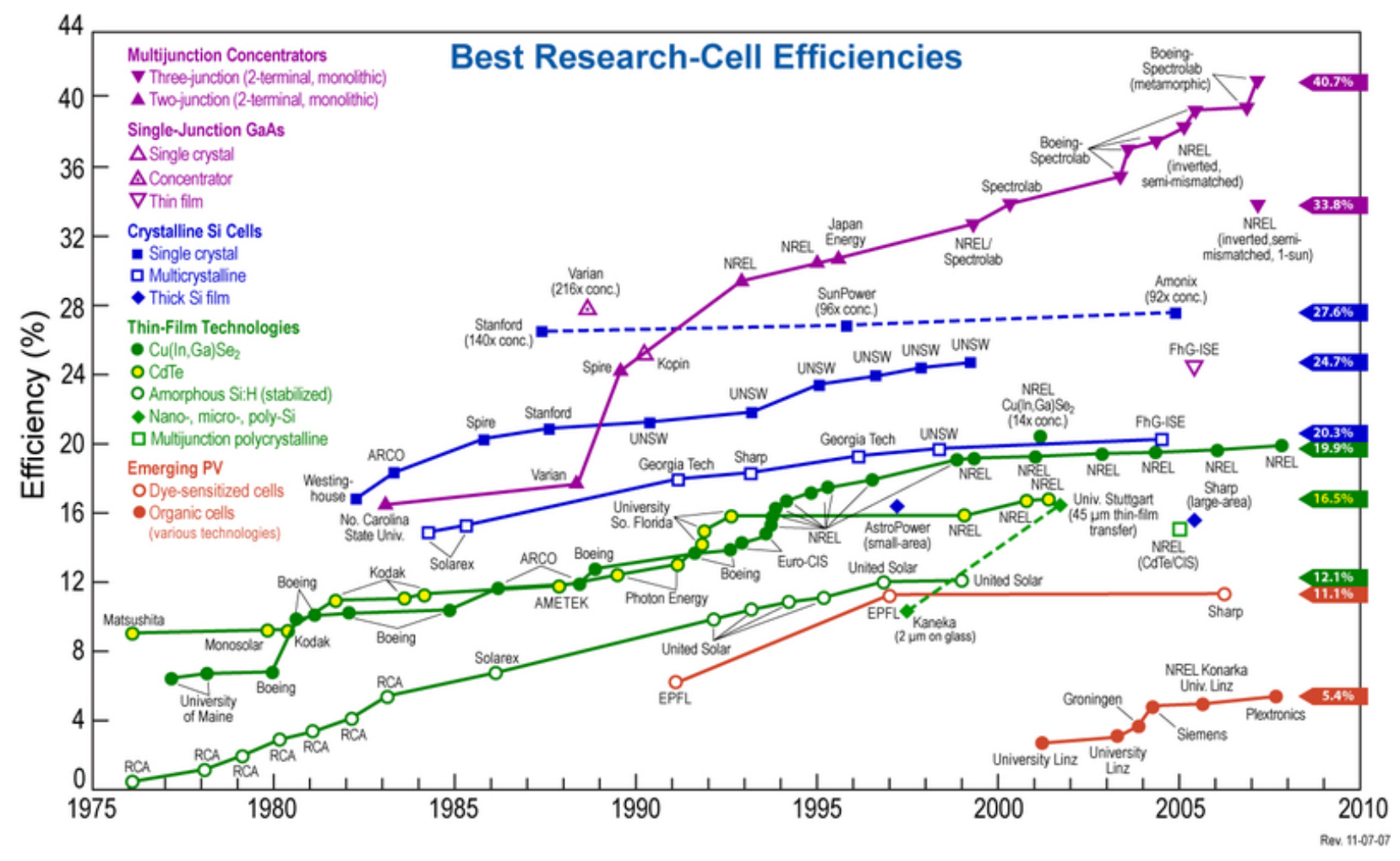

Figure 2-3 - Solar Cell Efficiencies [42]

\subsection{Levelized Cost of Energy}

The levelized cost of energy (LCOE) is an important ranking for different energy production methods. It breaks down the cost of generating power based on the entire system lifetime operating costs. This number is reported in the form of price per amount of energy, cents/kWh for example. Figure 2-4 shows these numbers from June 2007 for many different types of energy generation methods. Solar photovoltaics actually ranks as one of the higher LCOE methods, but prices are expected to drop dramatically in coming years.

SunPower released a report on LCOE for solar systems outlining system costs over the next few years. Their report states that from 2008-2011 the price of silicon will drop by $50 \%$ and more productive manufacturing will reduce the amount of silicon needed by $60 \%$ [2]. This will 
lead to a large cost reduction for PV panels. At the same time, efficiencies will increase leading to a better LCOE ranking for solar PV.

There are a few other ranking methods that show the importance of solar PV in the near future. Energy payback time is the time needed to have the system produce the amount of energy that was consumed during its production. Current thin-film technologies have an energy payback time of around 1-1.5 years. The energy returned on energy invested (EROEI) is a more sustainable measure taking into account the amount of energy required to maintain the system. EROEI numbers on thin-film solar PV systems are around 10-30 years currently. With PV systems expected to last at least 20-30 years, this EROEI number shows that it is a very sustainable method of energy production.

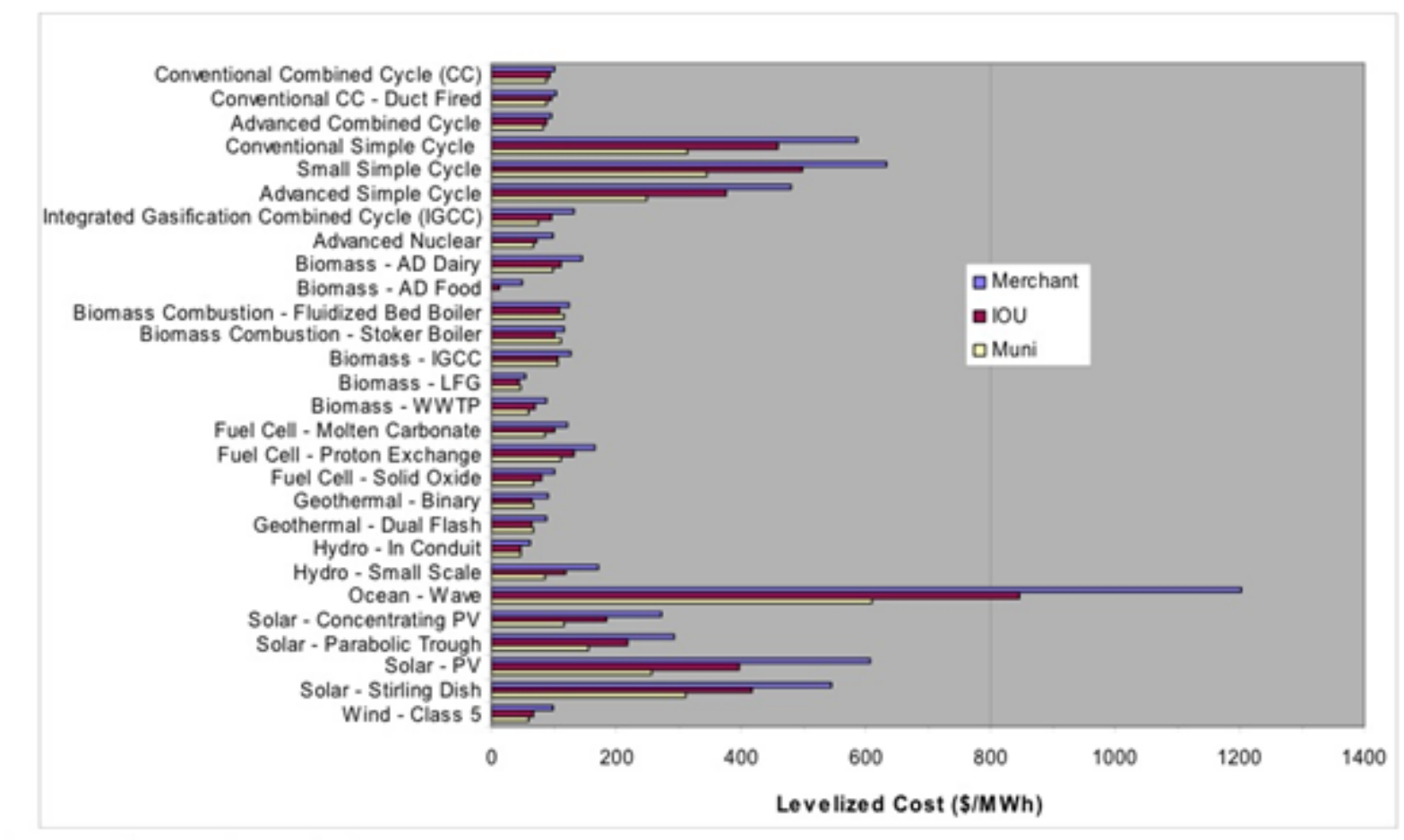

Source: Energy Commission

Figure 2-4 - Levelized Cost of Energy for Various Energy Production Methods [35] 


\subsection{Similar Systems}

There are no other systems currently being developed that meet the unique specifications of the SuPER system. SuPER is student based project learning for bringing power to a third world country. All work is open-source and posted on the internet for open use. It is a non-profit, approximately 400 Watt-hour system, with a price point around $\$ 500$. Currently, there are no other projects in development, or completed, that meet these same requirements. Many similar projects are being worked on to bring solar powered lighting to third world countries, but not the ability to hook up other useful appliances.

It is well known in industry that solar power can drastically increase the standard of living in third world countries, but they have yet to develop systems like SuPER. There is a hesitation in going into full-fledged production of solar panels for rural areas of the world because of profit margins. Some figure of merit for price per watt exists, but that figure has yet to be reached. It could be because the demand for large scale solar projects has lowered production for smaller units (that would most likely be used in small rural villages). This has actually increased the price of $37 \mathrm{~W}$ and $75 \mathrm{~W}$ solar panels in recent years [3]. Despite this, there are a few companies developing smaller solar powered solutions for third world countries.

\subsubsection{Comparable Projects in Academia}

Many universities are beginning to offer sustainable energy courses which have gotten students involved with projects for a similar goal. The U.S. Environmental Protection Agency's National Center for Environmental Research (NCER) is helping to fund many sustainable projects through grants. One project, "Design of a Small-Scale Solar Chimney for Sustainable Power" at Minnesota State University - Mankato is directed at providing energy to developing areas of the world [4]. It will use the sun's energy to power small devices like cell phones, lights, 
and possibly laptop computers with the similar goal of renewable energy and low maintenance. However, the work from this project is not open source and no price point has been given for the system.

Another project from the Massachusetts Institute of Technology titled, "A Novel Solar Thermal Combined Cycle with Bio-Methane Carbon Capture for Distributed Power Generation" also received a grant from NCER to create a power system for the developing world which will use local resources for construction [5]. This project is sustainable because it allows communities to use what they have locally to build it, but again this is not open source and no price point for the system is given. This system also does not use photovoltaics, but instead used an organic Rankine cycle (ORC) engine which causes solar heat to turn turbines for energy generation and storage in batteries.

The Rochester Institute of Technology also received a grant from the NCER for the project titled, "Self-Contained Human and Solar Powered LED Lighting System for Use in the Developing World." This project looks to replace fuel-based lamps with a renewable energy source [6]. One of their research options is to use photovoltaics and battery storage for implementing the off-grid lighting solution. This project is but a subset of what the entire SuPER system will eventually accomplish.

There is another project sponsored by the NCER titled, "Solar Lighting for Remote Rural Communities" that offers a similar replacement for kerosene lanterns. It uses a 75 Amp-hour car battery to store energy generated from an $80 \mathrm{~W}$ solar panel. The users would be required to buy a lantern built out of LEDs and a 4.5Amp-hour battery that would last for 24 hours down to a $50 \%$ discharge level. This unit is supposed to cost less than 10 USD and be easy to repair, maintain, and upgrade [7]. 


\subsubsection{Comparable Projects in Industry}

Industry has noticed the potential for growth in renewable energies for developing nations, but few systems have been implemented. Much of the sustainable energy market in these countries has centered around solar power. Photovoltaic systems can vary in size, price, and performance making them ideal for small villages, schools, or individuals. There are obstacles to developing and deploying these systems in some of the most poor and remote areas of the world. These include getting permission from the governments involved, finding and interacting with the locals, transporting and setting up the equipment, and financing for the users. A few companies have been able to successfully help some of the 2 billion people lacking electricity, but most of these systems are just for LED lighting, and none of them can offer everything SuPER does.

Promethean Power Systems is a startup company centered on solar powered refrigeration systems for developing nations [8]. They would provide a refrigeration unit for milk, fruits, and vegetables that runs off about $100 \mathrm{~W}$ of solar power. This system is on the same order for the amount of power it intends to supply as SuPER and also comes with a custom controller for powering loads. Another goal of this system is simple operation and low cost, similar to SuPER's design goals. However, this system only provides a fraction of the functionality of SuPER.

In 2008, Kyocera started installation of $600 \mathrm{~W}$ solar power generating systems with storage batteries in 15 schools in Uganda [9]. These systems come with basic equipment that will aid the schools' educational activities including television and lighting. This system more closely relates to SuPER's design and end goals. Users will be able to capture and store the sun's energy for later use and not just for lighting. Having additional appliance hook ups enables users to 
expand the functionality of their energy system, whether it is adding a refrigeration unit, laptop, or water pump. These systems were donated by Kyocera, so it is unclear what the price point is for this and whether similar systems can be purchased and installed elsewhere in the developing world for a modest cost.

There is no doubt that people want to help bring electricity to the third world, but in industry, where profits are key, this goal of helping humanity seems to fall short. Projects need to be low cost, or donated, to these rural civilizations. Outside of that, many of the products available are centered around solar power for a single user, such as a cell phone charger. None of these systems are offering a cheap, village centered power source, with low-maintenance for decades.

\subsection{Previous Implementations}

\subsubsection{Phase 00}

The phase 00 implementation is the beginning of the SuPER project and was laid out by Eran Tal [10]. This was the system architecture phase where the general looks and specifications of the system would be determined. Different studies were done to determine what an end user would need out of the system and what components could be used for those functions. The number and size of photovoltaic panels and batteries were determined and the associated voltage and current ratings for the system power bus. One $150 \mathrm{~W}$ solar panel and one $98 \mathrm{Ah}$ battery were chosen for the power generation and storage components.

Sensor and control circuitry was also defined during this phase. The types of loads that would be used on the system determined the types of sensors and switches needed to control the system. The control system was designed to run as ' $\mathrm{C}$ ' code on a laptop running RedHat Linux. 
A National Instruments NIDAQ USB 6900 device was chosen as the interface between the laptop and the system. This device is used to convert analog input voltages to digital data, send the data over USB to the laptop that is running the control software, and output digital commands to control the system switches. A PIC microcontroller was also implemented for the maximum power point tracking (MPPT) algorithm to send a varying pulse width modulated (PWM) signal to the DC-DC converter. 


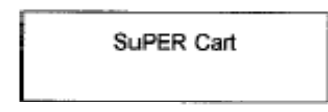

Stage: Construction of

main structure

Owner: Eran

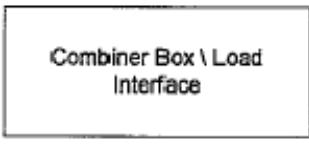

Stage: Specify combiner box ratings choose components.

Owner: Jennifer

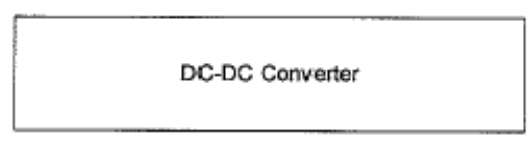

Stage: Finalize Spec and Design. Order Parts

Owner: Robert

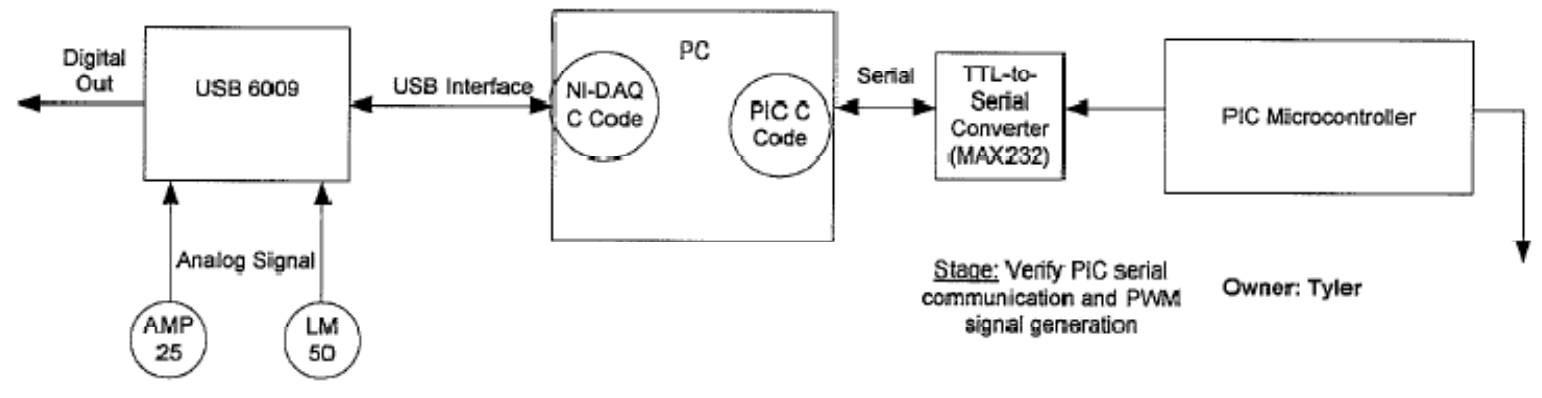

Stage: Verify sensor readings and digital output Owner; Gustavo control

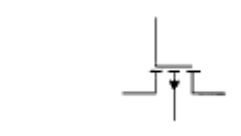

Stage: Main switch component selection

Owner: Eran

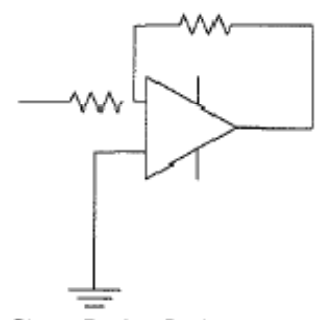

Phase 00

Stage: Design Op-Amp Owner: Eran

sensor gain circuit and

choose components

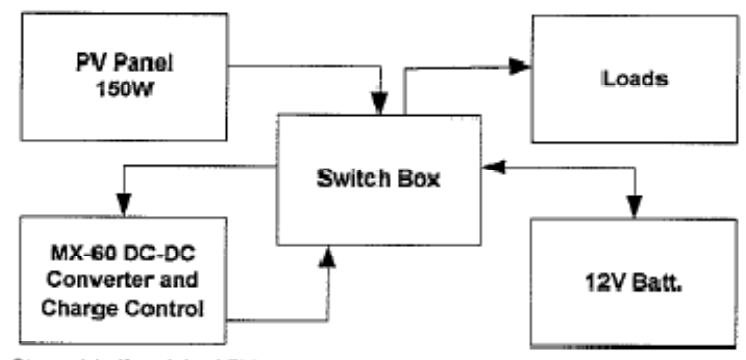

Stage: Verify original PV system works as expected

Owner: Eran

Figure 2-5 - SuPER Phase 00 System Diagram 


\subsubsection{Phase 0}

Phase 0 can best be described by finalizing the design-to specifications and the start of subsystem implementations. With the DC-DC converter design finalized, a custom PCB was built and it began initial testing. A combiner box and main switch board were made to house and connect all of the system's power lines. The SuPER cart wiring was laid out so components could take their place in the final cart design. The sensor board design was finalized, along with code to sample and store the voltage, current, and temperature measurements. Data logging was implemented for the battery charge and discharge characteristics to obtain data for emulating the Outback MX-60 charge controller. The PWM interface from the PIC microcontroller to the DCDC converter was also verified. 


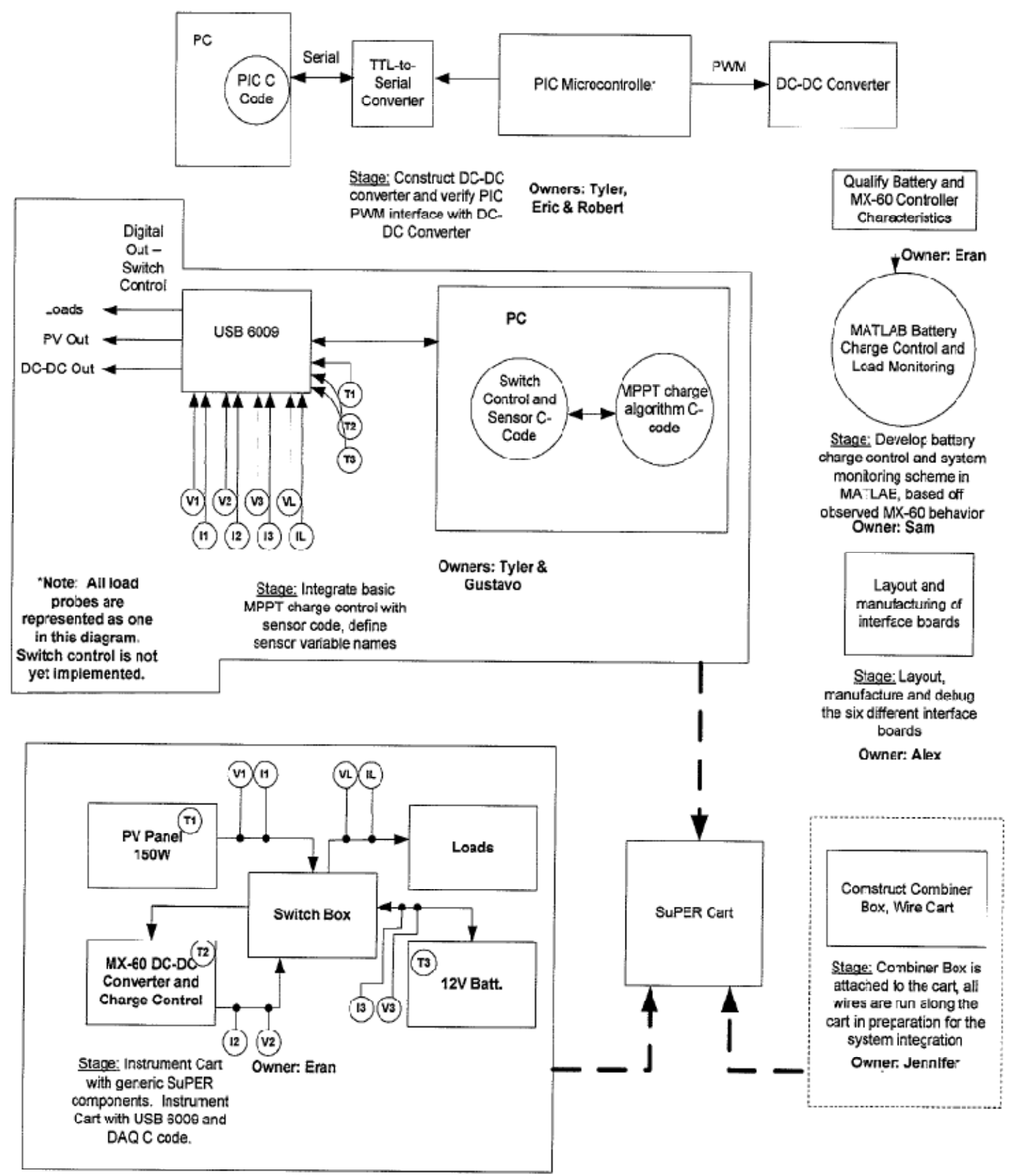

Phase 0

Figure 2-6 - SuPER Phase 0 System Diagram 


\subsubsection{Phase 1}

Phase 1 consisted of integrating the SuPER components into the final system. There were major complications however, as the DC-DC converter was not fully functional. This prevented a fully closed-loop test from being performed; instead the Outback MX-60 charge controller was used in place for the in-house DC-DC converter and control software. This testing was able to verify that the rest of the circuit performed as intended, including switch control, accurate logging and display of sensory data, and accurate PWM frequencies for the MPPT algorithm.

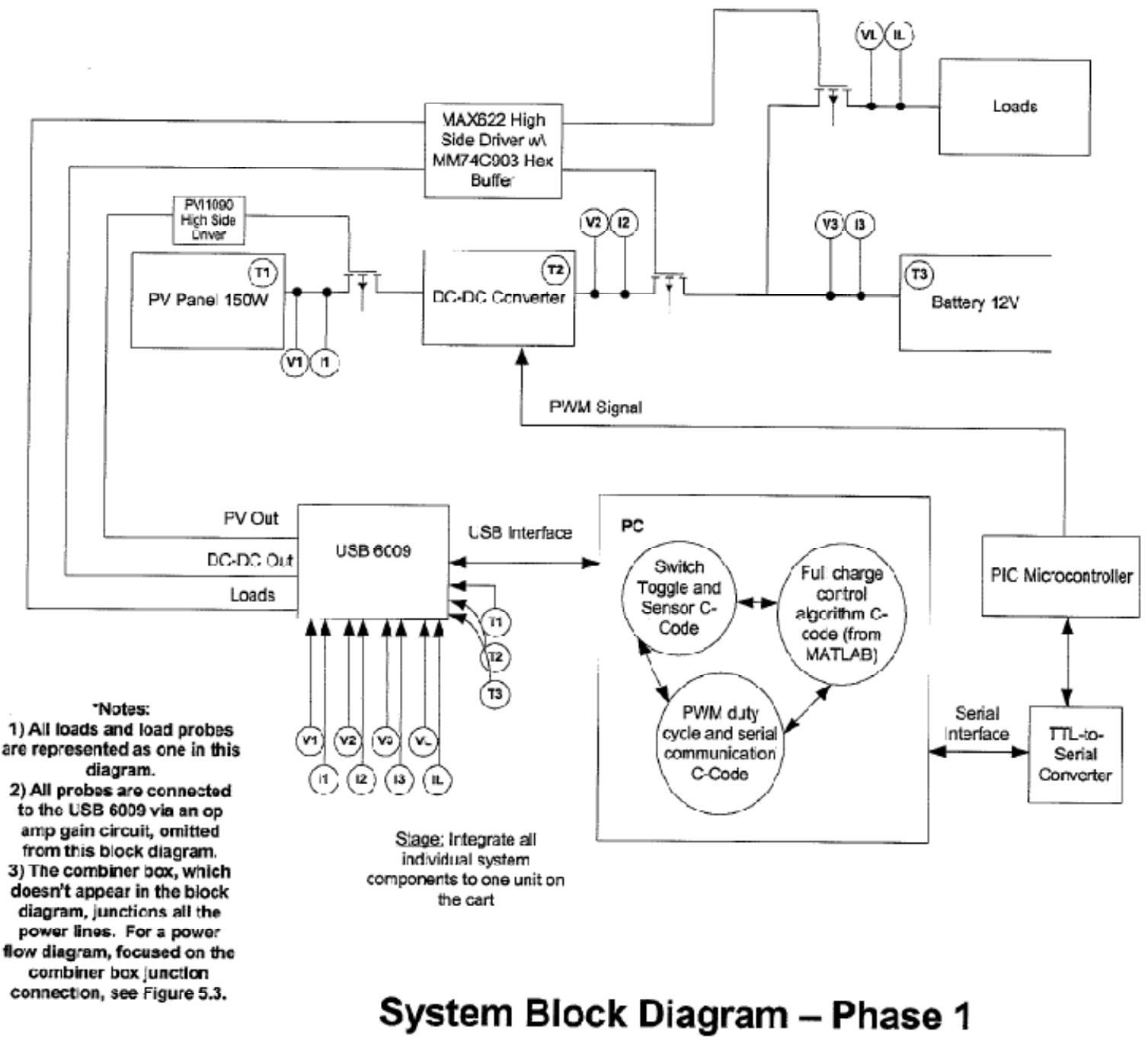

Figure 2-7 - SuPER Phase 1 System Diagram 


\subsubsection{Phase 1.5}

This phase was planned as phase 2 which included updating the DC-DC converter design and improving system control and data logging. This phase lacked a central design plan, having many projects implemented independently over many years without much regard to how the entire system would be affected. It has left the SuPER system with configuration management issues, as many items on the SuPER cart are incomplete or not well documented. During this phase, the Digilent Spartan 3E FPGA development board was introduced into the system. The main purpose was to replace the laptop with a smaller, low power device that could also interface to external memory. The FPGA would run an embedded version of Linux, called uClinux. This was a good academic exercise, but ultimately not the right course for the SuPER project's future, as section 3.2 will illustrate. 


\section{SuPER Phase 2 Design}

The goal of my thesis was to change SuPER from an academic prototype to a field ready system that would reliably and safely produce electricity for a full 20 year lifespan. The phase 2 design will incorporate all the knowledge learned from the previous phases into a new system design that can last 20 years. Figure 3-1 shows the new system diagram for the phase 2 design. It incorporates a printed circuit assembly (PCA) which will be used to digitize data at the loads, battery, and PV panel. This data is sent to another PCA that will act as the controller to monitor the system and store its usage statistics. Multiple loads can be connected to the systems $12 \mathrm{~V}$ DC power bus. There is the potential to hook up a wind turbine in the future for more sustainable energy uses. Not pictured is a microgrid which is being developed to provide energy transmission throughout an area surrounding the SuPER cart.

The phase 2 design is broken up into a number of subsystems that can be worked on independently and then integrated for the final build. These subsystems include: the controller, digitizer, user interface, wind turbine, microgrid, ultra capacitor, printed circuit assemblies, and data logging on an SD memory card. This chapter focuses on why specific design decisions were made for each of the subsystems. Also, the subsections below cover a functional decomposition

of the system and trade studies for operating systems, FPGAs, microcontrollers, communication bus protocols, and individual components (switches and sensors). This chapter is rounded out with a parts list and cost breakdown which compares phase 2 to the previous system implementations. 


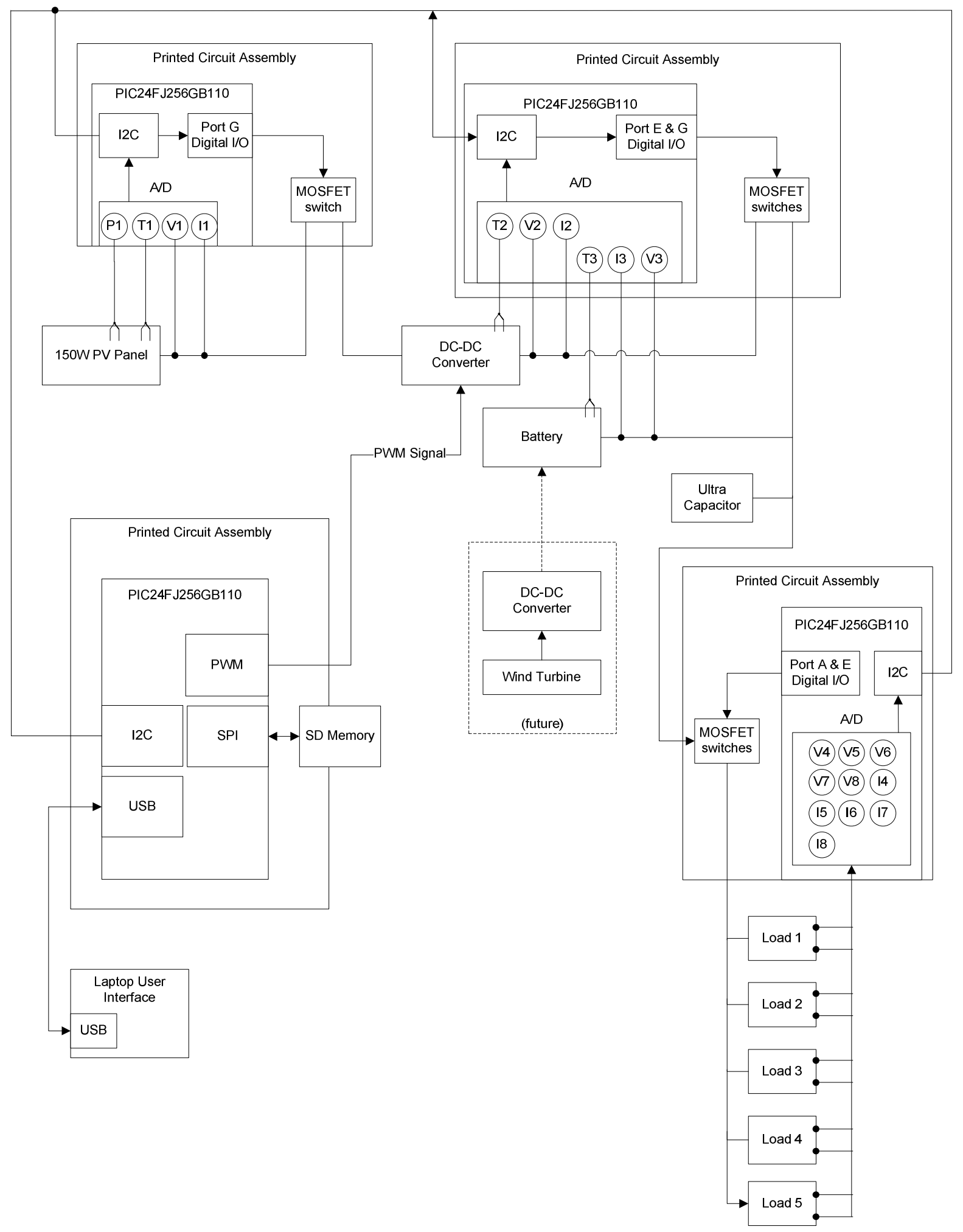

Figure 3-1 - SuPER Phase 2 System Diagram 


\subsection{Functional Decomposition}

A functional decomposition is performed during the design phase of a system to determine what functions the system actually needs to provide. It does not offer any specific implementation details on what is to be built, but rather breaks down functionality into subsystem level sized components. The bottommost blocks are generally going to be turned into their own subsystems which can be implemented separately and then brought together during integration. Requirements will be developed for the subsystems so they can be designed and built separately. The decomposition gets down to the real issue of what services or components are needed without saying how they should be designed. 


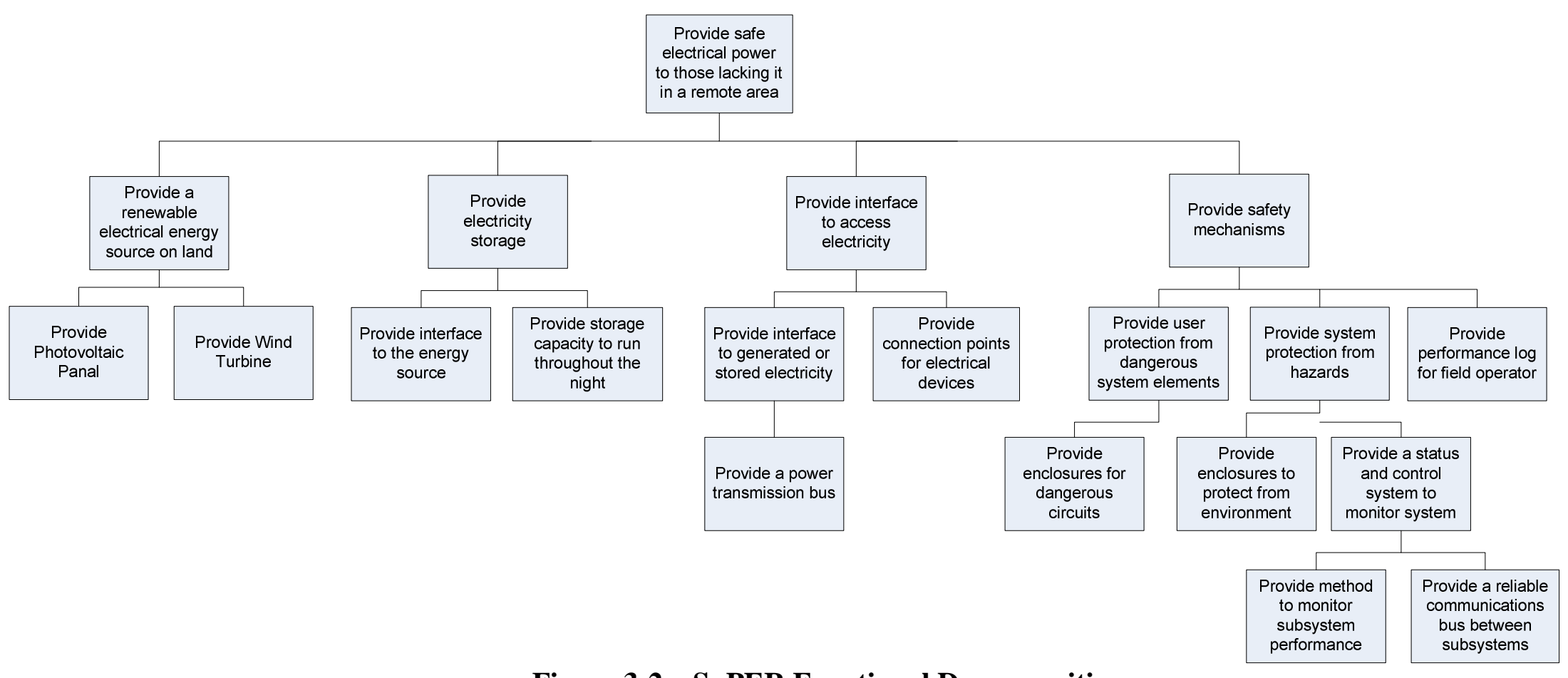

Figure 3-2 - SuPER Functional Decomposition 


\subsection{Operating System and FPGA Disadvantages}

Previous phases of the SuPER project have struggled to use operating system or FPGA functionality to run the system. The problems encountered in these approaches aren't necessarily the designers' errors, but rather the many configuration management issues that arise from using such complex pieces of hardware and software. The design cycle time for using both of these is much too long and complex.

The use of an operating system can be a good first approach if it is readily available and the students working on the project are familiar with development on it. The first implementation of SuPER was developed with a version of RedHat Linux. The fact that RedHat is free and open source was of great benefit to the project initially, but when designing for long term stability and use, problems arise. First off, the simplest way to run RedHat was on a laptop and this meant that SuPER would require an entire, power hungry computer, just to run some simple code. This large system would also be difficult (and expensive) to repair during field operations. Diagnosing computer problems can be timely and it is unlikely that the system supervisor would have the spare parts needed to make a quick fix. The laptop was also required to run National Instruments software for communication with expensive and bulky data acquisition devices. If RedHat had any sort of software update, there was always potential for conflicts to arise. Over a 20 year period, it is unlikely that the same exact hardware and software would continuously be supported, and the amount of software fixes and updates would be a configuration management nightmare.

In addition, the laptop is bulky, expensive, and offers many features that will never be used in a system like SuPER. The SuPER prototype was built like a cart, offering a flat working surface that the laptop could be placed on. The laptop is heavy and its footprint is only outsized 
by the PV panel. An entire laptop has a plethora of features that would not be utilized by SuPER and thus take up space and money. Even today, a comparable laptop is around $\$ 300$ or more, which is far too much of the cost for a system with a target price of $\$ 500$. The idea to switch everything to an FPGA was a step in the right direction, but also has its downsides.

An FPGA offers a more compact and power saving method for running the control software. The footprint of the FPGA was much smaller than the laptop and this device also brought power consumption down from about $60 \mathrm{~W}$ to $3 \mathrm{~W}$. This is a huge savings in space and power, but the design cycle was much longer and more complex. The FPGA used was the Digilent Spartan 3E Starter Board which is developed using Xilinx software tools. The software could be used in a limited way by students, but if a full version was to be purchased it would cost in the range of a few thousand dollars. The FPGA itself is around $\$ 150$, which is again, too big a chunk of the target $\$ 500$ price point for the entire system.

Attempts were made at incorporating various add-ons to the FPGA that would help bridge the gap in functionality to the laptop. Students tried porting various watered down versions of Linux called petalinux and uClinux to the Spartan3E board. In addition, they also tried incorporating new features like a file system, an SPI driver, an SD memory card, PWM output, and load switch control. Some of these additions worked, many had problems, and it seemed more like hacking functionality in than building a cohesive platform from the beginning. After many competent and successful students struggled to add functionality to an operating system on an FPGA, it was decided that SuPER needs to go in a new direction. Microcontrollers will be at the center of the system's redesign due to their increase in performance, low prices, and enduring performance in digital computing. 


\subsection{Microcontroller Advantages}

Microcontrollers have a number of characteristics which make them the ideal component for use in the SuPER system. Since 1993, companies like Microchip and Atmel have extended the performance of these devices and lowered their costs at the same time. These companies also provide free software, so just about any challenge can be quickly overcome through the help of great documentation and open source projects on the internet. With the number of embedded devices growing at such a fast rate, the microcontroller market is still expanding and these computer on a chip devices can satisfy the SuPER system's needs for less than $\$ 10$. Just as the FPGA was a compact alternative for the laptop, the microcontroller is an even more compact replacement.

The microcontroller offers the right amount of functionality and the potential for extended use over the target lifetime of 20 years for SuPER. These devices are low power and offer numerous peripherals, so the perfect little system can be developed for use on and between subsystems. They can be coded in the familiar language of ' $\mathrm{C}$ ' which has been around for decades and will most likely stay around for use in the embedded field. This also offers an easy upgrade platform since one microcontroller can be replaced with another with only minor changes to the system. The pins could be routed in a slightly new way and the code may need minor modification, but then the entire phase 2 SuPER system wouldn't need a redesign. They are so cheap that only one device needs to be chosen and it can be used on all the system boards. This is also convenient for replacement parts as many different versions will not need to be tracked.

These devices have been used for almost two decades and have proven very reliable. They can withstand the broad range of temperatures that the system will encounter when it is 
operating in the field. Low power modes ensure that this device will have less of an impact on the user, allowing them to use the generated power for appliances and various tasks. Seeing how many students are exposed to microcontrollers throughout their college careers, there will be no shortage of competent engineers who can exploit this amazing little device for the benefit of the SuPER project.

\subsection{Digital Communication Bus Selection}

The addition of a digital communication bus is the major area of redesign in phase 2 of the SuPER project. Using a digital communications bus will help increase the accuracy of the control system as analog voltages are digitized and sent to the controller. This will help reduce the amount of noise that can corrupt the A/D measurements. The controller will also be able to send out commands on the bus to turn switches on or off. The bus will allow for more accurate control and monitoring of the system as it connects the SuPER Digitizer boards to the SuPER Controller. There are options to use a number of different bus protocols on any given microcontroller and Table 3-1 gives a brief description of the factors that were looked at in deciding. The ideal bus would be one that is high speed, low complexity, and fault tolerant. The ideal case doesn't exist yet, but there is a good spread of these features inherent in the InterIntegrated Circuit (I2C), Serial Peripheral Interface (SPI), and Controller Area Network (CAN) busses.

The SPI bus initially seemed like a good choice with its high speed and low code complexity, but there are a few drawbacks [22]. The higher speeds prevent the SPI bus from transmitting greater than about 1 meter with excessive noise corruption. If speeds were lowered to less than $1 \mathrm{MHz}$ or repeaters added in the longest path, it may be possible to extend this distance. However, this would defeat the purpose of the high speed bus and also add extra 
hardware complexity, both of which are undesired. Also, adding additional devices would require an extra slave select line for each device, which adds wiring complexity and takes away I/O pins on the microcontroller.

The CAN bus is a standard in industrial and automotive applications because of its durability and efficiency [23]. It has superior noise immunity because of its differential lines, but this has a bad side in adding a larger number of wires to the system. There would need to be 9 wires connecting every device to the CAN bus, but the good thing is that the data can be transmitted relatively far and at higher speeds (40m @ 1MHz). The major disadvantage in terms of the SuPER project is the code complexity. The CAN bus is setup with frames for sending messages between nodes and has a complex protocol. It would be a great bus to have in the SuPER system, but as of now not many microcontrollers include CAN controllers and an easier coding scheme is preferred.

The I2C bus was chosen for the SuPER project because of its low complexity and respectable data rates [21]. Only 2 wires are needed for the bus structure and nodes can be added to these lines at any point. The nodes can be spaced up to about 10 meters apart without the addition of any other signal boosters, allowing the SuPER Controller to communicate with the furthest away object in the system, the PV panel. Windows VCOMM API calls, or something similar, can be used to write a user interface on a PC and talk to the SuPER system. 
Table 3-1 - Digital Communication Bus Selection

\begin{tabular}{|c|c|c|c|}
\hline \multicolumn{4}{|c|}{ Digital Communication Bus Selection } \\
\hline & I2C & SPI & CAN \\
\hline $\min \#$ of wires & 2 & 4 & 9 \\
\hline Supported speeds & $10 \mathrm{KHz}$ to $3.4 \mathrm{MHz}$ & $1 \mathrm{MHz}$ to $70 \mathrm{MHz}$ & $\sim 40 \mathrm{KHz}$ to $1 \mathrm{MHz}$ \\
\hline distance & $\begin{array}{l}\text { up to } 10 \mathrm{~m} \text { without } \\
\text { any external } \\
\text { components if data } \\
\text { rates are in the } \\
\text { lower range }\end{array}$ & $\begin{array}{l}\text { on the order of } 1 \mathrm{~m} \\
\text { unless the speed is } \\
\text { brought down to the } \\
12 \mathrm{C} \text { range or repeaters } \\
\text { are used }\end{array}$ & 40 meters at $1 \mathrm{MHz}$ \\
\hline additional devices & $\begin{array}{l}\text { Can be added by } \\
\text { simply connecting } \\
\text { them to the SDA } \\
\text { and SCL lines from } \\
\text { the Master device }\end{array}$ & $\begin{array}{l}\text { add an extra /SS line } \\
\text { for each device }\end{array}$ & $\begin{array}{l}\text { Any device with CAN } \\
\text { controller can be } \\
\text { connected to } \\
\text { existing bus }\end{array}$ \\
\hline code complexity & $\begin{array}{l}\text { can be more } \\
\text { complex than SPI, } \\
\text { but still relatively } \\
\text { easy }\end{array}$ & low complexity & $\begin{array}{l}\text { Based on CAN } \\
\text { message frames, } \\
\text { high complexity }\end{array}$ \\
\hline
\end{tabular}

\subsection{Component Selection}

The electronic components were selected based on the performance they provided and also how they would fare over the lifetime of the system. Previous phases of the SuPER project incorporated student projects which consisted of projects using whatever parts were available, cheapest, or easiest to work with at the time. This works well in the moment, but in terms of the 20 year lifespan of the proposed system, it does not. With the redesign of the system including the addition of a digital communications bus, all electronics must be carefully chosen so the system will perform well. To reduce part count, components that all have an operating voltage in the range of $3.3 \mathrm{~V}$ to $5 \mathrm{~V}$ will be considered a better alternative. This allows different sections of the system to be run off of one distributed power bus, further reducing complexity. If different subsystems need similar components, the device with the highest performance will be used throughout the system to reduce part count as much as possible. The components that needed to 
be looked include the microcontrollers, current sensors, temperature sensors, switches, and voltage scaling components.

\subsubsection{Microcontroller}

Bringing in a microcontroller as the control center for the system is one of the biggest improvements, but there are many factors that must be considered when choosing this part. The first selection criterion was manufacturer. Two companies that are familiar with students at Cal Poly (and people around the world) are Microchip and Atmel. These companies have both been creating more powerful microcontrollers over the past years with costs actually going down. They both offer free development software as incentives to buy their hardware and there are many online resources for working with their products. Previous SuPER users decided to go with the Microchip PIC family devices for their ease of use, low complexity, and vast online documentation. Atmel is a strong competitor, but their devices are slightly more powerful and would require a 32-bit microcontroller, as opposed to the many 16-bit options with Microchip.

Having chosen the PIC family of microcontrollers, it was now time to determine the exact functionality that would be required out of the device. Table 3-2 has a comparison of the previously used PIC on SuPER (PIC18LF4320), and four alternatives from their current 16-bit families. The DSPIC30F is a family of digital signal processing microcontrollers from Microchip offering much higher performance for a relatively low price increase. The PIC24 family is also a 16-bit device that has slightly less processing power than the digital signal processing chips, but many peripherals that would be utilized by SuPER. After designing many of the subsystems for Phase 2 of SuPER, it was possible to select the PIC24FJ256GB110 as our microcontroller.

One of the first concerns was whether this chip would be able to handle enough inputs and outputs as required by the various printed circuit assemblies (PCA) configured as either a 
digitizer or controller. It was determined that having I2C and USB would be the most beneficial as it would allow the control algorithm to continuously receive inputs and process them while allowing the USB bus to connect to an external user device without interrupting the control flow. An SPI bus would be needed for interfacing the memory card while a PWM interface could be used for controlling the DC-DC converter. Most of the devices cover these necessities, but the PIC24FJ64GB004 and PIC24FJ256GB110 also include a USB 2.0 OTG interface which eliminates the need for an external converter for PC interfacing. The PIC24 family actually has the potential for more of these peripherals if they are needed in the future. The PIC24 is at a disadvantage when it comes to CAN busses however. It does not contain any while the DSPIC30F has one. This would offer a great opportunity for a communication upgrade in the future, but the other features of the PIC24 outweigh the fact that it is missing a CAN controller.

The major factor in pin count would be with all of the A/D lines needed for the digitizers. A maximum of 10 lines would be required at the digitizer board connected to the load bus to account for voltage and current measurements for five different loads. With the other digitizer configurations attached to the PV panel and battery, the number of A/D lines needed comes out to about 20. The PIC24 sacrifices the A/D measurement resolution, having only 10-bits instead of the 12-bits on the DSPIC30F series. 10-bits are accurate enough for the SuPER control logic. There is also a real time clock and calendar function on the PIC24 device which may be able to be used for time stamping data measurements as they are logged. The PIC24FJ256GB110 100pin package allows enough extra I/O pins so all controller and digitizer connections can have a unique pin on the device. This ensures there will be no overlap or configuration issues when using the PCA in different locations throughout the system. The extra pins also allow the possibility to expand functionality in the future. 
Table 3-2 - Microcontroller Selection

\begin{tabular}{|c|c|c|c|c|c|}
\hline \multicolumn{6}{|c|}{ Microcontroller Selection } \\
\hline & $\begin{array}{l}\text { PIC18LF4320- } \\
\text { I/P }\end{array}$ & $\begin{array}{l}\text { DSPIC30F4013- } \\
\text { 30IP-ND }\end{array}$ & $\begin{array}{l}\text { PIC24FJ64 } \\
\text { GA102 }\end{array}$ & $\begin{array}{l}\text { PIC24FJ64 } \\
\text { GB004 }\end{array}$ & $\begin{array}{l}\text { PIC24FJ256 } \\
\text { GB110 }\end{array}$ \\
\hline Architecture & 8-bit & 16-bit & 16-bit & 16-bit & 16-bit \\
\hline $\begin{array}{l}\text { Operating } \\
\text { Voltage }\end{array}$ & $2 \mathrm{~V}-5.5 \mathrm{~V}$ & $2.5 \mathrm{~V}-5.5 \mathrm{~V}$ & $2 \mathrm{~V}-3.6 \mathrm{~V}$ & $2 \mathrm{~V}-3.6 \mathrm{~V}$ & $2 \mathrm{~V}$ to $3.6 \mathrm{~V}$ \\
\hline $\mathrm{I} 2 \mathrm{C}$ & & 1 & 2 & 2 & 3 \\
\hline SPI & $1 \mathrm{I} 2 \mathrm{C}$ or SPI & 1 & 2 & 2 & 3 \\
\hline PWM & 2 & 4 & 5 & 5 & 9 \\
\hline CAN & 0 & 1 & 0 & 0 & 0 \\
\hline $\mathrm{I} / \mathrm{O}$ & 36 & 30 & 21 & 35 & 84 \\
\hline $\mathrm{A} / \mathrm{D}$ & $13 / 10 \mathrm{~b}$ & $13 / 12 b$ & $10 / 10 \mathrm{~b}$ & $13 / 10 \mathrm{~b}$ & $16 / 10 \mathrm{~b}$ \\
\hline RTCC & no & no & yes & yes & yes \\
\hline $\begin{array}{l}\text { low power } \\
\text { modes }\end{array}$ & yes & yes & yes & yes & yes \\
\hline Package & 40-pin DIP & 40-pin DIP & 28-pin DIP & 44-pin TQFP & 100-pin TQFP \\
\hline USB & no & no & no & yes & yes \\
\hline
\end{tabular}

\subsubsection{Control Switches}

The control switches will be devices used to control the flow of power throughout the SuPER system. The main characteristic needed is that they need to be turned fully on or fully off via the output of a microcontroller. Reducing part count is important, so the less external components needed to achieve this, the better. Two devices were looked at for this operation, power MOSFETs and thyristors. Table 3-3 shows some metrics used to determine the best option, including switching speed, how to turn the device on or off, control hardware and software needed, and cost.

Thyristors are made up of four alternating layers of $\mathrm{P}$ and $\mathrm{N}$-type material [11] that can be used as bistable switches. This means they can be turned on when the gate is pulsed and they turn off if the gate voltage is reversed. Three different variants were looked at as options for switches on the SuPER system: the silicon-controlled rectifier (SCR), the gate turn-off (GTO) thyristor, and the MOSFET controlled thyristor (MCT). The SCR does not require any gate 
current once it is on as long as the conducting current through the device stays above a holding current threshold. On the other hand, the GTO and MCT require a small amount of current through the gate to keep it turned on. The SCR can be turned off with a reverse polarity on the gate, but this is more of a design flaw and not the normal mode of operation. This option may work for some applications, but it is not a reliable method of controlling the switches of the SuPER system. Also, the amount of current needed to turn off the SCR can be up to $20 \%$ of what it is conducting [12] and a microcontroller cannot supply this on its own. However, the GTO and MCT are designed to turn off with a negative gate voltage and at a lower drive current.

The real advantage with the power MOSFETs is that one signal can be used to control the device status [34]. By asserting one pin from a microcontroller the MOSFET can be on, deasserting it will turn it off, and while this does draw more current there are other benefits with this device. The power MOSFET is the cheapest option, with the MCT as the only comparable alternative. It has a fast switching speed (on the order of 100ns compared to 10ns for the MCT) that will enhance the safety mechanisms of shutting off dangerously high power lines. However, the MCT will not be ruled out as a viable option and could be a good upgrade for future revisions of the SuPER system. It is very fast, has a low current draw, and is low price. 
Table 3-3 - Control Switch Selection

\begin{tabular}{|c|c|c|c|c|}
\hline \multicolumn{5}{|c|}{ Control Switch Selection } \\
\hline & \multirow[b]{2}{*}{ Power MOSFET } & \multicolumn{3}{|c|}{ Thyristor } \\
\hline & & SCR & GTO & MCT \\
\hline $\begin{array}{l}\text { Switching } \\
\text { Speed }\end{array}$ & Fast & Slow & Slowest & Fastest \\
\hline Turn on & $\begin{array}{l}\text { Must continuously } \\
\text { bias, but devices } \\
\text { exist with logic } \\
\text { level gate turn on } \\
\text { voltages }\end{array}$ & $\begin{array}{l}\text { Send pulse to turn on } \\
\text { transistor and the } \\
\text { device will stay } \\
\text { biased on its own }\end{array}$ & $\begin{array}{l}\text { Send pulse to } \\
\text { turn on and } \\
\text { then a small } \\
\text { positive gate } \\
\text { current must } \\
\text { be } \\
\text { continuously } \\
\text { applied for } \\
\text { reliable } \\
\text { operation }\end{array}$ & Similar to GTO \\
\hline Turn off & $\begin{array}{l}\text { Deassert the } \\
\text { control signal on } \\
\text { the gate }\end{array}$ & $\begin{array}{l}\text { Applying a negative } \\
\text { voltage pulse to the } \\
\text { gate. This exploits } \\
\text { the characteristics of } \\
\text { the device and isn't } \\
\text { designed for. No } \\
\text { guarantee it will } \\
\text { work or it may take } \\
\text { substantial current. }\end{array}$ & $\begin{array}{l}\text { Applying a } \\
\text { negative } \\
\text { voltage pulse } \\
\text { to the gate }\end{array}$ & $\begin{array}{l}\text { Similar to GTO, } \\
\text { but less drive } \\
\text { power required }\end{array}$ \\
\hline $\begin{array}{l}\text { Control } \\
\text { Hardware }\end{array}$ & $\begin{array}{l}\text { Only } 1 \text { digital } \\
\text { output pin from } \\
\text { the } \\
\text { microcontroller } \\
\text { needed for biasing }\end{array}$ & \multicolumn{3}{|c|}{$\begin{array}{l}\text { Would need } 2 \text { microcontroller pins and external } \\
\text { components to generate negative voltage pulse. }\end{array}$} \\
\hline $\begin{array}{l}\text { Control } \\
\text { Software }\end{array}$ & $\begin{array}{l}\text { Same as previous } \\
\text { SuPER } \\
\text { implementations. } \\
\text { Either asserted or } \\
\text { not. }\end{array}$ & \multicolumn{3}{|c|}{ Added complexity with multiple output lines } \\
\hline Estimated Cost & $\$ 1-\$ 7$ & $\$ 4-\$ 8$ & $\$ 8$ & $\$ 1-\$ 2$ \\
\hline
\end{tabular}

Power MOSFETs have been used in previous phases of the SuPER system, but many different ICs were used instead of one common device. Previous devices are listed in Table 3-4 
along with some of their specifications. There were multiple different MOSFETs chosen because different students completed their projects at different times and had varying requirements for what their MOSFET should handle. These different items were chosen to handle power flow between different subsystems in previous implementations. This includes lines between the PV panel and DC-DC converter and connections amongst the battery, DC-DC converter, ultra capacitor, and discharge resistor, and the load bus. Different currents flow between these items, but selecting one MOSFET will reduce the part count and allow buying in bulk to ensure spares are available.

Table 3-5 Table 3-5 shows a new MOSFET choice from Fairchild Semiconductor which would satisfy all areas of the SuPER project. It has a constant current rating of 75A @ 25C which would be enough to handle the highest currents in the system which is around 54A from the ultra capacitor when a larger DC motor is started [13]. This would be highly overrated for certain switches, like on a low power load, but this could also extend its lifetime as it is not operating anywhere near its maximum. This particular MOSFET, model HUF75645S3ST, also has a high power rating, is cheaper, and comes with logic level gate control. This would allow the $3.3 \mathrm{~V}$ output from a microcontroller to turn the switch on by itself without the need for additional high-side drivers or buffers, drastically reducing the part count. This model also uses the familiar D2PAK design which allows the entire MOSFET to be soldered to a patch on the PCB for dissipating heat, thereby eliminating the need for a heatsink if it had been through hole. This HUF75645S3ST is not a choice set in stone, any device with similar characteristics to Table 3-5 below can be used. 
Table 3-4 - Previous MOSFETs Used on SuPER

\begin{tabular}{|l|r|r|r|r|}
\hline \multicolumn{5}{|c|}{ Previous MOSFETs used on SuPER } \\
\hline & IRF2804SPBF & IRF2804S & IRFS4310 & IRF540PBF \\
\hline Current & $75 \mathrm{~A}$ & $75 \mathrm{~A}$ & $140 \mathrm{~A}$ & $28 \mathrm{~A}$ \\
\hline Power & $300 \mathrm{~W}$ & $330 \mathrm{~W}$ & $330 \mathrm{~W}$ & $150 \mathrm{~W}$ \\
\hline Package & D2Pak & D2Pak & D2Pak & Through Hole \\
\hline Price & $\sim \$ 3.50$ & $\$ 7.00$ & $\sim \$ 4.50$ & $\$ 2.88$ \\
\hline $\begin{array}{l}\text { Logic } \\
\text { Level Gate }\end{array}$ & No & No & No & No \\
\hline Additional & MAX1822 and & MAX622 and & MAX622 & $\begin{array}{r}\text { MAX622 and } \\
\text { MM74C906 } \\
\text { HW }\end{array}$ \\
MM74C906N & $\begin{array}{r}\text { MM74906 or } \\
\text { SN7406 }\end{array}$ & & \\
\hline
\end{tabular}

Table 3-5 - Upgraded MOSFET Selection

\begin{tabular}{|l|r|}
\hline \multicolumn{2}{|c|}{ New MOSFET Selection } \\
\hline Possible Device & HUF75645S3ST \\
\hline Current & $75 \mathrm{~A}$ \\
\hline Power & $310 \mathrm{~W}$ \\
\hline Package & D2Pak \\
\hline Price & \$3.00 \\
\hline $\begin{array}{l}\text { Logic Level } \\
\text { Gate }\end{array}$ & Yes, 2V - 4V gate \\
\hline Additional HW & none \\
\hline
\end{tabular}

\subsubsection{Current Sensor}

There have been numerous current sensors utilized in previous SuPER phases; this redesign will select one sensor to replace all of these in order to provide accurate current flow data to the SuPER Controller. Past students have used the ZAP25, ZAP50, and ACS750SCA-050 current sensors as needed for their contributions to the system. These sensors didn't have any major problems with them and actually worked pretty well in the previous system. However, a better sensor was found which is from the same company as the ACS750SCA-050, Allegro Microsystems Inc. As Table 3-6 below shows, the ACS758 series has a slightly higher accuracy, faster response time, and is capable of operating with a voltage supply of 3.3V. It will also be 
capable of detecting currents up to 50A, which is plenty for every circuit component. At $\$ 7.00$ per detector it is much cheaper than Amploc Current Sensors' ZAP brand. A substitute component may be used instead of the ACS758 series, given that it meets similar performance characteristics such as $3.3 \mathrm{~V}$ to $5 \mathrm{~V}$ operation, high accuracy, and around $50 \mathrm{~A}$ detection for a similar price range.

Table 3-6 - Current Sensor Selection

\begin{tabular}{|c|c|c|c|c|}
\hline \multicolumn{5}{|c|}{ Current Sensor Selection } \\
\hline & ZAP25 & ZAP50 & $\begin{array}{l}\text { ACS750SCA- } \\
050\end{array}$ & $\begin{array}{l}\text { ACS758LCB- } \\
050\end{array}$ \\
\hline Sensor Type & Closed loop & Closed loop & Open loop & Open loop \\
\hline Current - Sensing & $25 \mathrm{~A}$ & $50 \mathrm{~A}$ & $50 \mathrm{~A}$ & $50 \mathrm{~A}$ \\
\hline Accuracy & $+-2 \%$ & $+-2 \%$ & $+-2 \%$ & $-1.2 \% \sim 2 \%$ \\
\hline Sensitivity & $37 \mathrm{mV} / \mathrm{A}$ & $23 \mathrm{mV} / \mathrm{A}$ & $40 \mathrm{mV} / \mathrm{A}$ & $40 \mathrm{mV} / \mathrm{A}$ \\
\hline Current - Supply & $10 \mathrm{~mA} \max$ & $10 \mathrm{~mA} \max$ & $7 \mathrm{~mA}$ & $10 \mathrm{~mA}$ \\
\hline Voltage - Supply & $4.5 \mathrm{~V}-10 \mathrm{~V}$ & $4.5 \mathrm{~V}-10 \mathrm{~V}$ & $4.5 \mathrm{~V}-5.5 \mathrm{~V}$ & $3 \mathrm{~V}-5.5 \mathrm{~V}$ \\
\hline Response Time & 3us & 3us & $27 \mathrm{us}$ & 4us \\
\hline Estimated Cost & $\$ 12$ & $\$ 16$ & $\$ 6$ & $\$ 7.00$ \\
\hline
\end{tabular}

\subsubsection{Voltage Scaling}

Although scaling voltages will require additional components, it is necessary for the correct operation of parts of the system. General purpose op amps are familiar to academia and offer a simple way to scale voltages. The LM324 is a general purpose quad operation amplifier that costs around $\$ 0.50$ per device. It has an operating voltage that includes single rail operation from $3.3 \mathrm{~V}$ to $5 \mathrm{~V}$, which follows the same ranges as the other devices chosen. This allows the system to continue using just one power bus for electronics throughout the subsystems and avoiding problems with other dual rail op amps. The quad design means there are four op amps built onto the same monolithic IC. For such a low price, it is convenient to have less ICs total on a given PCB, even if not all the op amps are being used. These devices will mostly be used on 
the SuPER Digitizer boards to scale input voltages to the VCC range that the A/D converters on the microcontroller will be using.

\subsubsection{Temperature Sensor}

Two types of temperature probes have been analyzed to determine the best option for integration into the SuPER system. Resistive temperature detectors (RTDs) and thermocouples have similar performance levels, but much different costs over their individual life cycles. The categories used to determine the best sensor looks at the temperature range of each device, accuracy, stability, response time, sensitivity, lifetime, and cost [33].

There are multiple types of thermocouples (B, E, J, K, R, S, and T) and RTDs (100, 500, 1000 ohms). The RTDs change resistance with temperature and require a small constant current through them to allow voltage measurements through an A/D. This small current source is $1 \mathrm{~mA}$ and the RTD must be configured in a certain way to allow these voltage readings. Two, three, and four wire configurations are common for RTD setups; more wires give more accurate and reliable readings, but also add complexity. Thermocouples work by generating a voltage between the junction of two metals and the different types use different metals for more accurate readings or higher temperature ranges.

RTDs and thermocouples both have a wide temperature range that will more than suit the needs of SuPER. The RTD has better accuracy and sensitivity, but a slower response time to temperature changes [32]. However, the difference in response times is negligible because the SuPER system does not require any temperature readings faster than a few seconds. The only thing that could generate a huge spike in temperature would be something from an electrical malfunction. If something shorted and current spiked in a subsystem, the current sensors would tip the control software off before the current induced temperature increase would be noticed. 
Stability and lifetime heavily affect the cost of each probe and lead to the RTD being the best choice. RTDs can maintain stability within $1{ }^{\circ} \mathrm{C}$ for years and are less susceptible to drifting. Thermocouples are more finicky, they can drift immediately upon installation and other factors like wire used and environment heavily affect their stability. Thermocouples require a specific wire to be used during installation based on the type of device chosen, which adds to which parts must be available because it can't use standard hook up wire. With stability drifting almost immediately, it should be clear that these sensors degrade in performance easily and they would certainly need to be replaced at least once over the lifetime of the SuPER system. High quality RTDs on the other hand may last the entire lifetime. RTDs do cost slightly more, but for less hassle and failure it is worth it.

Table 3-7 - Temperature Probe Selection

\begin{tabular}{|c|c|c|}
\hline \multicolumn{3}{|c|}{ Temperature Probe Selection } \\
\hline & RTD & Thermocouple \\
\hline Temp Range & $-200^{\circ} \mathrm{C}$ to $500^{\circ} \mathrm{C}$ & $-180^{\circ} \mathrm{C}$ to $2320^{\circ} \mathrm{C}$ \\
\hline Accuracy & $<2^{\circ} \mathrm{C}$ & $>2^{\circ} \mathrm{C}$ \\
\hline Stability & $\begin{array}{l}\text { Maintain stability } \\
\text { within } 1^{\circ} \mathrm{C} \text { for } \\
\text { years. Less } \\
\text { susceptible to } \\
\text { drifting. }\end{array}$ & $\begin{array}{l}\text { Limits aren't as strict, they } \\
\text { can begin drifting within } \\
\text { hours of use. Heavily } \\
\text { dependent on the type of } \\
\text { wire used and the situation } \\
\text { they're in }\end{array}$ \\
\hline Response & $5-10$ seconds & $<1$ second \\
\hline Sensitivity & High & Low \\
\hline Lifetime & $\begin{array}{l}\text { Platinum RTDs can } \\
\text { last a lifetime, } \\
\text { dependent on } \\
\text { environment. }\end{array}$ & $\begin{array}{l}\text { Constantly degrading, } \\
\text { must be maintained and } \\
\text { replaced periodically. }\end{array}$ \\
\hline Cost & $\sim \$ 15-\$ 20$ & $\begin{array}{l}\sim \$ 5 \text { - } \$ 10 . \text { Thermocouple } \\
\text { wire must be used, } \\
\text { replacements over } 20 \text { years } \\
\text { to consider. }\end{array}$ \\
\hline
\end{tabular}




\subsubsection{Analog MUX}

The chosen PIC microcontroller only supplies 16 A/D channels, but up to 20 or more may be needed. An analog MUX will allow more signals to route to just one A/D pin on the microcontroller. The Analog Devices ADG426BNZ 16-channel MUX allows up to 16 of the 20 required A/D signal readings to route into a single pin on the microcontroller. It will be necessary to use more $\mathrm{I} / \mathrm{O}$ lines in controlling this MUX and it will add some software complexity to multiplex the signals correctly, but it will allow all A/D readings to occur on a single PCB design.

\subsection{Lifespan and Reparability}

The goal of SuPER is to provide electricity to a remote area for 20 years, so much care was taken in designing phase 2 to extend its lifetime and make it easy to repair. One of the main goals in choosing electronic parts, as described in the section above, was to choose reliable parts and also find common functionality to reduce the overall part count. By using just one model of temperature sensor, current sensor, switch, op amp, or microcontroller it drastically cuts down on the number of parts that need to be tracked. This will prevent errors in installation or confusion about what devices actually exist in the system. The items can also be bought in bulk which will be cheaper and allow the operator to have spares on hand.

The printed circuit boards will also be brought down to one single design that is a union of all the functionality of the controller and digitizers. Each PCB will have all of the parts soldered on and ready to implement in any part of the system. Whether the board needs to be put in place to take the functionality of the controller, or any of the digitizers, it will simply be a matter plugging the right wires into the board and setting up the software so it knows where it was placed. If any of the PCBs breaks and needs repair the entire board can be replaced and 
loaded with the correct software. This will diminish any confusion over different PCB versions or implementations because there is only one PCB design. A connector will be used to route all signals that go off the board, this will also allow quick repair or installation, and bypass the need to solder any wires because of the quick connect/disconnect.

With a low target price for the entire SuPER system it is not feasible to buy the most expensive industry grade electronics. This phase 2 design looks to get the most performance and use out of the electronics we are capable of buying. Repairs are inevitable over 20 years, but this design tries to stick to the goal of under one hour for repair by making the design modular and using as few components as possible.

\subsection{Microgrid}

The microgrid is a way to put a small village onto its own personal power grid without laying infrastructure or paying the high costs an electric company would charge. The SuPER cart can distribute the energy it generates to different parts of a village through a $160 \mathrm{~V}$ transmission line. This higher voltage reduces the power loss during transmission, but will also require a future student to design an up converter for taking the system's $12 \mathrm{~V}$ up to $160 \mathrm{~V}$. Users on the other end would have a down converter to drop the $160 \mathrm{~V}$ down to $12 \mathrm{~V}$ as needed by applications such as cell phone charging in their own area of the village, away from the central power generation cart.

Matthew McFarland did work with simulations of a microgrid [14] and how it would affect the state of charge on the battery. See the Recommendations section for more information.

\subsection{Wind Turbine}

Including a wind turbine is another way for this sustainable energy project to generate clean energy for a remote location off the power grid. There are many factors to consider when 
implementing PV and wind energy in the same system and Matthew McFarland has also simulated these [14]. It is not good practice to allow the wind and PV panel to both be physically connected to the battery at the same time, as they both are trying to drive it in a different manner. There are numerous schemes that can be created for when to use wind power instead of solar power. For example, if solar insolation is low and wind speeds are high, it would make sense to charge the system using wind energy. Also, at night when the PV panels won't produce energy it is possible to run LED lighting or replenish the battery's energy via wind power. While loads are drawing a large amount of current it may be possible to have both energy generation systems at work, perhaps the wind power can be used solely for running a motor while the PV panel powers the battery in the system. This would avoid the case where the large power draw of the motor can drastically deplete the battery.

This thesis does not get into the fine details of implementing the wind turbine, but it does allow the possibility of it being added in the future. Section 5.6 will describe how the turbine can be hooked into the system at a later date. Future system designers will need to be conscious of how the control software will need to be upgraded to account for this.

\subsection{Packaging and Safety}

The current phase 1.5 implementation of SuPER in built off of the original cart design which is much too bulky for use in the field, see Figure 3-3. This original design also incorporated items that will not be necessary on the phase 2 design, like equipment for testing the motor and a flat work bench that components could be placed on. However, this won't be needed in the field, especially since the laptop will not be used in phase 2 . 


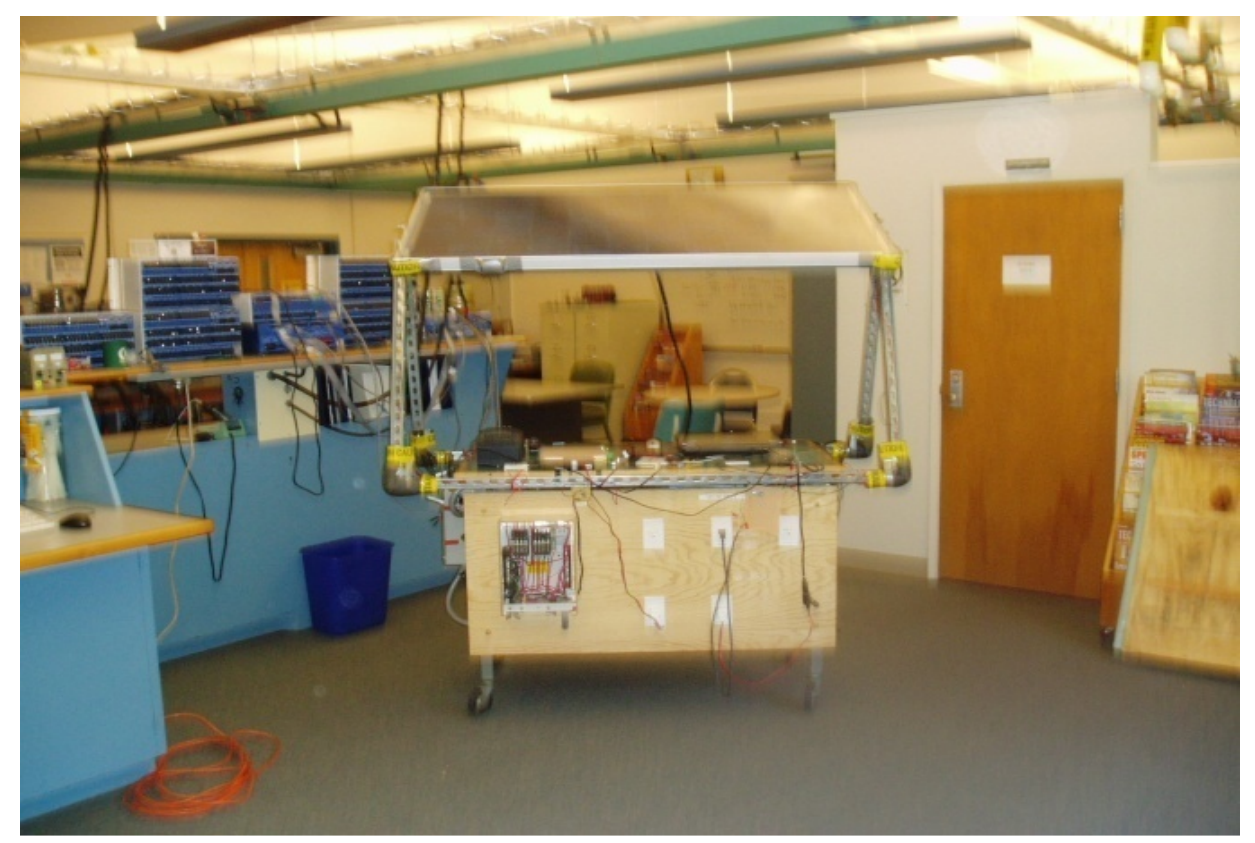

Figure 3-3 - SuPER Prototype

The new physical system layout should be compact, exhibit proper safety features, and follow standards like those given by the National Electrical Manufacturers Association, or NEMA. The system should have safety features which prevent a user from possible harm, such as high voltages or wind turbine blades. However, the system also needs its own protection from the user and other environmental factors. The user should not be allowed easy access to areas they don't need to be in, inadvertently causing damage. Environmental hazards such as the sun, wind, water, and dirt can also weaken the system lifetime. Electronic components need to have proper ventilation for thermal management, but also not be exposed to harsh weather. Figure 3-4 shows a NEMA standard box used for protection in the current SuPER implementation. It will also need to be designed before the phase 2 design of SuPER can be successfully implemented. The circuit breakers allow a user a physical way of turning on/off different subsystems. This will be valuable in case of a software malfunction which may leave the system in a dangerous state. Previous students investigated safety issues with the system and their work should be referenced 
when designing the phase 2 safety mechanisms. Refer to [15]. Figure 3-5 shows how the power will flow through the phase 2 design and where breaker switches need to be installed for manual control.

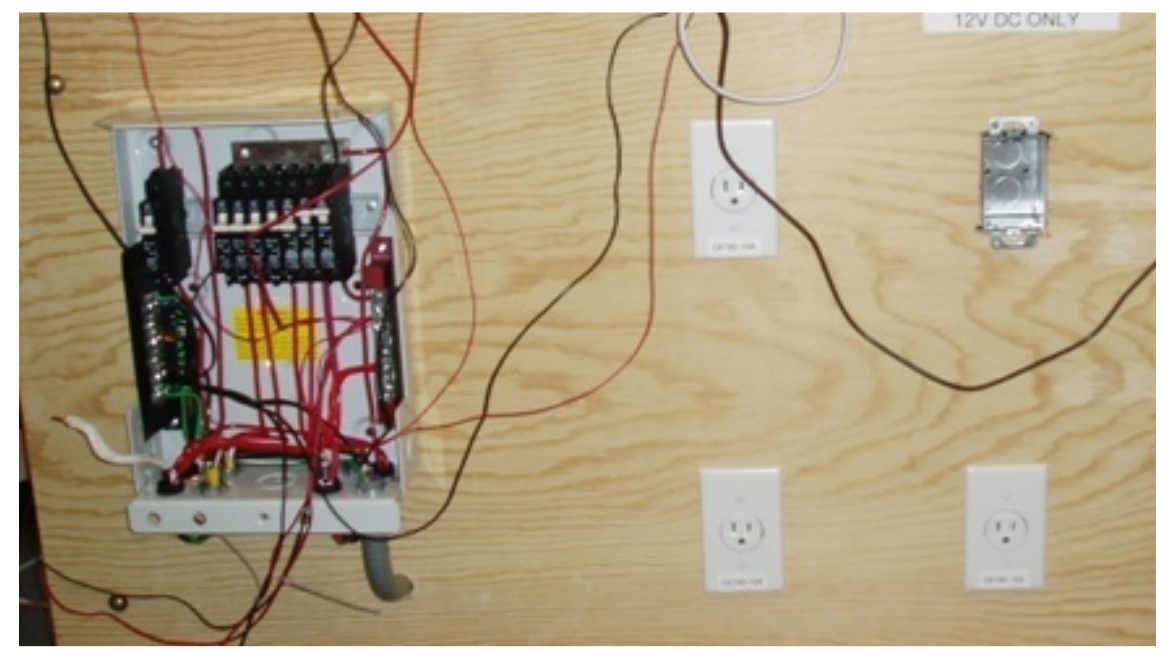

Figure 3-4 - Circuit breaker on SuPER phase 1.5 


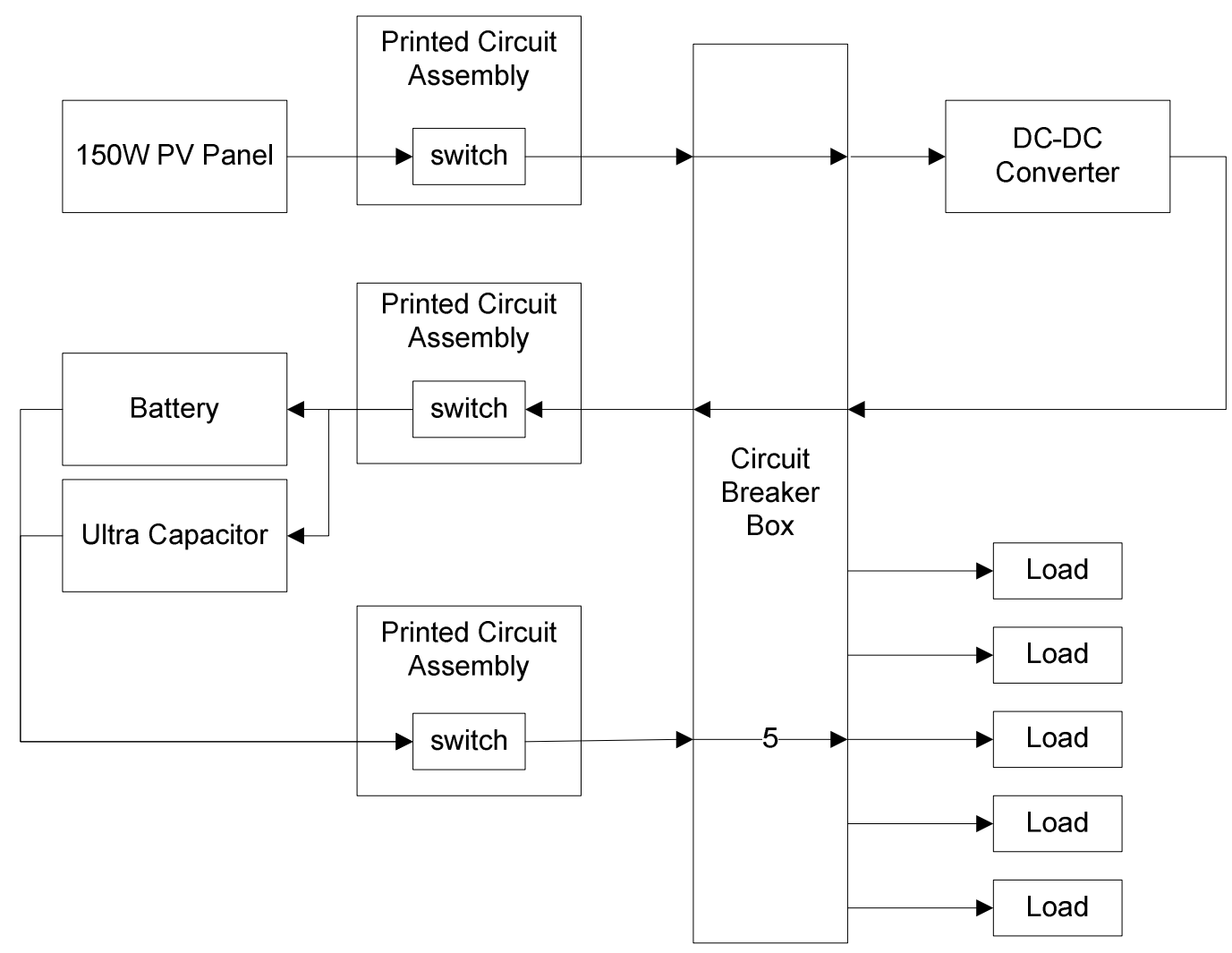

Figure 3-5 - Power flow through manual breaker box

\subsection{User Interface}

The user interface can be run on any device that contains a USB connection that will interface to the USB 2.0 OTG interface on the microcontroller. For the phase 2 design we will have it run on a laptop. The flowchart in Figure 3-6 shows how the user interface on the laptop should be setup, but no coding language is specified. It would be ideal to have it written in ' $\mathrm{C}$ ' whenever it is implemented in order to have all system software unified in language. However, this interface could be written in any language necessary as long as the appropriate USB API calls can be accessed for the operating system running on the laptop. The user interface allows a user to access the SuPER system controller to view logged data or view real-time performance. It should not interfere with the control software before, during, or after a connection is made. 


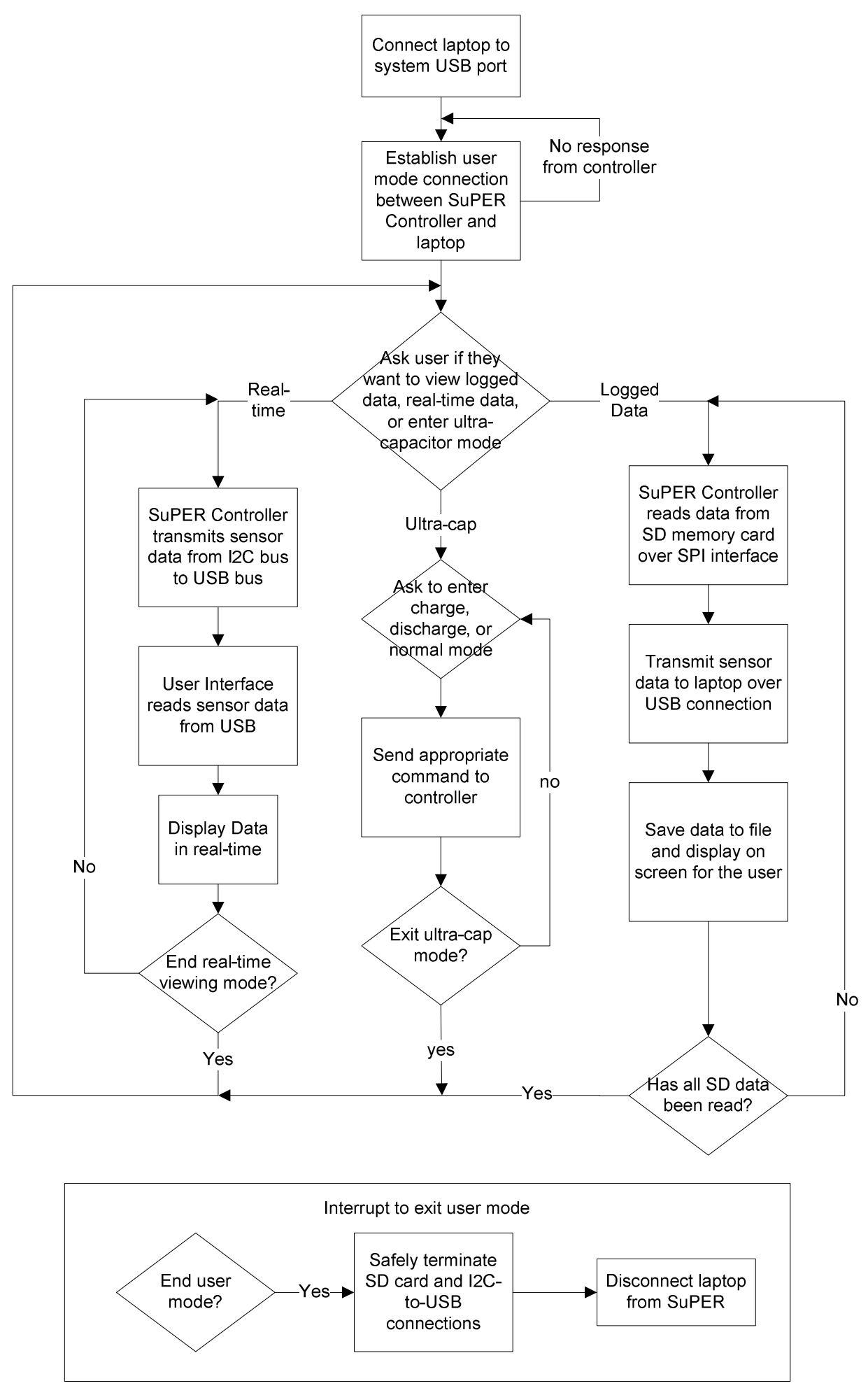

Figure 3-6 - User Interface software flowchart 


\subsection{Ultra-Capacitor}

The addition of an ultra-capacitor to the system will prevent battery levels from experiencing large spikes when powerful loads like a motor are turned on. When a large load is turned on it will draw an enormous instantaneous amount of energy which is undesirable if that energy comes solely from the battery. Figure 3-7, below, from Joseph Witts [13] shows that without an ultra-capacitor the battery's voltage experiences a significant drop and is loaded down to around $9 \mathrm{~V}$ (instead of $12 \mathrm{~V}$ ) while the motor is running. To keep the battery levels stable an ultra-capacitor can be added which will provide that boost to get something large like a motor started, without having to deplete the battery's state of charge.

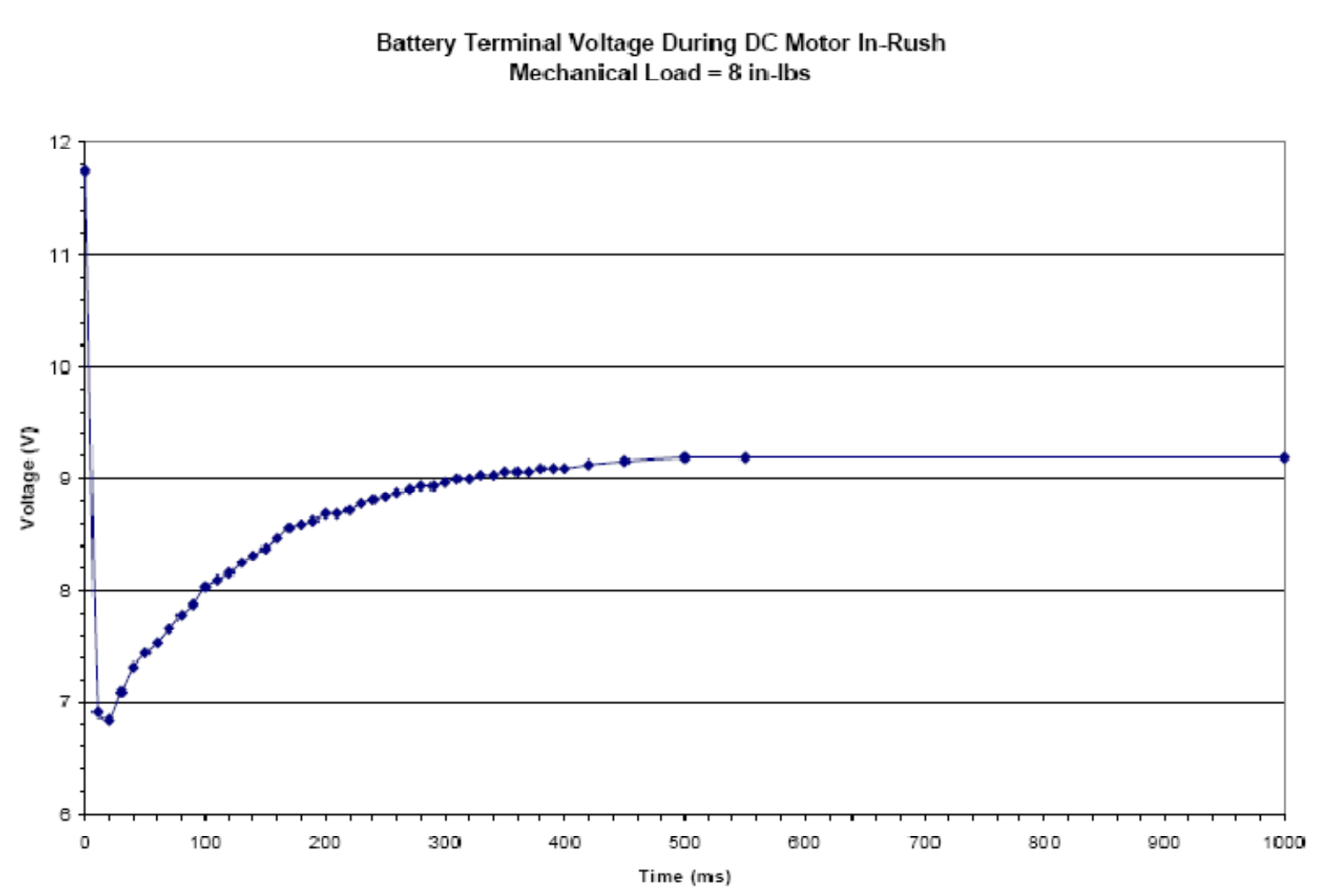

Figure 3-7 - Battery Terminal Voltage at DC Motor In-Rush 
The ultra-capacitor that was tested on previous implementations of the SuPER cart was the Maxwell Technologies 15V 58F ultra-capacitor. Similar products like the PBD-58/16.2M from PowerBurst Capacitors would provide a similar effect to what was tested by Joseph Witts. This ultra-capacitor has a working voltage of $16.2 \mathrm{~V}$ which is well above what the system battery should be supplying. This will prevent voltage overages which can shorten the lifespan of the ultra-capacitor. It is a 6-cell device with active cell balancing which also extends the life by preventing unnecessary breakdown. It is in a fully-enclosed housing making it perfect for the outdoor environment the SuPER cart will experience. According to the manufacturer's datasheet [16] after 10 years of use it stays within $20 \%$ initial capacitance rating and $100 \%$ initial internal resistance rating. Reliable components like this can extend the SuPER system lifetime by keeping the battery in a healthy state of charge.

\subsection{Part Count and Cost Breakdown}

A major goal of the phase 2 design is to bring the part count and cost down. Not only will this make the system cheaper and easier to build, but it will increase reliability and make repairs much easier. Table 3-8 is a conglomeration of the many student projects into one parts/cost breakdown. It matches up well with the information presented by Dr. Harris's 2008 solar presentation on SuPER [17]. He estimated the cost of the previous phases to be $\$ 2770$ without any of the loads. This agrees perfectly with Table 3-8 below when the cost of the white LEDs project is not included.

Table 3-9, however, shows the part count and price breakdown of this phase 2 design. This is a very conservative estimate of the cost for building one unique system. Costs would drop by a very appreciable amount if multiple systems were built and bulk pricing could be taken advantage of. This phase 2 analysis shows that the system would cost $\$ 2507$ without any of the 
loads. While this figure is not dramatically lower than the previous phase, it does reveal good information. The printed circuit assembly seems to be the major cost driver and this analysis shows pricing for single PCB runs. It is also expensive to populate all the assemblies with all of the sensors. The ultra capacitor is pricy and needs to be analyzed deeper to see if it really saves maintenance costs in terms of battery replacement. Recommendations will be made about these issues.

Reducing part count was a driver for this redesign and phase 2 benefits from the more cohesive system design. From the tables below, it is possible to see that the total part count dropped from 172 to 158 and the unique part count dropped from 79 to 43 . Not only are there fewer parts to buy and keep track of, but many of the systems use the same parts so repair and installation will be more user friendly. 
Table 3-8 - SuPER Parts List and Cost Breakdown for Phase 1.5

\begin{tabular}{|c|c|c|c|c|}
\hline \multicolumn{5}{|c|}{ SuPER parts list - Before Phase 2} \\
\hline Item & Model Number & Quantity & $\begin{array}{l}\text { Unit } \\
\text { price }\end{array}$ & $\begin{array}{l}\text { Total } \\
\text { Price }\end{array}$ \\
\hline \multicolumn{5}{|c|}{ COTS } \\
\hline 150W Solar PV Panel & BP 150SX & 1 & $\$ 600.00$ & $\$ 600.00$ \\
\hline 98 Ah AGM Battery & MK-8G31DT & 1 & $\$ 300.00$ & $\$ 300.00$ \\
\hline 58F Ultra Capacitor & BMOD0058 & 1 & $\$ 200.00$ & $\$ 200.00$ \\
\hline Laptop & $\begin{array}{l}\text { Dell Inspiron } \\
\text { B120 }\end{array}$ & 1 & $\$ 450.00$ & $\$ 450.00$ \\
\hline NI 14-bit DAQ & NI USB-6009 & 3 & $\$ 279.00$ & $\$ 837.00$ \\
\hline \multicolumn{5}{|c|}{ In House Subsystems } \\
\hline DC-DC Converter & & 1 & $\$ 51.95$ & $\$ 51.95$ \\
\hline LED Fixture & & 2 & $\$ 119.60$ & $\$ 239.20$ \\
\hline Sensor Board & & 1 & $\$ 24.86$ & $\$ 24.86$ \\
\hline PIC Board & & 1 & $\$ 26.00$ & $\$ 26.00$ \\
\hline Main Switch Board & & 1 & $\$ 254.29$ & $\$ 254.29$ \\
\hline PV Switch Board & & 1 & $\$ 23.91$ & $\$ 23.91$ \\
\hline \multicolumn{5}{|c|}{ Miscellaneous } \\
\hline Jumpers (20 pack) & & 1 & $\$ 1.00$ & $\$ 1.00$ \\
\hline \multicolumn{4}{|c|}{ Total Price } & $\$ 3,008.21$ \\
\hline \multicolumn{4}{|c|}{ Unique Part Count } & 79 \\
\hline \multicolumn{4}{|c|}{ Total Part Count } & 172 \\
\hline
\end{tabular}

\begin{tabular}{|l|l|r|r|r|}
\hline \multicolumn{5}{|c|}{ In House Subsystem Breakdown } \\
\hline \multicolumn{5}{|c|}{ DC-DC Converter } \\
\hline 500uH Inductor & IHV15BJ500 & 1 & $\$ 18.58$ & $\$ 18.58$ \\
\hline MOSFET & IRF3205ZPBF & 2 & $\$ 2.06$ & $\$ 4.12$ \\
\hline Gate Driver & IRS2004PBF & 1 & $\$ 1.70$ & $\$ 1.70$ \\
\hline Ultra-Fast Diode & MUR120-E3/4 & 2 & $\$ 0.37$ & $\$ 0.74$ \\
\hline Ultra-Fast Diode & MUR120G & 1 & $\$ 0.24$ & $\$ 0.24$ \\
\hline Super Barrier Diode & SBR2060CT & 1 & $\$ 1.00$ & $\$ 1.00$ \\
\hline Schottky Diode & MBR2045CTPBF & 1 & $\$ 1.25$ & $\$ 1.25$ \\
\hline 47ohm resistor & & 2 & $\$ 0.10$ & $\$ 0.20$ \\
\hline 0.47 uF capacitor & & 2 & $\$ 0.10$ & $\$ 0.20$ \\
\hline 10uF capacitor & & 1 & $\$ 0.12$ & $\$ 0.12$ \\
\hline $0.1 \mathrm{uF}$ capacitor & & 2 & $\$ 0.10$ & $\$ 0.20$ \\
\hline 3.3uF capacitor & & 2 & $\$ 0.24$ & $\$ 0.48$ \\
\hline 1000uF capacitor & & 4 & $\$ 0.78$ & $\$ 3.12$ \\
\hline Through Hole PCB & (estimation) & 1 & $\$ 10.00$ & $\$ 10.00$ \\
\hline Enclosure & & 1 & $\$ 10.00$ & $\$ 10.00$
\end{tabular}


Table 3-8 (continued)

\begin{tabular}{|c|c|c|c|c|}
\hline \multirow{2}{*}{\multicolumn{4}{|c|}{$\begin{array}{r}\text { Total Price } \\
\text { Unique Part Count }\end{array}$}} & $\$ 51.95$ \\
\hline & & & & 15 \\
\hline \multicolumn{4}{|c|}{\begin{tabular}{|l|} 
Total Part Count \\
\end{tabular}} & 24 \\
\hline \multicolumn{5}{|c|}{ LED Fixture } \\
\hline Cree XR-E LED & XR7090WT & 5 & $\$ 10.00$ & $\$ 50.00$ \\
\hline $\begin{array}{l}\text { Philips Lumileds Luxeon III } \\
\text { LED }\end{array}$ & LXHL-LW3C & 5 & $\$ 4.05$ & $\$ 20.25$ \\
\hline $\begin{array}{l}\text { Texas Instruments Power } \\
\text { Module }\end{array}$ & PTH12050WAH & 2 & $\$ 10.96$ & $\$ 21.92$ \\
\hline Heatsink & free or unknown & 1 & $\$ 0.00$ & $\$ 0.00$ \\
\hline Aluminum Sheet Metal & & 1 & $\$ 3.22$ & $\$ 3.22$ \\
\hline Arctic Silver Adhesive & & 1 & $\$ 19.95$ & $\$ 19.95$ \\
\hline 2 pack of switches & & 2 & $\$ 1.99$ & $\$ 3.98$ \\
\hline 100uF capacitor & & 1 & $\$ 0.08$ & $\$ 0.08$ \\
\hline resistor & & 2 & $\$ 0.10$ & $\$ 0.20$ \\
\hline \multicolumn{4}{|c|}{$\begin{array}{l}\text { Total Price } \\
\end{array}$} & $\$ 119.60$ \\
\hline \multicolumn{4}{|c|}{ Unique Part Count } & 9 \\
\hline \multicolumn{4}{|c|}{ Total Part Count } & 20 \\
\hline \multicolumn{5}{|c|}{ Sensor Board } \\
\hline Current Sensor & ZAP25 & 1 & $\$ 11.99$ & $\$ 11.99$ \\
\hline Voltage Regulator & LM50 50T-23 & 1 & $\$ 0.55$ & $\$ 0.55$ \\
\hline Quad Op Amp & LM324 & 1 & $\$ 1.24$ & $\$ 1.24$ \\
\hline Voltage Regulator & LM340 & 1 & $\$ 1.59$ & $\$ 1.59$ \\
\hline Copper & free or unknown & 1 & $\$ 0.00$ & $\$ 0.00$ \\
\hline $1 \mathrm{uF}$ capacitor & & 3 & $\$ 1.00$ & $\$ 3.00$ \\
\hline Jumpers & in miscellaneous & 1 & $\$ 0.00$ & $\$ 0.00$ \\
\hline $.56 \mathrm{kohm}$ resistor & & 1 & & \\
\hline $2.2 \mathrm{kohm}$ resistor & & 1 & & \\
\hline $10 \mathrm{kohm}$ resistor & & 1 & & \\
\hline $15 \mathrm{kohm}$ resistor & & 1 & & \\
\hline 50 kohm resistor & & 1 & & \\
\hline 150 kohm resistor & & 1 & & $\$ 6.49$ \\
\hline \multicolumn{4}{|c|}{ Total Price } & $\$ 24.86$ \\
\hline \multicolumn{4}{|c|}{ Unique Part Count } & 13 \\
\hline \multicolumn{4}{|c|}{ Total Part Count } & 15 \\
\hline \multicolumn{5}{|c|}{ PIC Board } \\
\hline Buffer & MMC74C90X & 1 & $\$ 2.00$ & $\$ 2.00$ \\
\hline Crystal Oscillator & & 1 & $\$ 1.50$ & $\$ 1.50$ \\
\hline Voltage Regulator & LM340 & 1 & $\$ 1.59$ & $\$ 1.59$ \\
\hline RS232 to TTL Converter & MAX232 & 1 & $\$ 1.62$ & $\$ 1.62$ \\
\hline
\end{tabular}


Table 3-8 (continued)

\begin{tabular}{|c|c|c|c|c|}
\hline PIC Microcontroller & & 1 & $\$ 3.00$ & $\$ 3.00$ \\
\hline $1 \mathrm{uF}$ capacitor & & 10 & $\$ 1.00$ & $\$ 10.00$ \\
\hline Resistor Kit & & 1 & $\$ 6.29$ & $\$ 6.29$ \\
\hline Jumper & in miscellaneous & 1 & $\$ 0.00$ & $\$ 0.00$ \\
\hline DB9 & & 1 & $\$ 4.59$ & \\
\hline Copper & free or unknown & 1 & $\$ 0.00$ & \\
\hline \multicolumn{4}{|c|}{ Total Price } & $\$ 26.00$ \\
\hline \multicolumn{4}{|c|}{ Unique Part Count } & 10 \\
\hline \multicolumn{4}{|c|}{ Total Part Count } & 19 \\
\hline \multicolumn{5}{|c|}{ Main Switch Board } \\
\hline Buffer & MMC74C90X & 1 & $\$ 2.00$ & $\$ 2.00$ \\
\hline Transistors & IRFBF30 & 5 & $\$ 1.99$ & $\$ 9.95$ \\
\hline Jumpers & in miscellaneous & 3 & $\$ 0.00$ & $\$ 0.00$ \\
\hline Power Connectors & & 6 & $\$ 1.70$ & $\$ 10.20$ \\
\hline Quad Op Amp & LM324 & 3 & $\$ 1.24$ & $\$ 3.72$ \\
\hline Current Sensor & ZAP25 & 5 & $\$ 11.99$ & $\$ 59.95$ \\
\hline 5A Adjustable Regulator & LM338 & 1 & $\$ 1.59$ & $\$ 1.59$ \\
\hline Voltage Regulator & LM340 & 1 & $\$ 1.59$ & $\$ 1.59$ \\
\hline Copper & free or unknown & 1 & $\$ 0.00$ & $\$ 0.00$ \\
\hline Board through PCB Express & & 1 & $\$ 147.00$ & $\$ 147.00$ \\
\hline $1 \mathrm{uF}$ capacitor & & 12 & $\$ 1.00$ & $\$ 12.00$ \\
\hline $1 \mathrm{kohm}$ resistor & & 10 & & \\
\hline $10 \mathrm{kohm}$ resistor & & 7 & & \\
\hline $15 \mathrm{kohm}$ resistor & & 7 & & \\
\hline $50 \mathrm{kohm}$ resistor & & 6 & & \\
\hline 150 kohm resistor & & 6 & & $\$ 6.29$ \\
\hline \multicolumn{4}{|c|}{ Total Price } & $\$ 254.29$ \\
\hline \multicolumn{4}{|c|}{ Unique Part Count } & 16 \\
\hline \multicolumn{4}{|c|}{ Total Part Count } & 75 \\
\hline \multicolumn{5}{|c|}{ PV Switch Board } \\
\hline \multirow[t]{2}{*}{ 5A Adjustable Regulator } & LM338 & 1 & $\$ 1.59$ & $\$ 1.59$ \\
\hline & PV1050 & 1 & $\$ 6.05$ & $\$ 6.05$ \\
\hline Tri-state quad buffer & MM74HC125 & 1 & $\$ 2.59$ & $\$ 2.59$ \\
\hline Transistor & IRFBE20 & 1 & $\$ 1.99$ & $\$ 1.99$ \\
\hline Jumper & in miscellaneous & 1 & $\$ 0.00$ & $\$ 0.00$ \\
\hline Power Connectors & & 2 & $\$ 1.70$ & $\$ 3.40$ \\
\hline $1 \mathrm{uF}$ capacitor & & 2 & $\$ 1.00$ & $\$ 2.00$ \\
\hline $1 \mathrm{kohm}$ resistor & & 2 & & \\
\hline $1.5 \mathrm{kohm}$ resistor & & 1 & & $\$ 6.29$ \\
\hline
\end{tabular}


Table 3-8 (continued)

\begin{tabular}{|r|r|}
\hline Total Price & $\$ 23.91$ \\
\hline Unique Part Count & 9 \\
\hline Total Part Count & 12 \\
\hline
\end{tabular}


Table 3-9 - SuPER Parts List and Cost Breakdown for Phase 2

\begin{tabular}{|c|c|c|c|c|}
\hline \multicolumn{5}{|c|}{ SuPER parts list - Phase 2} \\
\hline Item & Model Number & Quantity & $\begin{array}{l}\text { Unit } \\
\text { price }\end{array}$ & $\begin{array}{l}\text { Total } \\
\text { Price }\end{array}$ \\
\hline \multicolumn{5}{|c|}{ COTS } \\
\hline 150W Solar PV Panel & BP 150SX & 1 & $\$ 600.00$ & $\$ 600.00$ \\
\hline 98 Ah AGM Battery & MK-8G31DT & 1 & $\$ 300.00$ & $\$ 300.00$ \\
\hline 58F Ultra Capacitor & PBD-58/16.2M & 1 & $\$ 247.00$ & $\$ 247.00$ \\
\hline \multicolumn{5}{|c|}{ In House Subsystems } \\
\hline DC-DC Converter & & 1 & $\$ 51.95$ & $\$ 51.95$ \\
\hline LED Fixture & & 2 & $\$ 119.60$ & $\$ 239.20$ \\
\hline Printed Circuit Assembly & & 4 & $\$ 324.33$ & $\$ 1,297.32$ \\
\hline \multicolumn{5}{|c|}{ Miscellaneous } \\
\hline $\begin{array}{l}\text { 1GB Standard Capacity SD } \\
\text { Card }\end{array}$ & & 1 & $\$ 10.00$ & $\$ 10.00$ \\
\hline Jumpers (20 pack) & & 1 & $\$ 1.00$ & $\$ 1.00$ \\
\hline \multicolumn{4}{|c|}{ Total Price } & $\$ 2,746.47$ \\
\hline \multicolumn{4}{|c|}{ Unique Part Count } & 43 \\
\hline \multicolumn{4}{|c|}{ Total Part Count } & 158 \\
\hline
\end{tabular}

\begin{tabular}{|c|c|c|c|c|}
\hline \multicolumn{5}{|c|}{ In House Subsystem Breakdown } \\
\hline \multicolumn{5}{|c|}{ DC-DC Converter } \\
\hline $500 \mathrm{uH}$ Inductor & IHV15BJ500 & 1 & $\$ 18.58$ & $\$ 18.58$ \\
\hline MOSFET & IRF3205ZPBF & 2 & $\$ 2.06$ & $\$ 4.12$ \\
\hline Gate Driver & IRS2004PBF & 1 & $\$ 1.70$ & $\$ 1.70$ \\
\hline Ultra-Fast Diode & MUR120-E3/4 & 2 & $\$ 0.37$ & $\$ 0.74$ \\
\hline Ultra-Fast Diode & MUR120G & 1 & $\$ 0.24$ & $\$ 0.24$ \\
\hline Super Barrier Diode & SBR2060CT & 1 & $\$ 1.00$ & $\$ 1.00$ \\
\hline Schottky Diode & MBR2045CTPBF & 1 & $\$ 1.25$ & $\$ 1.25$ \\
\hline 47ohm resistor & & 2 & $\$ 0.10$ & $\$ 0.20$ \\
\hline $0.47 \mathrm{uF}$ capacitor & & 2 & $\$ 0.10$ & $\$ 0.20$ \\
\hline 10uF capacitor & & 1 & $\$ 0.12$ & $\$ 0.12$ \\
\hline $0.1 \mathrm{uF}$ capacitor & & 2 & $\$ 0.10$ & $\$ 0.20$ \\
\hline $3.3 \mathrm{uF}$ capacitor & & 2 & $\$ 0.24$ & $\$ 0.48$ \\
\hline $1000 \mathrm{uF}$ capacitor & & 4 & $\$ 0.78$ & $\$ 3.12$ \\
\hline PCB & & 1 & $\$ 10.00$ & $\$ 10.00$ \\
\hline Enclosure & & 1 & $\$ 10.00$ & $\$ 10.00$ \\
\hline \multicolumn{4}{|c|}{ Total Price } & $\$ 51.95$ \\
\hline \multicolumn{4}{|c|}{ Unique Part Count } & 15 \\
\hline \multicolumn{4}{|c|}{ Total Part Count } & 24 \\
\hline
\end{tabular}


Table 3-9 (continued)

\begin{tabular}{|c|c|c|c|c|}
\hline Cree XR-E LED & XR7090WT & 5 & $\$ 10.00$ & $\$ 50.00$ \\
\hline $\begin{array}{l}\text { Philips Lumileds Luxeon III } \\
\text { LED }\end{array}$ & LXHL-LW3C & 5 & $\$ 4.05$ & $\$ 20.25$ \\
\hline $\begin{array}{l}\text { Texas Instruments Power } \\
\text { Module }\end{array}$ & PTH12050WAH & 2 & $\$ 10.96$ & $\$ 21.92$ \\
\hline Heatsink & free or unknown & 1 & $\$ 0.00$ & $\$ 0.00$ \\
\hline Aluminum Sheet Metal & & 1 & $\$ 3.22$ & $\$ 3.22$ \\
\hline Arctic Silver Adhesive & & 1 & $\$ 19.95$ & $\$ 19.95$ \\
\hline 2 pack of switches & & 2 & $\$ 1.99$ & $\$ 3.98$ \\
\hline $100 \mathrm{uF}$ capacitor & & 1 & $\$ 0.08$ & $\$ 0.08$ \\
\hline resistor & & 2 & $\$ 0.10$ & $\$ 0.20$ \\
\hline \multicolumn{4}{|c|}{ Total Price } & $\$ 119.60$ \\
\hline \multicolumn{4}{|c|}{ Unique Part Count } & 9 \\
\hline \multicolumn{4}{|c|}{$\begin{array}{rc}\text { Total Part Count } \\
\end{array}$} & 20 \\
\hline \multicolumn{5}{|c|}{ Printed Circuit Assembly (estimate) } \\
\hline Custom PCB & & 1 & $\$ 147.00$ & $\$ 147.00$ \\
\hline PIC Microcontroller & PIC24FJ256GB110 & 1 & $\$ 7.38$ & $\$ 7.38$ \\
\hline MOSFET Switch & HUF75645S3ST & 11 & $\$ 3.22$ & $\$ 35.42$ \\
\hline Current Sensor & ACS758LCB-050 & 8 & $\$ 6.00$ & $\$ 48.00$ \\
\hline Quad Op Amp & LM324 & 6 & $\$ 1.23$ & $\$ 7.38$ \\
\hline Resistors & (estimate) & 40 & $\$ 0.10$ & $\$ 4.00$ \\
\hline Capacitors & (estimate) & 30 & $\$ 0.14$ & $\$ 4.20$ \\
\hline Honeywell Platinum RTD & HEL-777-A-T-0 & 3 & $\$ 18.05$ & $\$ 54.15$ \\
\hline Analog Devices $16 \mathrm{ch}$. MUX & ADG426BNZ & 1 & $\$ 9.75$ & $\$ 9.75$ \\
\hline TYCO SD Card Connector & $2041021-3$ & 1 & $\$ 2.05$ & $\$ 2.05$ \\
\hline USB Connector & & 1 & $\$ 1.00$ & $\$ 1.00$ \\
\hline 3.3V Voltage Regulator & & 1 & $\$ 2.00$ & $\$ 2.00$ \\
\hline 5V Voltage Regulator & & 1 & $\$ 2.00$ & $\$ 2.00$ \\
\hline \multicolumn{4}{|c|}{ Total Price } & $\$ 324.33$ \\
\hline \multicolumn{4}{|c|}{ Unique Part Count } & 13 \\
\hline \multicolumn{4}{|c|}{ Total Part Count } & 105 \\
\hline \multicolumn{5}{|c|}{ Circuit Breaker Box (estimate) } \\
\hline Enclosure & & 1 & $\$ 50.00$ & $\$ 50.00$ \\
\hline Breaker Switch & & 4 & $\$ 8.00$ & $\$ 32.00$ \\
\hline \multicolumn{4}{|c|}{ Total Price } & $\$ 82.00$ \\
\hline \multicolumn{4}{|c|}{ Unique Part Count } & 2 \\
\hline \multicolumn{4}{|c|}{ Total Part Count } & 5 \\
\hline
\end{tabular}




\section{Sub-System Requirements}

The following sections outline the requirements of the individual sub-systems for the phase 2 design of SuPER. They are meant to guide the project implementers in creating a subsystem that will perform well, but also integrate with the other sub-systems. The notes column of the following requirements offer implementation advice or ask questions that need to be answered by the designers. Subsystem requirements are defined below for: the controller, digitizer, printed circuit assemblies, data logging, user interface, white LEDs, system packaging, microgrid, wind turbine, and environmental chamber.

\subsection{SuPER Controller}

\begin{tabular}{|l|l|l|}
\hline Req ID & \multicolumn{1}{|c|}{ Description } & Notes \\
\hline SC_0080 & $\begin{array}{l}\text { The controller software shall } \\
\text { initiate the super system, provide } \\
\text { operational control using real time } \\
\text { status data, detect and recover from } \\
\text { error conditions, and terminate } \\
\text { system operation. }\end{array}$ & \\
\hline SC_0090 & $\begin{array}{l}\text { The controller shall provide a real } \\
\text { time clock and/or calendar function } \\
\text { for time-stamping data entries into } \\
\text { the SD memory card }\end{array}$ & $\begin{array}{l}\text { Real-Time } \\
\text { Clock/Calendar } \\
\text { (RTCC) on PIC }\end{array}$ \\
\hline SC_0100 & $\begin{array}{l}\text { The controller shall provide one } \\
\text { PWM interface with a frequency } \\
\text { between 10KHz and 100KHz }\end{array}$ & \\
\hline SC_0120 & $\begin{array}{l}\text { The duty cycle of the PWM signal } \\
\text { shall be altered in accordance with } \\
\text { the MPPT algorithm being run in } \\
\text { the control software }\end{array}$ & \\
\hline SC_0200 & $\begin{array}{l}\text { The controller shall provide at least } \\
\text { one SPI interface }\end{array}$ & $\begin{array}{l}\text { 1-10 MHz? } \\
\text { followed for hardware and software } \\
\text { when using the SPI module on the } \\
\text { microcontroller }\end{array}$ \\
\hline SC_0201 & $\begin{array}{l}\text { The controller must be able to read } \\
\text { and write to an SD memory card } \\
\text { specifications online }\end{array}$ & \\
\hline SC_0210 & \\
\hline
\end{tabular}




\begin{tabular}{|c|c|c|}
\hline & over the SPI interface & \\
\hline SC_0220 & $\begin{array}{l}\text { The controller must be able to write } \\
\text { twenty } 10 \text {-bit A/D measurements to } \\
\text { the SD memory card in } 5 \text { minute } \\
\text { intervals }\end{array}$ & \\
\hline SC_0221 & $\begin{array}{l}\text { The controller must time-stamp } \\
\text { data that is stored in the SD } \\
\text { memory card }\end{array}$ & use RTCC \\
\hline SC_0232 & $\begin{array}{l}\text { One year's worth of data must be } \\
\text { downloaded by the User Interface } \\
\text { in less than } 20 \text { minutes }\end{array}$ & $\begin{array}{l}\text { Refer to SuPER Data } \\
\text { Rate Analysis }\end{array}$ \\
\hline SC_0300 & $\begin{array}{l}\text { The controller shall provide at least } \\
\text { one } \mathrm{I} 2 \mathrm{C} \text { interfaces }\end{array}$ & \\
\hline SC_0301 & $\begin{array}{l}\text { I2C specifications should be } \\
\text { followed for hardware and software } \\
\text { when using the } \mathrm{I} 2 \mathrm{C} \text { module on the } \\
\text { microcontroller }\end{array}$ & $\begin{array}{l}\text { Look up proper } \mathrm{I} 2 \mathrm{C} \\
\text { specifications online }\end{array}$ \\
\hline SC_0320 & $\begin{array}{l}\text { The I2C interface shall be able to } \\
\text { receive twenty } 10 \text {-bit sensor values } \\
\text { in } 10 \text { milliseconds or less }\end{array}$ & $\begin{array}{l}\text { Refer to SuPER Data } \\
\text { Rate Analysis }\end{array}$ \\
\hline SC_0350 & $\begin{array}{l}\text { The controller shall allow up to } \\
\text { three PCBs configured with SuPER } \\
\text { Digitizer software to connect to its } \\
\text { I2C SDA and SCL lines }\end{array}$ & $\begin{array}{l}\text { Keep in mind } \mathrm{I} 2 \mathrm{C} \text { bus } \\
\text { capacitance maximum } \\
\text { values from } \mathrm{I} 2 \mathrm{C} \\
\text { specification }\end{array}$ \\
\hline SC_0355 & $\begin{array}{l}\text { The controller shall be able to } \\
\text { address and communicate } \\
\text { exclusively with any of the SuPER } \\
\text { Digitzer boards connected to its } \\
\text { I2C bus }\end{array}$ & \\
\hline SC_0357 & $\begin{array}{l}\text { The controller shall be able to send } \\
\text { commands and receive data from a } \\
\text { specific SuPER Digitizer board } \\
\text { connected to its I } 2 \mathrm{C} \text { bus }\end{array}$ & \\
\hline SC_0360 & $\begin{array}{l}\text { The microcontroller on the PCB on } \\
\text { which the SuPER Controller will } \\
\text { reside shall contain all software } \\
\text { code for implementation as either a } \\
\text { controller or digitizer board. Upon } \\
\text { startup, the controller will be } \\
\text { initiated to run the SuPER } \\
\text { Controller code, while the } \\
\text { digitizers will be initiated to run the } \\
\text { SuPER Digitizer code. }\end{array}$ & $\begin{array}{l}\text { Refer to System } \\
\text { Software Diagrams }\end{array}$ \\
\hline
\end{tabular}




\begin{tabular}{|c|c|c|}
\hline SC_0370 & $\begin{array}{l}\text { The controller shall provide one } \\
\text { USB interface }\end{array}$ & \\
\hline SC_0371 & $\begin{array}{l}\text { USB specifications should be } \\
\text { followed for hardware and software } \\
\text { when using the USB module on the } \\
\text { microcontroller }\end{array}$ & $\begin{array}{l}\text { Look up proper USB } \\
\text { specifications online }\end{array}$ \\
\hline SC_0375 & $\begin{array}{l}\text { The USB interface shall be able to } \\
\text { send real-time sensor data or stored } \\
\text { data on an SD memory card to a } \\
\text { user device such as a laptop }\end{array}$ & \\
\hline SC_0380 & $\begin{array}{l}\text { The USB interface shall be able to } \\
\text { accept commands from a user } \\
\text { device for controlling the ultra- } \\
\text { capacitor }\end{array}$ & $\begin{array}{l}\text { Develop command } \\
\text { words or some data } \\
\text { structure to pass cmds } \\
\text { over USB }\end{array}$ \\
\hline SC_0385 & $\begin{array}{l}\text { The controller may need to toggle } \\
\text { the load switches as the ultra- } \\
\text { capacitor changes charging modes }\end{array}$ & $\begin{array}{l}\text { Refer to ultra- } \\
\text { capacitor switch } \\
\text { operation }\end{array}$ \\
\hline SC_0390 & $\begin{array}{l}\text { The controller should acknowledge } \\
\text { that commands requested by the } \\
\text { laptop over USB have been } \\
\text { accomplished }\end{array}$ & \\
\hline SC_0400 & $\begin{array}{l}\text { The SuPER Controller shall } \\
\text { provide commands for turning the } \\
\text { digitizers' MOSFET switches on or } \\
\text { off over the I2C interface }\end{array}$ & $\begin{array}{l}\text { Develop command } \\
\text { words or some data } \\
\text { structure to pass cmds } \\
\text { over I2C }\end{array}$ \\
\hline SC_0500 & $\begin{array}{l}\text { The existing control software shall } \\
\text { be ported to the PIC } \\
\text { microcontroller and modified as } \\
\text { appropriate to satisfy the super } \\
\text { system requirements }\end{array}$ & $\begin{array}{l}\text { Refer to SuPER Code } \\
\text { Review document }\end{array}$ \\
\hline SC_0520 & $\begin{array}{l}\text { The control software must continue } \\
\text { running, uninterrupted, with real- } \\
\text { time sensor data while the USB } \\
\text { interface is sending the same sensor } \\
\text { data to the user interface }\end{array}$ & $\begin{array}{l}\text { Refer to System } \\
\text { Software Diagrams }\end{array}$ \\
\hline SC_0521 & $\begin{array}{l}\text { The control software shall have an } \\
\text { interrupt to detect if an external } \\
\text { physical emergency switch is } \\
\text { activated and terminate system } \\
\text { operation }\end{array}$ & $\begin{array}{l}\text { Refer to System } \\
\text { Software Diagrams }\end{array}$ \\
\hline SC_0522 & $\begin{array}{l}\text { The control software must continue } \\
\text { running if the read/write interface } \\
\text { to the SD memory card fails }\end{array}$ & $\begin{array}{l}\text { Refer to System } \\
\text { Software Diagrams }\end{array}$ \\
\hline
\end{tabular}




\begin{tabular}{|l|l|l|} 
SC_0540 & $\begin{array}{l}\text { The control software must have } \\
\text { error detection and recovery } \\
\text { schemes, including instances when } \\
\text { attached devices fail }\end{array}$ & $\begin{array}{l}\text { Refer to SuPER } \\
\text { Software Error } \\
\text { Conditions in thesis } \\
\text { paper }\end{array}$ \\
\hline SC_0541 & $\begin{array}{l}\text { The control software must shut the } \\
\text { system down if any voltage, } \\
\text { temperature, or current levels } \\
\text { exceed critical levels }\end{array}$ & $\begin{array}{l}\text { critical levels need to } \\
\text { be defined }\end{array}$ \\
\hline SC_0600 & $\begin{array}{l}\text { The control software shall provide } \\
\text { intelligent load control to prevent } \\
\text { the battery from discharging below } \\
\text { 80\% }\end{array}$ & $\begin{array}{l}\text { Matt McFarland's } \\
\text { code will prevent } \\
\text { users from using } \\
\text { power }\end{array}$ \\
\hline SC_0700 & $\begin{array}{l}\text { The control software shall monitor } \\
\text { and control the amount of power } \\
\text { that is distributed from the central } \\
\text { SuPER cart through the microgrid }\end{array}$ & Define limit \\
\hline
\end{tabular}




\subsection{SuPER Digitizer}

\begin{tabular}{|c|c|c|}
\hline Req ID & Description & Notes \\
\hline SD_0200 & $\begin{array}{l}\text { The digitizer shall be able to input } \\
\text { up to } 20 \text { channels for analog to } \\
\text { digital conversion }\end{array}$ & $\begin{array}{l}\text { Will have to make } \\
\text { use of the 16:1 } \\
\text { Analog MUX }\end{array}$ \\
\hline SD_0300 & $\begin{array}{l}\text { The digitizer shall have one I2C } \\
\text { interface to communicate with the } \\
\text { SuPER Controller }\end{array}$ & \\
\hline SD_0301 & $\begin{array}{l}\text { I2C specifications should be } \\
\text { followed for hardware and software } \\
\text { when using the I } 2 \mathrm{C} \text { module on the } \\
\text { microcontroller }\end{array}$ & $\begin{array}{l}\text { Look up proper I2C } \\
\text { specifications online }\end{array}$ \\
\hline SD_0310 & $\begin{array}{l}\text { A single SuPER Digitizer board } \\
\text { shall be able to transmit up to } 10 \\
\text { 10-bit sensor measurements over } \\
\text { the ICC interface to the SuPER } \\
\text { Controller every } 10 \text { milliseconds }\end{array}$ & \\
\hline SD_0330 & $\begin{array}{l}\text { The digitizer shall send all } \mathrm{A} / \mathrm{D} \\
\text { telemetry measurements when } \\
\text { queried by the controller }\end{array}$ & \\
\hline SD_0340 & $\begin{array}{l}\text { The digitizer shall listen and } \\
\text { respond to requests from the } \\
\text { SuPER Controller to turn on or off } \\
\text { any of the MOSFET switches } \\
\text { contained on its PCB }\end{array}$ & $\begin{array}{l}\text { Develop command } \\
\text { words or some data } \\
\text { structure to pass } \\
\text { cmds over I2C }\end{array}$ \\
\hline SD_0341 & $\begin{array}{l}\text { The digitizer should acknowledge } \\
\text { it has completed a requested } \\
\text { command which is sent from an } \\
\text { attached device }\end{array}$ & \\
\hline SC_0360 & $\begin{array}{l}\text { The microcontroller on the PCB on } \\
\text { which the SuPER Controller will } \\
\text { reside shall contain all software } \\
\text { code for implementation as either a } \\
\text { controller or digitizer board. Upon } \\
\text { startup, the controller will be } \\
\text { initiated to run the SuPER } \\
\text { Controller code, while the } \\
\text { digitizers will be initiated to run } \\
\text { the SuPER Digitizer code }\end{array}$ & $\begin{array}{l}\text { Refer to System } \\
\text { Software Diagrams }\end{array}$ \\
\hline SD_0400 & $\begin{array}{l}\text { The digitizer must be able to } \\
\text { transmit data over an } \mathrm{I} 2 \mathrm{C} \text { interface } \\
\text { up to } 5 \text { meters in length }\end{array}$ & $\begin{array}{l}\text { Keep in mind I2C } \\
\text { bus capacitance } \\
\text { maximum values } \\
\text { from I2C } \\
\text { specification }\end{array}$ \\
\hline
\end{tabular}




\subsection{Modularized PCBs}

\begin{tabular}{|c|c|c|}
\hline Req ID & Description & Notes \\
\hline PCB_0090 & $\begin{array}{l}\text { The SuPER Controller and SuPER } \\
\text { Digitizer shall be built on a single } \\
\text { PCB which contains the union of } \\
\text { their functionality without any } \\
\text { design overlap }\end{array}$ & $\begin{array}{l}\text { Refer to thesis } \\
\text { paper for } \\
\text { components used }\end{array}$ \\
\hline PCB_0110 & $\begin{array}{l}\text { The PCB shall provide a voltage } \\
\text { supply between } 2.0 \mathrm{~V} \text { and } 3.6 \mathrm{~V} \text { to } \\
\text { power a PIC } 24 \mathrm{FJ} 256 \mathrm{~GB} 110 \\
\text { microcontroller }\end{array}$ & \\
\hline PCB_0130 & $\begin{array}{l}\text { The PCB shall have all off-board } \\
\text { signals mate with the board in a } \\
\text { standard connector and then route } \\
\text { signals to on-board components } \\
\text { via traces on the PCB }\end{array}$ & \\
\hline PCB_0131 & $\begin{array}{l}\text { The connector for off-board signal } \\
\text { routing should be high-quality to } \\
\text { prevent degradation in signal } \\
\text { quality because of loose pin } \\
\text { contacts or total failure because of } \\
\text { pin separation }\end{array}$ & \\
\hline PCB_0135 & $\begin{array}{l}\text { The PCB should have appropriate } \\
\text { terminals and PCB trace widths to } \\
\text { account for high-current power } \\
\text { distribution that will flow through } \\
\text { the MOSFET switches }\end{array}$ & \\
\hline PCB_0140 & $\begin{array}{l}\text { The PCB design shall provide a } \\
\text { standard interface to all sensors } \\
\text { and switches, and power } \\
\text { distribution to support } \\
\text { components }\end{array}$ & $\begin{array}{l}\text { LM324 Quad Op- } \\
\text { Amps to get a full } \\
\text { voltage swing for } \\
\text { more accurate and } \\
\text { normalized A/D } \\
\text { readings }\end{array}$ \\
\hline PCB_0150 & $\begin{array}{l}\text { The PCB shall be designed in } \\
\text { accordance with generic PCB } \\
\text { design standards such as IPC- } \\
\text { 2221A }\end{array}$ & \\
\hline PCB_0180 & $\begin{array}{l}\text { The PCB shall follow layout } \\
\text { guidelines from the component } \\
\text { datasheets and contain the } \\
\text { necessary external components to } \\
\text { mimic the functionality provided } \\
\text { during design by the development } \\
\text { board }\end{array}$ & \\
\hline
\end{tabular}




\begin{tabular}{|l|l|l|} 
PCB_0190 & $\begin{array}{l}\text { Standard pcb design practices } \\
\text { shall be used so that the boards } \\
\text { can be manufactured and } \\
\text { assembled by multiple vendors }\end{array}$ & \\
\hline PCB_0200 & $\begin{array}{l}\text { Documentation shall be provided } \\
\text { to support design changes for } \\
\text { enhancements and bug fixes in the } \\
\text { future }\end{array}$ & Change Tracking \\
\hline
\end{tabular}




\subsection{Data Logging on SD Memory Card}

\begin{tabular}{|c|c|c|}
\hline Req ID & Description & Notes \\
\hline DL_0100 & $\begin{array}{l}\text { Data logging shall be accomplished } \\
\text { by writing sensor values to an SD } \\
\text { memory card }\end{array}$ & \\
\hline DL_0110 & $\begin{array}{l}\text { The SD memory card shall } \\
\text { interface to the microcontroller } \\
\text { over an SPI interface }\end{array}$ & \\
\hline DL_0111 & $\begin{array}{l}\text { SPI specifications should be } \\
\text { followed for hardware and } \\
\text { software when using the SPI } \\
\text { module on the microcontroller }\end{array}$ & $\begin{array}{l}\text { Look up proper SPI } \\
\text { specifications online }\end{array}$ \\
\hline DL_0120 & $\begin{array}{l}\text { SuPER system API calls should be } \\
\text { used to communicate between the } \\
\text { SD memory card and } \\
\text { microcontroller }\end{array}$ & $\begin{array}{l}\text { Refer to System } \\
\text { Software Diagrams }\end{array}$ \\
\hline DL_0200 & $\begin{array}{l}\text { The SD memory card shall have its } \\
\text { oldest data replaced if the card } \\
\text { reaches its maximum capacity }\end{array}$ & \\
\hline DL_0210 & $\begin{array}{l}\text { If an SD memory card is not } \\
\text { installed, or fails, the control } \\
\text { software on the SuPER Controller } \\
\text { must continue running }\end{array}$ & $\begin{array}{l}\text { Refer to System } \\
\text { Software Diagrams }\end{array}$ \\
\hline DL_0220 & $\begin{array}{l}\text { The SD memory card shall hold at } \\
\text { least one year's worth of sensor } \\
\text { measurements as system status } \\
\text { information }\end{array}$ & $\begin{array}{l}\text { Refer to SuPER Data } \\
\text { Rate Analysis }\end{array}$ \\
\hline DL_0230 & $\begin{array}{l}\text { The SD memory card shall have all } \\
\text { sensor data stored every } 5 \text { minutes }\end{array}$ & $\begin{array}{l}\text { Data could be averaged } \\
\text { over } 5 \text { minute intervals }\end{array}$ \\
\hline DL_0240 & $\begin{array}{l}\text { The SD memory card should have } \\
\text { all its contents read and sent to the } \\
\text { User Interface in under } 20 \text { minutes }\end{array}$ & $\begin{array}{l}\text { Data rates for SPI and } \\
\text { USB will need to be } \\
\text { referenced }\end{array}$ \\
\hline DL_0250 & $\begin{array}{l}\text { The SD memory card shall be able } \\
\text { to have all its content deleted at } \\
\text { once }\end{array}$ & $\begin{array}{l}\text { Refer to System } \\
\text { Software Diagrams }\end{array}$ \\
\hline
\end{tabular}




\subsection{Graphical User Interface}

\begin{tabular}{|c|c|c|}
\hline Req ID & Description & Notes \\
\hline UI_0100 & $\begin{array}{l}\text { The User Interface should be } \\
\text { written in the 'C' programming } \\
\text { language to keep all system } \\
\text { software unified. If this is not } \\
\text { possible, a close derivative should } \\
\text { be used. }\end{array}$ & Such as VC++ \\
\hline UI_0200 & $\begin{array}{l}\text { The User Interface shall be run on a } \\
\text { device with a USB port and be } \\
\text { capable of accessing USB API } \\
\text { functions }\end{array}$ & a laptop \\
\hline UI_0230 & $\begin{array}{l}\text { The User Interface should have a } \\
\text { connect function that will attempt } \\
\text { to establish communication with } \\
\text { the SuPER Controller }\end{array}$ & $\begin{array}{l}\text { Refer to System } \\
\text { Software Diagrams }\end{array}$ \\
\hline UI_0240 & $\begin{array}{l}\text { Once communication is established, } \\
\text { the User Interface will present a } \\
\text { menu asking the user if they would } \\
\text { like to view real-time data, } \\
\text { download the data log, or enter the } \\
\text { ultra-capacitor mode }\end{array}$ & $\begin{array}{l}\text { Refer to System } \\
\text { Software Diagrams }\end{array}$ \\
\hline UI_0250 & $\begin{array}{l}\text { The User Interface must not prevent } \\
\text { the control software running on the } \\
\text { SuPER Controller from continually } \\
\text { monitoring the system health and } \\
\text { status }\end{array}$ & \\
\hline UI_0300 & $\begin{array}{l}\text { When the option to view real-time } \\
\text { data is chosen by the user, the User } \\
\text { Interface will use USB to query the } \\
\text { SuPER Controller's USB interface } \\
\text { and send the current sensor and } \\
\text { status values to the user }\end{array}$ & \\
\hline UI_0310 & $\begin{array}{l}\text { The real-time sensor values should } \\
\text { be displayed visually in the User } \\
\text { Interface }\end{array}$ & $\begin{array}{l}\text { Graphs are best } \\
\text { visual tool for the } \\
\text { user }\end{array}$ \\
\hline UI_0320 & $\begin{array}{l}\text { The User Interface will have an } \\
\text { option to stop real-time data } \\
\text { viewing and return to the main } \\
\text { menu }\end{array}$ & $\begin{array}{l}\text { Refer to System } \\
\text { Software Diagrams }\end{array}$ \\
\hline UI_0400 & $\begin{array}{l}\text { When the option to view logged } \\
\text { data is chosen, the User Interface } \\
\text { will use USB to query the SuPER } \\
\text { Controller to access the SD }\end{array}$ & $\begin{array}{l}\text { Refer to System } \\
\text { Software Diagrams }\end{array}$ \\
\hline
\end{tabular}




\begin{tabular}{|c|c|c|}
\hline & memory card's contents & \\
\hline UI_0410 & $\begin{array}{l}\text { To view logged data, the User } \\
\text { Interface must download the entire } \\
\text { contents of the SD memory card to } \\
\text { the user's system in under } 20 \\
\text { minutes }\end{array}$ & $\begin{array}{l}\text { Refer to SuPER } \\
\text { Data Rate Analysis }\end{array}$ \\
\hline UI_0420 & $\begin{array}{l}\text { After data is downloaded from the } \\
\text { SD memory card, the User } \\
\text { Interface will ask the user if they } \\
\text { would like to delete all data on the } \\
\text { SD memory card }\end{array}$ & $\begin{array}{l}\text { Refer to System } \\
\text { Software Diagrams }\end{array}$ \\
\hline UI_0430 & $\begin{array}{l}\text { After all data is downloaded from } \\
\text { the SD memory card, the User } \\
\text { Interface will graphically display } \\
\text { the system status for all of the } \\
\text { downloaded data }\end{array}$ & $\begin{array}{l}\text { Show trends on a } \\
\text { graph. }\end{array}$ \\
\hline UI_0500 & $\begin{array}{l}\text { When the option to enter ultra- } \\
\text { capacitor mode is chosen the user } \\
\text { interface shall ask the user if they } \\
\text { want to charge, discharge, or use } \\
\text { the ultra-capacitor in normal } \\
\text { operations mode }\end{array}$ & \\
\hline UI_0510 & $\begin{array}{l}\text { After a menu choice is selected, the } \\
\text { user interface should ask the user } \\
\text { whether they want to exit ultra- } \\
\text { capacitor mode }\end{array}$ & \\
\hline
\end{tabular}




\subsection{White Light LED Load System}

\begin{tabular}{|l|l|l|}
\hline Req ID & \multicolumn{1}{|c|}{ Description } & Notes \\
\hline WL_0100 & $\begin{array}{l}\text { The high powered LED load } \\
\text { project should build off of lessons } \\
\text { learned from Joseph A. Zukowski's } \\
\text { senior project "Implementation of } \\
\text { High Powered LED Load into the } \\
\text { SuPER System" }\end{array}$ & \\
\hline WL_0110 & $\begin{array}{l}\text { Each LED shall maintain a } \\
\text { constant current in order to } \\
\text { maintain a constant efficacy }\end{array}$ & $\begin{array}{l}\text { LEDs in series } \\
\text { instead of parallel? }\end{array}$ \\
\hline WL_0130 & $\begin{array}{l}\text { Account for voltage drop in longer } \\
\text { wire lengths that may affect } \\
\text { biasing voltage on each LED and } \\
\text { lead to a degradation in } \\
\text { performance }\end{array}$ & $\begin{array}{l}\text { have voltage } \\
\text { regulators at LEDs? }\end{array}$ \\
\hline WL_0200 & $\begin{array}{l}\text { Implement the LEDs with proper } \\
\text { thermal management as prescribed } \\
\text { in the chosen LED's datasheet }\end{array}$ & \\
\hline WL_0300 & $\begin{array}{l}\text { The necessary current and voltage } \\
\text { measuring components shall be } \\
\text { present to make measurements for } \\
\text { the white LEDs load }\end{array}$ & \\
\hline WL_0310 & $\begin{array}{l}\text { This project should provide the } \\
\text { possibility to be a standalone load } \\
\text { based upon a 12V DC power } \\
\text { source }\end{array}$ & \\
\hline
\end{tabular}




\subsection{Enclosures and Packaging}

\begin{tabular}{|l|l|l|}
\hline \multicolumn{1}{|c|}{ Req ID } & \multicolumn{1}{|c|}{ Description } & Notes \\
\hline PACK_0090 & $\begin{array}{l}\text { Standards such as NEMA should } \\
\text { be followed when designing the } \\
\text { SuPER system packaging }\end{array}$ & \\
\hline PACK_0100 & $\begin{array}{l}\text { Enclosures should be found } \\
\text { which can protect electronics } \\
\text { from the environment such as } \\
\text { sun exposure, water damage, and } \\
\text { dirt }\end{array}$ & \\
\hline PACK_0105 & $\begin{array}{l}\text { Electronics should have some } \\
\text { ventilation to prevent } \\
\text { overheating and premature } \\
\text { wearout. }\end{array}$ & \\
\hline PACK_0110 & $\begin{array}{l}\text { Enclosures should be found } \\
\text { which protect users from high } \\
\text { voltages and high current } \\
\text { electronics }\end{array}$ & \\
\hline PACK_0120 & $\begin{array}{l}\text { The SuPER cart shall provide } \\
\text { load interfaces for connecting } \\
\text { devices to the 12VDC bus }\end{array}$ & \\
\hline PACK_0200 & $\begin{array}{l}\text { The SuPER cart should be } \\
\text { redesigned to be more compact } \\
\text { than the prototype cart, but still } \\
\text { utilize the 2 foot by 4 foot PV } \\
\text { panel form factor }\end{array}$ & \\
\hline PACK_0210 & $\begin{array}{l}\text { The SuPER cart should include a } \\
\text { manual override circuit breaker } \\
\text { box, similar to what was used in } \\
\text { the prototype }\end{array}$ & $\begin{array}{l}\text { See Section 3.9 in } \\
\text { thesis paper }\end{array}$ \\
\hline & & \\
\hline
\end{tabular}




\subsection{Microgrid}

\begin{tabular}{|c|c|c|}
\hline Req ID & Description & Notes \\
\hline MG_0100 & $\begin{array}{l}\text { The microgrid shall distribute } \\
\text { power from the SuPER cart to } \\
\text { external loads }\end{array}$ & \\
\hline MG_0110 & $\begin{array}{l}\text { The microgrid shall up convert } \\
\text { from } 12 \mathrm{~V} \text { to } 160 \mathrm{~V} \text { for power } \\
\text { transmission }\end{array}$ & \\
\hline MG_0120 & $\begin{array}{l}\text { The microgrid shall down convert } \\
160 \mathrm{~V} \text { to } 12 \mathrm{~V} \text { for use at external } \\
\text { loads }\end{array}$ & \\
\hline MG_0200 & $\begin{array}{l}\text { The microgrid should monitor } \\
\text { power and provide a means to } \\
\text { control power flow to load circuits }\end{array}$ & $\begin{array}{l}\text { Define the limits } \\
\text { and refer to control } \\
\text { software for } \\
\text { implementation }\end{array}$ \\
\hline MG_0300 & $\begin{array}{l}\text { Proper safety procedures should } \\
\text { be followed for implementing this } \\
\text { high voltage power transmission }\end{array}$ & \\
\hline
\end{tabular}




\subsection{Wind Turbine}

\begin{tabular}{|l|l|l|}
\hline Req ID & \multicolumn{1}{|c|}{ Description } & Notes \\
\hline WT_0100 & $\begin{array}{l}\text { The wind turbine shall have } \\
\text { software running on the SuPER } \\
\text { Controller for controlling its power } \\
\text { generation }\end{array}$ & \\
\hline WT_0105 & $\begin{array}{l}\text { The wind turbine control software } \\
\text { should have the capability of being } \\
\text { activated once the wind turbine is } \\
\text { connected to the SuPER system } \\
\text { after initial deployment }\end{array}$ & \\
\hline WT_0110 & $\begin{array}{l}\text { The control software may allow } \\
\text { the battery to be charged using } \\
\text { solar or wind power, but not both } \\
\text { at the same time }\end{array}$ & use wind power \\
when solar \\
insolation is low
\end{tabular}




\subsection{Environmental Chamber}

\begin{tabular}{|l|l|l|}
\hline Req ID & \multicolumn{1}{|c|}{ Description } & Notes \\
\hline EC_0090 & $\begin{array}{l}\text { An environmental chamber shall } \\
\text { be utilized to extend the battery's } \\
\text { useful life which reduces system } \\
\text { cost over a 20 year lifecycle }\end{array}$ & \\
\hline EC_0100 & $\begin{array}{l}\text { The environmental chamber for the } \\
\text { battery shall have its temperature } \\
\text { regulated digitally }\end{array}$ & \\
\hline EC_0110 & $\begin{array}{l}\text { Control software in the SuPER } \\
\text { Controller shall be implemented to } \\
\text { adjust the E.C. temperature as the } \\
\text { battery temperature changes }\end{array}$ & $\begin{array}{l}\text { Determine best } \\
\text { algorithm }\end{array}$ \\
\hline EC_0200 & $\begin{array}{l}\text { The battery shall have a resistive } \\
\text { temperature detector (RTD) } \\
\text { measure its temperature and send } \\
\text { the data to the SuPER Digitizer }\end{array}$ & \\
\hline EC_0210 & $\begin{array}{l}\text { The battery shall have connections } \\
\text { to measure its voltage, current, and } \\
\text { temperature through the SuPER } \\
\text { Digitizer board }\end{array}$ & \\
\hline EC_0220 & $\begin{array}{l}\text { The ambient temperature inside the } \\
\text { environmental chamber shall also } \\
\text { be measured by the digitizer board }\end{array}$ & \\
\hline EC_0230 & $\begin{array}{l}\text { This project shall develop a } \\
\text { thermal electric model for the } \\
\text { operation with the battery both } \\
\text { active (charging or discharging) or } \\
\text { passive (quiescent state) }\end{array}$ & \\
\hline
\end{tabular}




\section{$5 \quad$ Sub-System Interfacing}

This section describes the various connections present for the phase 2 implementation of the SuPER project. Figure 3-1 shows a block diagram of the entire SuPER system and its connections. Figure 5-1 below is the pinout for the chosen microcontroller and will be referenced frequently.

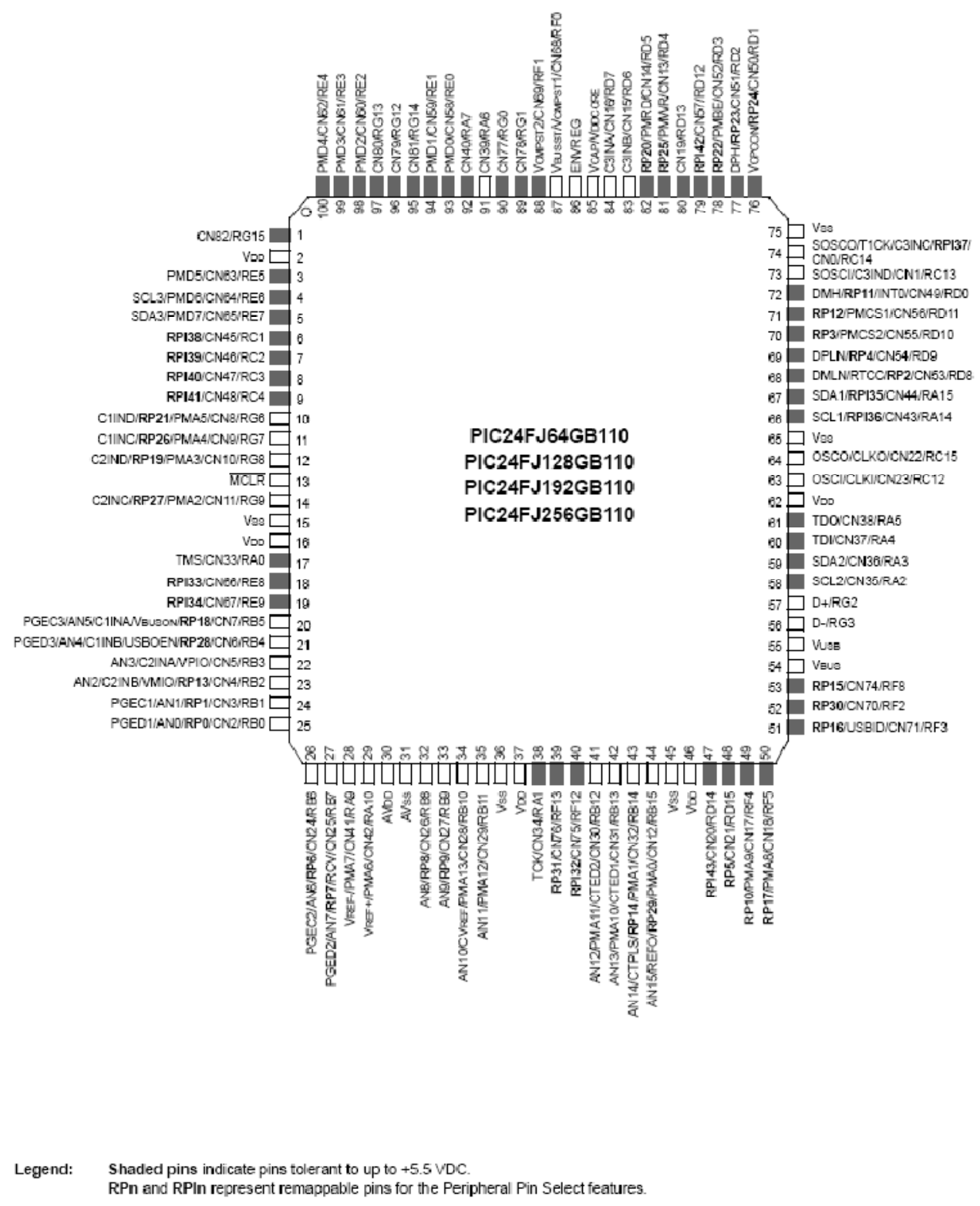

Figure 5-1 - PIC24FJ256GB110 Pinout [40] 


\subsection{SuPER Controller Interfaces}

This section describes the hardware connections between the SuPER controller and everything physically touching it in the system. This includes pinouts and descriptions of all the physical and electrical connections between the SuPER controller and the SuPER digitizers, DCDC converters, memory card, and user laptop.

\subsubsection{SuPER Controller Pinout}

This section will detail the pinout of the microcontroller used on the SuPER controller and the pinout of the connector for the entire PCB it is on.

\subsubsection{Microcontroller Pinout}

Table 5-1 defines the peripherals needed on the chosen microcontroller and the names and pins they can be found at on the PIC24FJ256GB110 microcontroller 100-pin TQFP package. The shaded boxes correspond to the pins needed specifically for the SuPER Controller. The actual microcontroller will be surface mounted to the PCB for the final design. During design and testing of the system it will be used as a peripheral interface module (PIM) that plugs into a 100-pin development board. The RP\# pins are remappable and don't have to follow this chosen setup. However, these pins were chosen in such a way that their locations on the physical 100pin package would be easier to route on the PCB. 
Table 5-1 - Printed Circuit Assembly Microcontroller Pinout for Controller

\begin{tabular}{|c|l|l|}
\hline \multicolumn{3}{|c|}{ SuPER Printed Circuit Assembly - Pinout for Microcontroller } \\
\hline Function & \multicolumn{1}{|c|}{ Name on Package } & \multicolumn{1}{c|}{ Pin \# on package } \\
\hline PWM & RP15 & 53 \\
\hline I2C & SCL1, SDA1 & 66,67 \\
\hline SPI & RP3, RP4, RP11, RP12 & $70,69,72,71$ \\
\hline & D+, D-, USBID, VBUS, & $57,56,51,54,20$, \\
USB & VBUSON, VBUSST, & $87,87,88,76,55$ \\
& VCMPST1, VCMPST2, & \\
\hline RTCC & RUSB & 68 \\
\hline $\begin{array}{c}\text { A/D for } \\
\text { Loads: }\end{array}$ & AN15 \& RA1, RB12, & $44 \& 38,41,42,43$, \\
1 A/D \& 6 & & 40,39 \\
I/O & & \\
\hline $\begin{array}{c}\text { A/D for PV: } \\
\text { 3 A/D }\end{array}$ & AN8, AN9, AN10 & $32,33,34$ \\
\hline A/D for DC- & AN0, AN1, AN2, AN3, & $25,24,23,22,21,26$ \\
DC \& & AN4, AN6 & \\
Battery: & & \\
6 A/D & & $91,92,93,94,98$, \\
\hline $\begin{array}{l}\text { 10 I/O for } \\
\text { MOSFET } \\
\text { control }\end{array}$ & RA6, RA7, RE0, RE1, R613, RE3, RE4, RG12, & $99,100,96,97,95$ \\
\hline
\end{tabular}

\subsubsection{SuPER Controller-to-SuPER Digitizer Description}

The interface between the SuPER Controller and Digitizer will consist of an I2C connection between the PIC24FJ256GB110 microcontrollers located on each board. One of the digitizers can send up to 10 10-bit digital telemetry measurements during each sampling period. Across all the digitizer boards this comes out to 19 analog to digital conversions to account for all voltage, current, and temperature measurements. Section 6.3 SuPER Digitizer Software Description will outline the software application programming interface (API) for this connection. There is a standard bus description for the $\mathrm{I} 2 \mathrm{C}$ protocol which will be implemented between the SuPER Controller and Digitizer, refer to Appendix A for its operation. 


\subsubsection{SuPER Controller-to-SuPER Digitizer Electrical Characteristics}

The implementation here will run around the low-speed mode of $100 \mathrm{Kbps}$. This low speed will ensure that the clock and data lines are less susceptible to interference. The voltage levels should be at the microcontroller operating voltage of $3.3 \mathrm{~V}$. This connection, in addition to the other nodes on the I2C bus, must not allow the I2C bus capacitance to exceed $400 \mathrm{pF}$.

\subsubsection{SuPER Controller-to-SuPER Digitizer Physical Characteristics}

The SuPER Controller and SuPER Digitizer will have a 2-wire interface which will be contained within the connector that routes signals off each of the PCBs. Efforts should be taken to keep the wire lengths as short as possible to reduce electromagnetic interference. Two pins from the controller connection will meet with 2 pins of each digitizer connector. The PCB development group should document which locations are chosen for the PCB connector to ensure that the SDA and SCL signals are routed between the controller and every digitizer board correctly.

\subsubsection{SuPER Controller-to-DC-DC Converter Description}

The interface between the controller and DC-DC converter consists of a pulse width modulation (PWM) line. The PWM signal will be used to maximize efficiency of charging along the maximum power point tracking (MPPT) curve.

\subsubsection{SuPER Controller-to-DC-DC Converter Electrical Characteristics}

The PWM signal from the microcontroller to the gate driver on the DC-DC converter will operate between $30 \mathrm{KHz}$ and $100 \mathrm{KHz}$. The gate driver can operate at the $3.3 \mathrm{~V}$ logic level which is what the microcontroller outputs. 


\subsubsection{SuPER Controller-to-DC-DC Converter Physical Characteristics}

The physical PWM wire will be coming out of a pin on the PCB connector. The connection to the gate driver on the DC-DC converter will need to have a solid electrical connection (consider soldering directly to the DC-DC converter board).

\subsubsection{SuPER Controller-to-SD Memory Card Description}

The SuPER Controller must be able to store data for later retrieval to view system performance. This information will be saved on an SD memory card. The SD memory card will be interfaced over the serial peripheral interface (SPI).

\subsubsection{SD Memory Card Pinout and Operation}

The SD memory card has the following pinout as shown in Table 5-2. For the connection to the microcontroller's SPI interface use the pinout for "SPI Mode" shown below.

Table 5-2 - Secure Digital Pinout [25]

\begin{tabular}{|l|l|l|l|}
\hline \multicolumn{4}{|c|}{ Secure Digital Pinout } \\
\hline Pin \# & Pin Name & SD Mode & SPI Mode \\
\hline 1 & DAT3/CS & Data Line 3 & Chip Select/Slave Select [/SS] \\
\hline 2 & CMD/DI & Command Line & Master Out/Slave In [MOSI] \\
\hline 3 & VSS1 & Ground & Ground \\
\hline 4 & VDD & Supply (2.7V or 3.6V) & Supply [2.7V or 3.6V] \\
\hline 5 & Clock & Clock & Clock [SCK] \\
\hline 6 & VSS2 & Ground & Ground \\
\hline 7 & DAT0/D0 & Data Line 0 & Master In/Slave Out [MISO] \\
\hline 8 & DAT1/IRQ & Data Line 1 & Unused or IRQ \\
\hline 9 & DAT2/NC & Data Line 2 & Unused \\
\hline
\end{tabular}

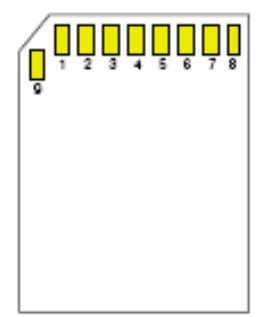

Figure 5-2 - Secure Digital Card with Pin Numbers [24] 


\subsubsection{SuPER Controller-to-SD Memory Card Electrical Characteristics}

The SuPER Controller will have a 4-wire SPI bus between the SD card and itself. This consists of the MISO, MOSI, /SS, and CLK lines. Refer to Appendix B for SPI operation. The clock between will be run at $10 \mathrm{MHz}$ and data will be read or written to the SD card over the MISO and MOSI lines, respectively. In addition to the 4 SPI lines, there are ground and power supply lines which will operate near the microcontroller's operating voltage of $3.3 \mathrm{~V}$.

\subsubsection{SuPER Controller-to-SD Memory Card Physical Characteristics}

The physical connection from the SuPER Controller to the SD memory card will be made on the PCB through use of a mounted SD card holder. The PCB will have traces laid out from the PIC24FJ256GB110 to the card holder to account for the 4 SPI lines, 2 ground lines, and 1 power line. The PCB mounted connector will give a more secure connection and allow for greater data rates because of its close proximity to the microcontroller.

\subsubsection{SuPER Controller-to-Laptop Description}

In order for a user to communicate with the system, some protocol must be used between the SuPER Controller and a laptop in the field. The PIC24FJ256GB110 contains a USB 2.0 OTG interface that can be used to communicate between the SuPER system and laptop. With the presence of USB ports on just about every major computer device these days, it has widespread acceptance now and in the future.

\subsubsection{SuPER Controller-to-Laptop Electrical Characteristics}

The controller to laptop connection will need to follow USB 2.0 OTG specifications, see Appendix C - USB 2.0 OTG Protocol. 


\subsubsection{SuPER Controller-to-Laptop Physical Characteristics}

The physical connection to the user PC will be a USB Type A port that is standard on personal computers. The termination type on the $\mathrm{PCB}$ for the microcontroller will be a micro-AB receptacle.

\subsection{SuPER Digitizer Interfaces}

This section describes the hardware connections between the SuPER Digitizer and everything physically touching it. This includes pinouts and descriptions of the physical and electrical connections to the SuPER Controller, DC-DC converter, battery, and PV panel.

\subsubsection{SuPER Digitizer Pinout}

This section will detail the pinout of the microcontroller used on the SuPER digitizer and the pinout of the connector for the entire PCB it is on.

\subsubsection{Microcontroller Pinout}

Table 5-3 defines the peripherals needed on the chosen microcontroller, including their respective names and pin locations on the PIC24FJ256GB110 microcontroller 100-pin TQFP package. The shaded boxes correspond to the pins needed specifically for the SuPER Digitizer. However, each digitizer will use a different number of A/D converters and I/O pins for MOSFET control based on its subsystem location. The actual microcontroller will be surface mounted to the PCB for the final design. During design and testing of the system it will be used as a peripheral interface module (PIM) that plugs into a 100-pin development board. The RP\# pins are remappable and don't have to follow this chosen setup. However, these pins were chosen in such a way that their locations on the physical 100-pin package would be more convenient for routing on the PCB. 
Table 5-3 - Printed Circuit Assembly Microcontroller Pinout for Digitizer

\begin{tabular}{|c|l|l|}
\hline \multicolumn{3}{|c|}{ SuPER Printed Circuit Assembly - Pinout for Microcontroller } \\
\hline Function & \multicolumn{1}{|c|}{ Name on Package } & \multicolumn{1}{c|}{ Pin \# on package } \\
\hline PWM & RP15 & 53 \\
\hline I2C & SCL1, SDA1 & 66,67 \\
\hline SPI & RP3, RP4, RP11, RP12 & $70,69,72,71$ \\
\hline & $\begin{array}{l}\text { D+, D-, USBID, VBUS, } \\
\text { VBUSON, VBUSST, } \\
\text { USB } \\
\text { VCMPST1, VCMPST2, }\end{array}$ & $\begin{array}{l}57,56,51,54,20, \\
\text { VUSB }\end{array}$ \\
\hline RTCC & RTCC & $68,88,76,55$ \\
\hline $\begin{array}{c}\text { A/D for } \\
\text { Loads: } \\
\text { A/D \& } 6 \\
\text { I/O }\end{array}$ & AN15 \& RA1, RB12, & $44 \& 38,41,42,43$, \\
\hline $\begin{array}{c}\text { A/D for PV: } \\
\text { 3 A/D }\end{array}$ & AN8, AN9, AN10 & 40,39 \\
\hline $\begin{array}{c}\text { A/D for DC- } \\
\text { DC \& } \\
\text { Battery: } \\
\text { 6 A/D }\end{array}$ & AN0, AN1, AN2, AN3, AN6 & $25,24,23,22,21,26$ \\
\hline $\begin{array}{c}\text { 10 I/O for } \\
\text { MOSFET } \\
\text { control }\end{array}$ & $\begin{array}{l}\text { RA6, RA7, RE0, RE1, } \\
\text { RE2, RE3, RE4, RG12, }\end{array}$ & \\
\hline
\end{tabular}

\subsubsection{Digitizer Board MOSFET Switch Pinout}

Some digitizer boards will control more MOSFETs than others due to the proximity of the board to the loads, battery, or PV panel. See Table 5-4 below for more information on which microcontroller pins will be used to control which switches. Refer to section 5.8.2 for the operation of switches S0-S3 related to the battery and ultra-capacitor. Switch S4 will be the connection between the battery and DC-DC converter. Switches L1-L5 will be used to control the connection of loads 1-5, respectively. Switch P1 will be used for the connection between the PV panel and DC-DC converter. 


\section{Table 5-4 - SuPER Digitizer Board MOSFET Pinouts}

\begin{tabular}{|c|c|c|c|}
\hline \multicolumn{4}{|c|}{ MOSFET Pinouts for SuPER Digitizer boards } \\
\hline $\begin{array}{c}\text { Board } \\
\text { Location }\end{array}$ & $\begin{array}{c}\text { \# of } \\
\text { MOSFETs }\end{array}$ & $\begin{array}{c}\text { Switch } \\
\text { Name }\end{array}$ & $\begin{array}{c}\text { uC pin } \\
\text { name / } \\
\text { number }\end{array}$ \\
\hline \multirow[t]{5}{*}{ Loads } & \multirow[t]{5}{*}{5} & L1 & RA6 / 91 \\
\hline & & L2 & RA7 / 92 \\
\hline & & L3 & RE0 / 93 \\
\hline & & $\mathrm{L} 4$ & RE1 / 94 \\
\hline & & L5 & RE2 / 98 \\
\hline \multirow[t]{5}{*}{ Battery } & \multirow[t]{5}{*}{5} & S0 & RE3 / 99 \\
\hline & & S1 & RE4 / 100 \\
\hline & & S2 & RG12 / 96 \\
\hline & & S3 & RG13 / 97 \\
\hline & & S4 & RG14 / 95 \\
\hline PV Panel & 1 & $\mathrm{P} 1$ & RG0 / 90 \\
\hline
\end{tabular}

\subsubsection{Digitizer Board Analog MUX Pinout}

In Table 5-3 above, the function "A/D for Loads: 1 A/D \& $6 \mathrm{I} / \mathrm{O}$ " is where the MUX will input multiple signals into a single A/D converter on the microcontroller. This is needed because the chosen microcontroller only has 16 A/D pins, but 19 measurements need to be taken. All voltage and current measurements from the loads will be sent through this analog MUX device (all other A/D measurements will map directly to $\mathrm{A} / \mathrm{D}$ channels on the microcontroller). Table 5-6 below shows how the address pins on the device must be asserted to correctly route the signals to the A/D input (AN15, pin 44 on the PIC24FJ256GB110). 
Table 5-5 - Analog MUX Pinout on Digitizer Board

\begin{tabular}{|c|c|}
\hline \multicolumn{2}{|c|}{$\begin{array}{c}\text { Analog MUX Pinout for SuPER } \\
\text { Digitizer board at loads }\end{array}$} \\
\hline $\begin{array}{c}\text { A/D Meas. } \\
\text { Name }\end{array}$ & $\begin{array}{c}\text { Analog MUX pin } \\
\text { name / number }\end{array}$ \\
\hline V4 & $\mathrm{S} 1 / 19$ \\
\hline V5 & $\mathrm{S} 2 / 20$ \\
\hline V6 & $\mathrm{S} 3 / 21$ \\
\hline V7 & $\mathrm{S} 4 / 22$ \\
\hline V8 & $\mathrm{S} 5 / 23$ \\
\hline I4 & $\mathrm{S} 6 / 24$ \\
\hline I5 & $\mathrm{S} 7 / 25$ \\
\hline I6 & $\mathrm{S} 8 / 26$ \\
\hline I7 & $\mathrm{S} 9 / 11$ \\
\hline I8 & $\mathrm{S} 10 / 10$ \\
\hline
\end{tabular}

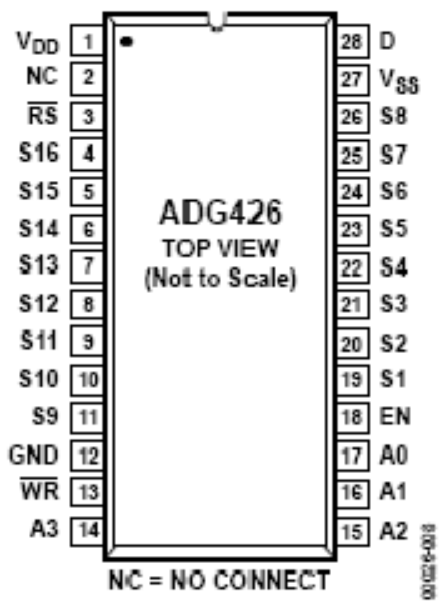

Figure 10. DIP/SSOP

Figure 5-3 - Analog MUX IC Pinout [43] 
Table 5-6 - Analog MUX Truth Table [43]

\begin{tabular}{l|l|l|l|l|l|l|l}
\hline A3 & A2 & A1 & A0 & EN & $\overline{\text { WR }}$ & $\overline{\text { RS }}$ & On switch \\
\hline$X$ & $X$ & $X$ & $X$ & $X$ & 5 & 1 & Retains previous switch condition \\
$X$ & $X$ & $X$ & $X$ & $X$ & $X$ & 0 & None (address and cnable latches cleared) \\
$X$ & $X$ & $X$ & $X$ & 0 & 0 & 1 & None \\
0 & 0 & 0 & 0 & 1 & 0 & 1 & 1 \\
0 & 0 & 0 & 1 & 1 & 0 & 1 & 2 \\
0 & 0 & 1 & 0 & 1 & 0 & 1 & 3 \\
0 & 0 & 1 & 1 & 1 & 0 & 1 & 4 \\
0 & 1 & 0 & 0 & 1 & 0 & 1 & 5 \\
0 & 1 & 0 & 1 & 1 & 0 & 1 & 0 \\
0 & 1 & 1 & 0 & 1 & 0 & 1 & 7 \\
0 & 1 & 1 & 1 & 1 & 0 & 1 & 8 \\
1 & 0 & 0 & 0 & 1 & 0 & 1 & 9 \\
1 & 0 & 0 & 1 & 1 & 0 & 1 & 10 \\
1 & 0 & 1 & 0 & 1 & 0 & 1 & 11 \\
1 & 0 & 1 & 1 & 1 & 0 & 1 & 12 \\
1 & 1 & 0 & 0 & 1 & 0 & 1 & 13 \\
1 & 1 & 0 & 1 & 1 & 0 & 1 & 14 \\
1 & 1 & 1 & 0 & 1 & 0 & 1 & 15 \\
1 & 1 & 1 & 1 & 1 & 0 & 1 & 16 \\
\hline
\end{tabular}

\subsubsection{SuPER Digitizer -to- SuPER Controller Description}

See the complement section: 5.1.2 SuPER Controller-to-SuPER Digitizer Description.

\subsubsection{SuPER Digitizer -to- Switches Description}

The SuPER Digitizer will be the device through which MOSFET switches are mounted and controlled. This is due to the fact that the digitizer boards are in close proximity to the devices which need switch control: PV panel, DC-DC converter, and the loads. Digital signals from the microcontroller will control the MOSFET gates, turning them on/off. Section 6.3.3 will contain a description of the software interface used to control the MOSFETs through the digitizers via commands sent from the controller.

\subsubsection{SuPER Digitizer -to- Switches Electrical Description}

The 3.3V signal coming out of the digital $\mathrm{I} / \mathrm{O}$ pins of the microcontroller should be enough to switch the MOSFET on/off. There are limits to the amount of current that can be sinked or sourced by any I/O pin of the PIC microcontroller, so testing should be done to confirm 
all switches can be driven simultaneously. Any one I/O pin can sink or source up to $25 \mathrm{~mA}$ while the entire device must be under $200 \mathrm{~mA}$ for current sinked or sourced by all ports combined.

\subsubsection{SuPER Digitizer -to- Switches Physical Description}

The PCB will have copper traces connecting the microcontroller output pins to the gate of the MOSFET switches.

\subsection{DC-DC Converter Interfaces}

This section covers the physical and electrical connections between the DC-DC converter and the PV panel, battery, and SuPER Controller.

\subsubsection{DC-DC Converter -to- SuPER Controller Description}

See the complement section: 5.1.3 SuPER Controller-to-DC-DC Converter Description.

\subsubsection{DC-DC Converter -to- PV Panel Description}

The energy supplied by the PV panel passes through the DC-DC converter so its voltages can be stepped down to the system bus voltage.

\subsubsection{DC-DC Converter -to- PV Panel Electrical Characteristics}

This is the first connection in the power distribution of the SuPER system. A nominal $35 \mathrm{~V}$ from the PV panel is brought to the DC-DC converter to be stepped down to $12 \mathrm{~V}$. This line can carry up to 4.35 Amps of current.

\subsubsection{DC-DC Converter -to- PV Panel Physical Characteristics}

The path between the DC-DC converter and PV panel flows through a SuPER Digitizer board. There are copper traces which carry the current across the digitizer where it can turn on or 
off the connection through a MOSFET. If copper traces are used on the PCB for routing any part of this power flow, they must be wide enough to handle the maximum current of $4.35 \mathrm{~A}$.

\subsubsection{DC-DC Converter -to- Battery Description}

A major part of the SuPER system is to store energy from the PV panel that has been stepped down to $12 \mathrm{~V}$. There is currently a MK-8G31DT $12 \mathrm{~V}$ deep cycle gel battery rated at 97.6 Amp-hours in the system.

\subsubsection{DC-DC Converter -to- Battery Electrical Characteristics}

There will be voltages between $11 \mathrm{~V}$ and $15 \mathrm{~V}$ between the DC-DC converter and battery. Up to 13 Amps can be flowing through the connection at peak solar insolation.

\subsubsection{DC-DC Converter -to- Battery Physical Characteristics}

The path between the DC-DC converter and battery flows through a SuPER Digitizer board. There are copper traces which carry the current across the digitizer where it can turn on or off the connection through a MOSFET. Proper terminals will be needed for connection to the battery terminals.

\subsection{Laptop Interfaces}

\subsubsection{Laptop-to-SuPER Controller Description}

See the complement section: 5.1.5 SuPER Controller-to-Laptop Description.

\subsection{PV Panel Interfaces}

\subsubsection{PV Panel-to-DC-DC Converter Description}

The PV panel generates the power for the SuPER system and acts as a current source, outputting a varying amount of current based on the solar insolation it receives. At its peak, the 
panel will output around 35V at 4.35 Amps and send it to the DC-DC converter to be stepped down for use with the $12 \mathrm{~V}$ system bus. The power lines are routed through a MOSFET switch contained on one of the SuPER Digitizer PCBs. This allows the connection to be broken in the case of a dangerous malfunction. Through this MOSFET the power is routed to the input of the DC-DC converter.

\subsection{Wind Turbine Interfaces}

\subsubsection{Wind Turbine-to-DC-DC Converter Description}

The wind turbine can add another power generating source for the SuPER system, but cannot be added to the same connection as the PV panel. When a new DC-DC converter is designed for specific use with the wind turbine, it will contain connection points for implementation at a future time. See the Recommendations section for more information.

\subsection{Load Interfaces}

\subsubsection{Load-to-SuPER Digitizer Description}

The loads will receive their power via routing through a MOSFET switch on a SuPER Digitizer board to the battery. Refer to section 5.2.3 for more information about this connection.

\subsubsection{Load-to-User Description}

The users of the SuPER system will be given access to the stored power through power outlets. The phase 1.5 implementation of SuPER employs normal household electrical sockets that are wired to the $12 \mathrm{~V}$ system bus, see Figure 5-4 below. The sockets are labeled for use with only $12 \mathrm{~V}$ appliances, not the normal $120 \mathrm{VAC}$ that a standard socket would provide. Because the packaging of the phase 2 design will be different from the larger cart design of previous implementations, the load configurations could change as well. The different loads should have 
their numbers clearly visible and the fact that they supply 12VDC should be prominently displayed. The sockets chosen below were a good idea to quickly implement the prototype, but if a more convenient socket is found that interfaces to the actual load devices better, it should be documented and used.

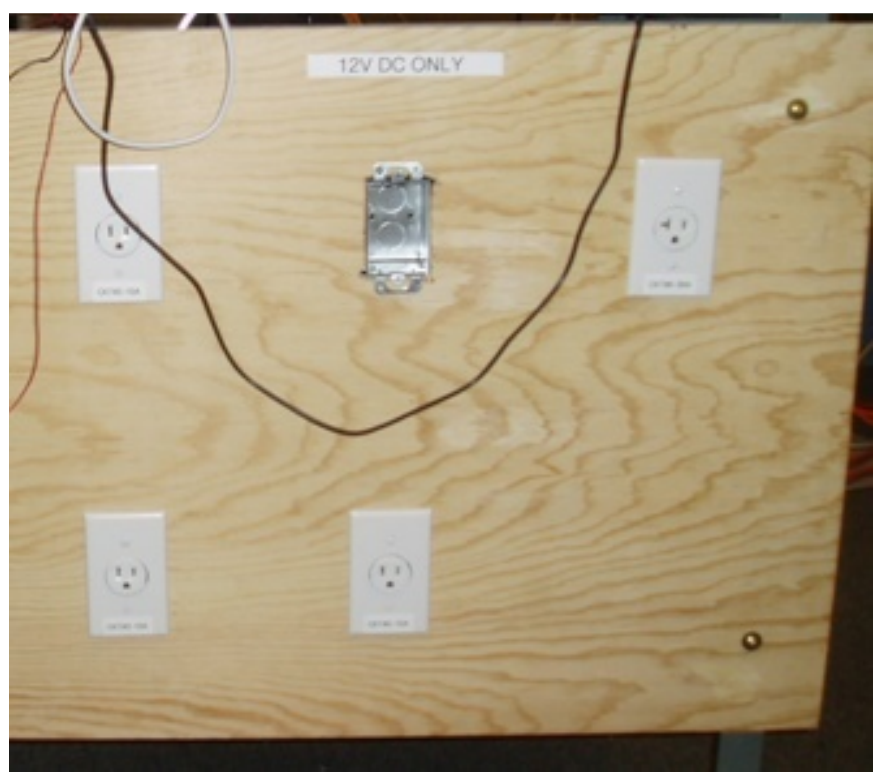

Figure 5-4 - Phase 1.5 Load Interfaces

\subsection{Battery Interfaces}

\subsubsection{Battery-to-SuPER Digitizer Description}

The battery will be monitored by the SuPER Digitizer PCB components for temperature, voltage, and current. The digitizer will also contain a MOSFET switch labeled S4 in Figure 5-5 below that controls the connection between the battery and DC-DC converter. Refer to section 5.2.3 for more information about the switch connection.

\subsubsection{Battery-to-Ultra Capacitor Description}

The battery will connect to the ultra capacitor via a series of switches and resistors [13], as shown in Figure 5-5. Switch 4 below is used to cut power from the battery to the DC-DC 
converter in case of an emergency. Switch 3 below can be used to cut the flow of power from the battery to the rest of the system (without severing the connection between the battery and DCDC converter). Switch 0 is closed when the ultra capacitor needs discharging. Switch 1 is closed with switch 3 to charge the ultra capacitor. Switch 0 and switch 3 are closed for discharging the ultra capacitor. Switch 2 is closed along with switch 3 for normal operation of the SuPER system, where the load bus has access to the battery's stored power. Refer to the table below for all four switch settings for each operation mode. Section 5.2.3 has a description of controlling these switches and section 5.2.1.2 shows the pinout information from the microcontroller to these switches. The ultra capacitor uses screw terminals for wire connection.

\section{Table 5-7 - Switch Control for Ultra-capacitor Modes}

\begin{tabular}{|c|c|c|c|c|}
\hline Ultra-cap Mode & S0 & S1 & S2 & S3 \\
\hline Charge & 0 & 1 & 0 & 1 \\
\hline Discharge & 1 & 0 & 0 & 1 \\
\hline Normal & 0 & 0 & 1 & 1 \\
\hline
\end{tabular}

Switch closed $=1 ;$ Switch open $=0$.

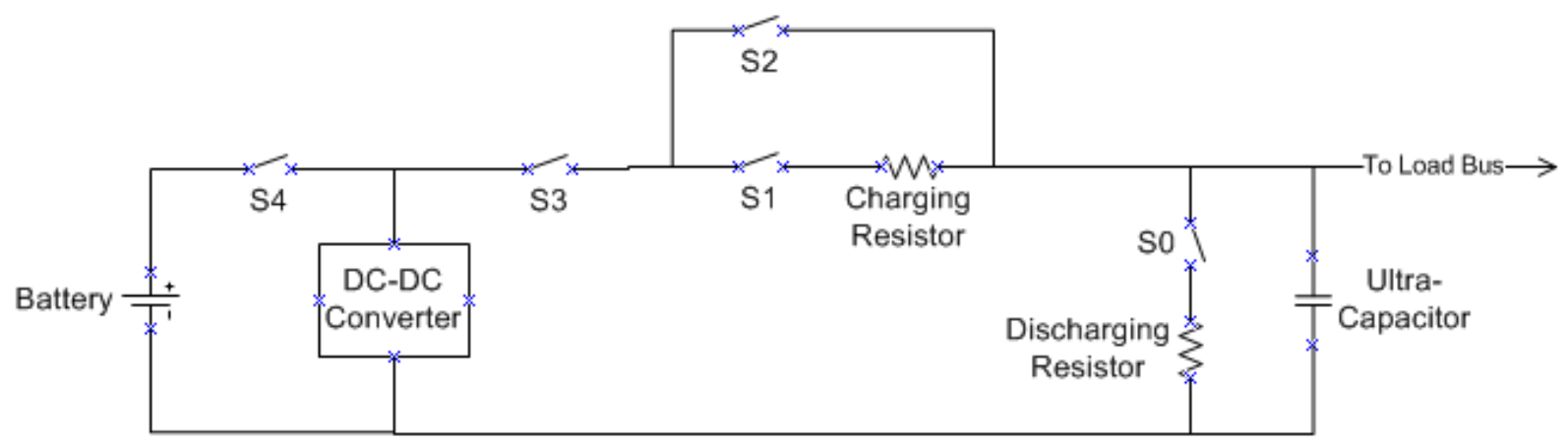

Figure 5-5 - Switch Locations for Controlling Power Flow 


\section{SuPER Software}

The application programming interface (API) will be the general interface used to communicate through software between the various subsystems. Interfaces will be defined in this section for the SuPER Controller, SuPER Digitizer, SD memory card, DC-DC converter, Analog MUX, MOSFETs, and Laptop. The functions given in this section are a guide to developing full solutions and are by no means the solutions themselves. They may need to be combined, added to, subtracted from, or deleted as seen fit by the group implementing each subsystem.

\subsection{Charge Controller and Simulation Software Description}

There are multiple charge modes for the system battery to ensure proper performance and safety. Appendix E - Charge Controller 'C' Code was written by Matthew McFarland for his thesis project and is the general baseline for the charge controller which will be implemented in the SuPER Controller. It was written for use in the simulation environment he used for modeling the system's power performance through seven day scenarios. Implemented on the SuPER Controller, it will need to be modified to work appropriately in ' $C$ ' code. When charging the system battery from the PV panel's DC-DC converter, there are two modes of charging. First, there is normal charge mode which is activated from $13.5 \mathrm{~V}-13.9 \mathrm{~V}$. Above $13.9 \mathrm{~V}$ the charge mode changes to float. Float charging has a lower charge rate and operates from $13.9 \mathrm{~V}-14.5 \mathrm{~V}$.

When a wind turbine is added in the future, it will create its own special charge modes; these will be referenced in the Recommendations section.

This code is a major upgrade for the previous version used on SuPER phase 1.5. Previous simulation software could only run for two days before troubles arose and it was due to an error in the charge controller software. Matt McFarland's code correctly switches charge modes and 
even has the possibility to test for intelligent load control. It allows for testing of different control methods to prevent the battery from falling below $80 \%$ state of charge. In addition, this simulation allows the user to run different scenarios to evaluate how different loads will affect system performance, whether they are a refrigerator, television, laptop, LEDs, etc. Through this simulation environment it will be possible to test and validate the code which will eventually run on the SuPER Controller. This is very important to the goals of SuPER because it will maintain a healthy operating state for the system and help extend its operating lifetime.

\subsection{SuPER Controller Software Description}

The SuPER Controller is the hub of all communications in the SuPER system. It sends out commands, receives and stores data, and enables the user to interact with the system. These many connections require a standardized way of communicating along the digital bus structure. Figure 6-1 below shows the system communication bus layout. Figure 6-2 shows the software flow for the control software residing on the SuPER Controller board. Figure 6-3 shows the software flowchart for handling USB connections to the SuPER Controller. These figures are explained in more depth throughout section 6.2. 


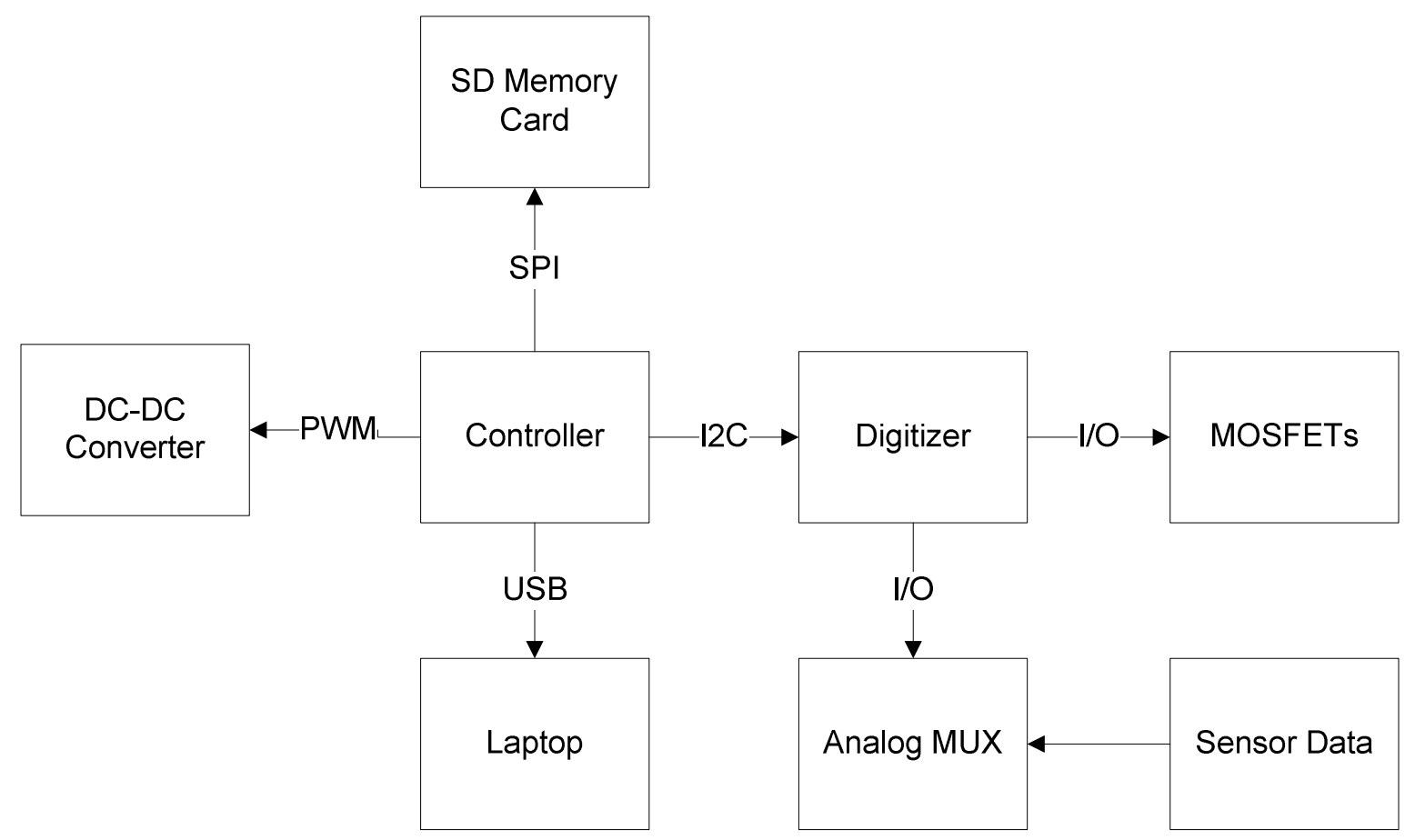

Figure 6-1 - Communication Schemes between the SuPER Subsystems 


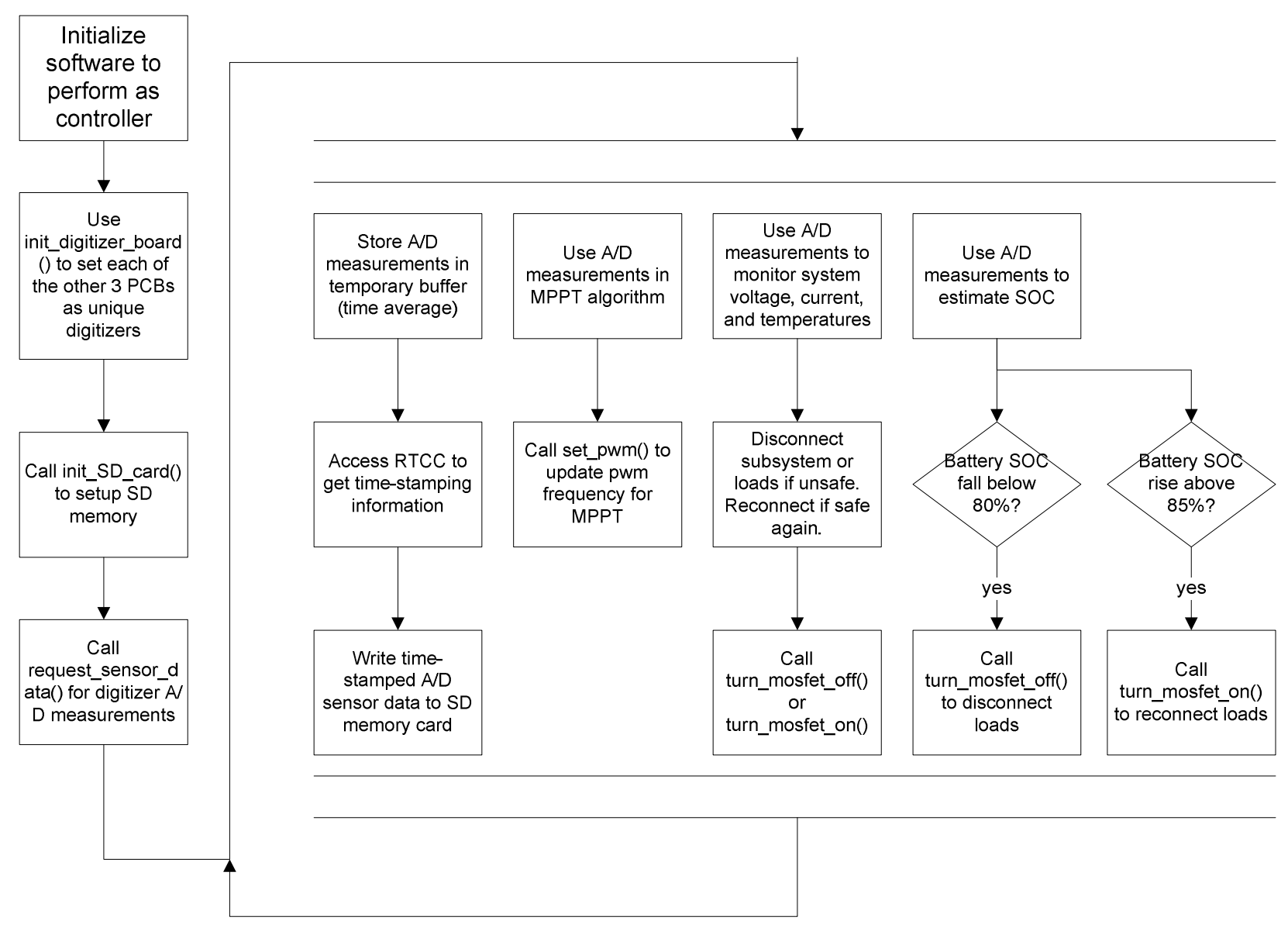

Figure 6-2 - Control Software Flowchart 


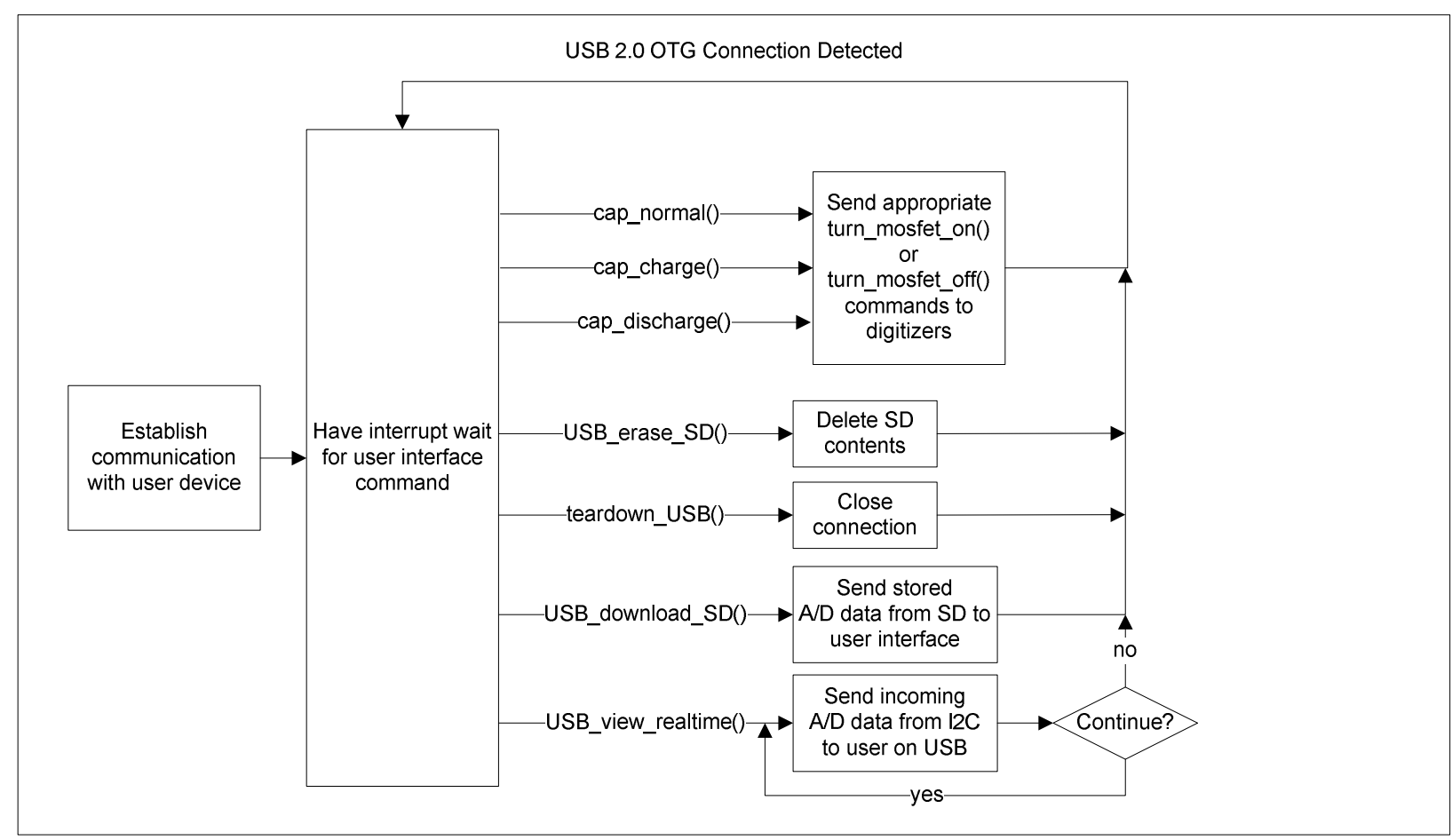

Figure 6-3 - Controller USB 2.0 OTG Software Flowchart

\subsubsection{SuPER Controller-to-DC-DC Converter API}

The controller interface to the DC-DC converter consists of a single PWM signal coming out of the controller between $30 \mathrm{KHz}$ and $100 \mathrm{KHz}$. An example would be to use a function named set_pwm() that would take an input parameter specifying the frequency to set for the PWM output signal.

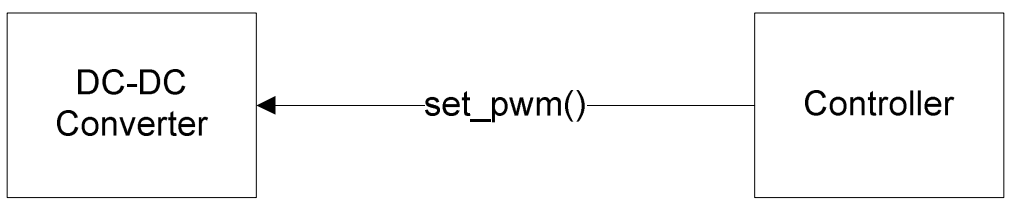

Figure 6-4 - Controller to DC-DC Converter Example Software Description 


\subsubsection{SuPER Controller-to-SD Memory Card API}

For interfacing the SD memory card to the controller an SPI interface will be used. There is actually an "SPI Mode" in the SD specification and this should be adhered to, along with the other specifications outlined in that document. An example implementation for use on SuPER would include the following functions, shown in Figure 6-5, which would need to be expanded based on the SD specification. There is an init_SD_card() function to recognize the card and start communication with it. Reset_SD_card() would be useful in case of a malfunction where the interface would need to be reset. There are also functions reading and writing from and to the SD card. In accordance with the user interface, there is a function called erase_SD() for deleting the entire contents of the SD card once the user has read it through the user interface. Refer to appendix B for more information on the SPI interface.

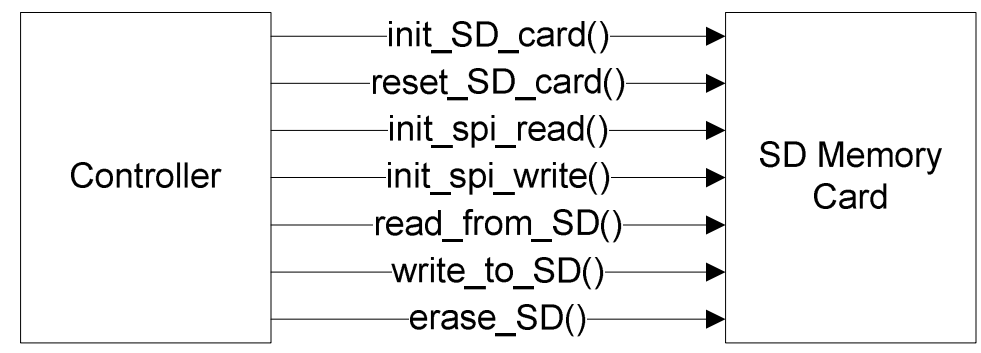

Figure 6-5 - Controller to SD Memory Card Example Software Description

\subsubsection{SuPER Controller-to-Laptop API}

The controller will connect to a user laptop over a USB interface. Figure 6-6 shows example functions that could be used for communication, beginning with initialization and teardown functions for starting and ending the communication session. Refer to appendix $\mathrm{C}$ for more information on the microcontroller's USB 2.0 OTG interface. The laptop could also have 
the ability to call USB_download_SD() or USB_view_realtime() for displaying respective data to the user interface. USB_erase_SD() could be used after the user has downloaded the entire SD card contents. Write_to_USB() is a simple function call that would be used to send either the real-time data or SD card data to the user interface. The ultra-capacitor connected to the system also has different modes of operation controlled through the user interface. These include modes for normal operation, charging, or discharging the ultra-capacitor. A command structure will need to be developed in order for the laptop data to be recognized as commands on the controller. It would be good practice to have the controller acknowledge to the Laptop that the command was asserted. Refer to the user interface software flowchart, Figure 3-6, for more information.

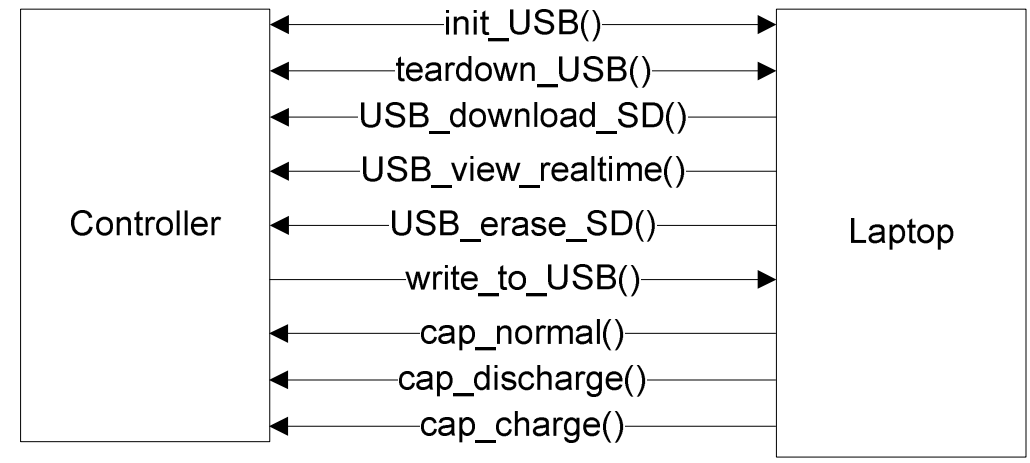

Figure 6-6 - Controller to Laptop Example Software Description

\subsubsection{SuPER Controller-to-SuPER Digitizer API}

The connection between controller and digitizer will be over an I2C bus and Figure 6-7 has example function calls to accomplish this communication. The controller will transmit commands to the digitizer and receive sensor data measurements from it. A command structure will need to be developed in order for the controller to recognize specific commands 
(turn_mosfet_on() and turn_mosfet_off()) on the digitizer. The function "init_digitizer_board()" will be used to specify which location the digitizer board is at. Each PCB has the hardware and software to be any of the 3 digitizers or the controller. This function will tell a specific digitizer board that it is located at the loads, PV panel, or battery/DC-DC converter. Through this initialization the board will run only the code necessary to perform the duty needed in that location. Initialization functions should be used for reading and writing on the $\mathrm{I} 2 \mathrm{C}$ bus between the controller and digitizer. Refer to Appendix A - I2C Protocol for more information on the I2C protocol.

The controller will request the A/D sensor measurements be sent from a certain location and the correct board must reply with the information requested. Two functions are given below for accomplishing this, but they will undoubtedly need to be expanded to achieve this functionality. The digitizer should also respond to the controller's commands for turning individual MOSFET switches on or off. It would be good practice to have the digitizer acknowledge to the controller that the command was asserted.

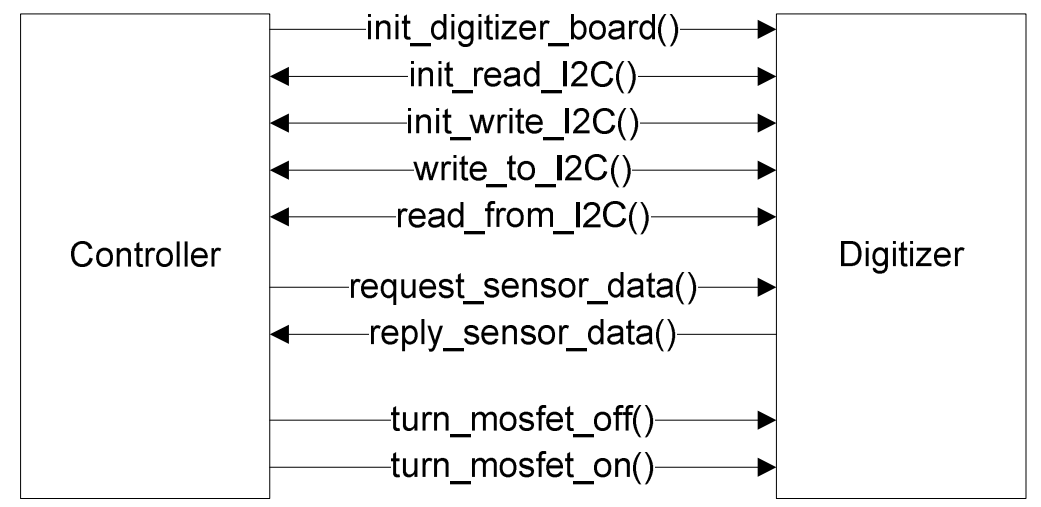

Figure 6-7 - Controller to Digitizer Example Software Description 


\subsection{SuPER Digitizer Software Description}

The SuPER Digitizer is like a slave device to the SuPER Controller and must respond to commands given to it; Figure 6-8 illustrates how the software on the digitizer will operate. The controller will mainly ask for the analog-to-digital conversion measurements the digitizers pick up from voltage, current, and temperature probes. It will also need to respond to commands for controlling MOSFET switches which are located on the PCB.

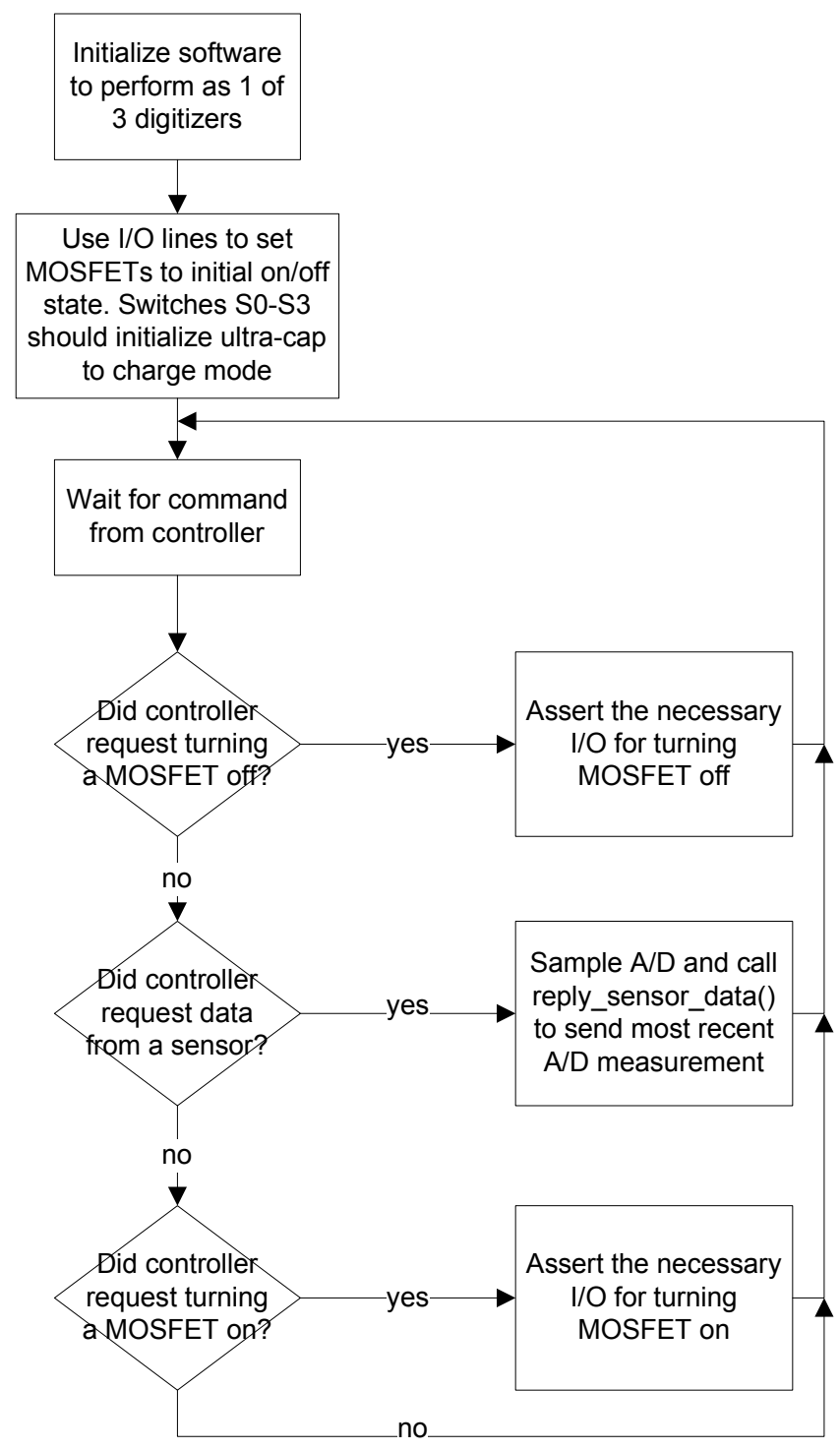

Figure 6-8 - Digitizer Software Flowchart 


\subsubsection{SuPER Digitizer-to-SuPER Controller API}

See the complement section: 6.2.4 SuPER Controller-to-SuPER Digitizer API.

\subsubsection{SuPER Digitizer-to-Analog MUX API}

For digitizing the voltage and current measurements from the loads, the digitizer board located there will have those 10 signals routed to an analog MUX. This will multiplex the data onto one $\mathrm{A} / \mathrm{D}$ pin of the microcontroller ensuring that a large number of $\mathrm{A} / \mathrm{D}$ measurements can be made on one PCB design. Refer to section 5.2.1.3 for pinout and truth table information for controlling this analog MUX.

\subsubsection{SuPER Digitizer-to-MOSFETs API}

The digitizer boards will toggle MOSFET switches on or off through the assertion of I/O pins on the microcontroller connected to the MOSFET gates. Refer to section 5.2.1.2 for more information on the pinouts for each digitizer board to its MOSFETs.

\subsection{SuPER Software Error Conditions}

There are always errors that will occur in complex systems, but error detection and recovery can help prevent major system failures. Software testing is very important because of the many different paths through which data can flow in a system. Anticipating where failures can occur and planning for their recovery will reduce the risk of equipment failure or human injury. Students that design and test the subsystems will inevitably discover more error conditions that need attention. The following sections are an attempt to account for serious software issues (and their solutions) that may arise while the system is operational, but should not be thought of as a catch all.

\section{1) Controller and digitizer unable to communicate}


- Have controller watchdog timer wait and then try again OR

- Have digitizer watchdog timer wait and then try again OR

- If digitizer loses communication for too long, shut down the switches from the digitizer board without waiting for controller OR

- Have digitizer run its own local algorithms for controlling the switches temporarily

\section{2) User interface stops receiving data from controller}

- Have a watchdog timer wait temporarily OR

- Reset the user interface and go back to main menu

\section{3) Controller USB connection is lost when laptop still connected}

- Safely terminate whichever activity was being performed

- If user was downloading SD memory contents, let the system return to storing sensor data on the card

- If user was viewing real-time data pause the real-time data feed to USB

- If ultra-capacitor was charging or discharging have it return to normal mode

- Try to re-establish connection and wait for user command from laptop

\section{4) SD memory card stops responding}

- Try resetting SD card

- Continue running the real-time control algorithms even if data storage not possible

\section{5) SD memory card is full}

- Begin overwriting data from the beginning of the card 


\section{Reliability Analysis}

The reliability analysis for the SuPER system will be performed using a few different metrics that only scratch the surface of system reliability. The use of mean-time between failure (MTBF) statistics, a reliability function, and a failure modes and effects analysis (FMEA) will be investigated. The MTBF, in conjunction with the mean-time to repair (MTTR) estimation, can be used to predict the overall system availability. Some MTBF figures are found in component datasheets, some from empirical and field evidence, and the rest of the information is obtained through the Military's "Reliability Prediction of Electronic Equipment - Notice F" also known as MIL-HDBK-217F. Although the MTBF figures from this handbook are generalized, it will serve very useful in setting up a usable model for determining overall system MTBF. This model assumes everything is in series and that if one component fails the entire system will fail.

The FMEA is a tool used throughout the life cycle of a product to determine where potential failures can occur in the system [26]. For each function the system provides, an engineer will find the severity, probability, and current detection capabilities available for finding failure modes before they find the customer. These three ratings (severity, probability, and detection) are determined by combining previous experiences with these components and knowledge of the current system implementation. Once the three ratings are determined, they are multiplied together to get the risk priority number (RPN). This RPN can be used to prioritize which areas of the system have the greatest potential for failure. Doing this kind of analysis multiple times throughout the design phase will mitigate risk during future implementation.

For this project, an MTBF calculator developed by Advanced Logistics Development [45] was used because it was free and incorporated MIL-217F data. The program allows a user to choose operating environment, temperature, and electronic components to evaluate. After more 
specific component parameters are input the program will give the MTBF for that part in hours. There are many opinions from reliability engineers that say the MIL-STD data isn't 100\% accurate [18]. This is true, but a lot of reliability numbers are just predictions and the point of this analysis for the SuPER system is to setup a general model which can be expanded in the future. The MTBF calculator does allow some component de-rating if the part isn't being used at $100 \%$ load. For the power MOSFETs this de-rating comes into play because the actual amount of power dissipated in the device comes nowhere near what it can handle. This dramatically improves the lifetime.

The individual subsystem MTBFs were calculated by dividing 1 by the sum of all of the component MTBF numbers, shown in equation 1 below [44]. The same process was followed for determining the overall system MTBF by dividing 1 by all of the subsystem MTBF values. System availability was found using equation 2 [41] which incorporates the MTBF and MTTR.

$$
\begin{gathered}
\frac{1}{\sum_{1}^{N} \frac{1}{M T B F_{N}}} \\
\text { Availability }=\frac{\text { System MTBF }}{\text { System MTBF }+ \text { MTTR }}
\end{gathered}
$$

In addition to the MTBF values, there is the $\lambda$ parameter which is 1 million hours divided by the MTBF. It is just a different way of looking at the numbers. Reliability is the probability the system will reach its intended lifetime [19] and can be found using equation 3 below. For a system with everything in series the parameter $\lambda_{S}$ is simply the addition of all of the component $\lambda$ 
values. This equation gives a probability that is time-dependent, unlike the MTBF numbers which are a snapshot in time assuming everything stays in a steady state.

$$
R_{S}(t)=\exp \left(-\lambda_{s} t\right)
$$

Table 7-1 shows the results for phase 2 of the SuPER system in a ground, benign environment at $50^{\circ} \mathrm{C}$. It includes the MTBF and $\lambda$ values for components, subsystems, and the entire system, along with the calculated system availability. MTTR is assumed to be one hour as that is the goal for repair. Appendix G - MTBF Parameters contains information on how the component MTBF values were obtained. 
Table 7-1 - System Reliability Metrics

\begin{tabular}{|c|c|c|c|c|c|}
\hline Part & Quantity & $\begin{array}{l}\text { Component } \\
\text { MTBF (hrs) }\end{array}$ & $\begin{array}{c}\text { Component } \lambda \\
\text { (failures / } \\
1000000 \mathrm{hrs} \text { ) }\end{array}$ & $\begin{array}{c}\text { Subsystem } \\
\text { MTBF } \\
\text { (hrs) }\end{array}$ & $\begin{array}{c}\text { Subsystem } \lambda \\
\text { (failures / } \\
1000000 \\
\text { hrs) }\end{array}$ \\
\hline \multicolumn{6}{|c|}{ PV Panel } \\
\hline $150 \mathrm{~W}-1 \mathrm{~m}^{2} \mathrm{PV}$ array & 1 & 5256000 & 0.190259 & 5256000 & 0.190259 \\
\hline \multicolumn{6}{|c|}{ Battery } \\
\hline 100Ah AGM battery & 1 & 43200 & 23.148148 & 43200 & 23.148148 \\
\hline \multicolumn{6}{|c|}{ Ultra-Capacitor } \\
\hline 58F Ultra-capacitor & 1 & 87600 & 11.415525 & 87600 & 11.415525 \\
\hline \multicolumn{6}{|c|}{ DC-DC Converter } \\
\hline $\begin{array}{r}\text { FR-4 PCB with through- } \\
\text { hole soldering }\end{array}$ & 1 & 105042018 & 0.009520 & & \\
\hline $\begin{array}{r}\text { IRF3205ZPBF } \\
\text { MOSFET }\end{array}$ & 2 & 2266001 & 0.441306 & & \\
\hline MBR2045CTPBF Diode & 2 & 24180984 & 0.041355 & & \\
\hline SBR2060CT Diode & 1 & 157059350 & 0.006367 & & \\
\hline IHV15BJ500 Inductor & 1 & 7464951474 & 0.000134 & 1019012 & 0.981343 \\
\hline \multicolumn{6}{|c|}{ Printed Circuit Assembly } \\
\hline $\begin{array}{l}\text { FR-4 PCB with through- } \\
\text { hole and SMT soldering }\end{array}$ & 1 & 9010957 & 0.110976 & & \\
\hline Microprocessor & 1 & 23091360 & 0.043306 & & \\
\hline $\begin{array}{l}\text { HUF75645S3ST } \\
\text { MOSFET Switch }\end{array}$ & 10 & 887204 & 1.127136 & & \\
\hline SD Memory Card & 1 & 1000000 & 1.000000 & & \\
\hline LM324 Quad Op Amp & 5 & 759000000 & 0.001318 & & \\
\hline Assorted Resistors & 40 & 337287569 & 0.002965 & & \\
\hline 5V Voltage Regulator & 1 & 759000000 & 0.001318 & & \\
\hline 3.3V Voltage Regulator & 1 & 4000000000 & 0.000250 & & \\
\hline $\begin{array}{r}\text { ACS758LCB-050 } \\
\text { Current Sensor }\end{array}$ & 8 & 808000000 & 0.001238 & & \\
\hline $\begin{array}{r}\text { RTD Temperature } \\
\text { Sensor }\end{array}$ & 3 & 128000 & 7.812500 & 27778 & 35.999796 \\
\hline
\end{tabular}

System MTTR (hrs) 1

System MTBF (hrs) 5564

System Lambda $\quad 180$
System Reliability:

At 20 years $\quad 0.00$

System Availability $\quad 99.9820$ 
These numbers don't exactly fit with a system that is aiming for at least a 20 year

lifespan. The MTBF value comes out low which also leads to a much too high Lambda value for the system. I believe this is a good start for a system reliability model and it leads to many more thoughts that will be included in the Recommendations section. Using this information will be very helpful in determining a system maintenance plan to extend the lifetime to 20 years. 
Figure 7-1 $(a, b, c)$ outline the general strategy used to determine the three metrics which compose the RPN for the FMEA.

\section{Severity Rating Seale}

\begin{tabular}{|c|c|l|}
\hline Rating & Description & \multicolumn{1}{|c|}{ Definition (Severity of Effect) } \\
\hline 10 & $\begin{array}{c}\text { Dangerously } \\
\text { high }\end{array}$ & $\begin{array}{l}\text { Failure could injure the customer or an em- } \\
\text { ployee. }\end{array}$ \\
\hline 9 & $\begin{array}{c}\text { Extrem ely } \\
\text { high }\end{array}$ & $\begin{array}{l}\text { Failure would create noncompliance with fed- } \\
\text { eral regulations. }\end{array}$ \\
\hline 8 & Very high & $\begin{array}{l}\text { Failure renders the unit inoperable or unfit for } \\
\text { use. }\end{array}$ \\
\hline 7 & High & $\begin{array}{l}\text { Failure causes a high degree of customer dis- } \\
\text { satisfaction. }\end{array}$ \\
\hline 6 & Moderate & $\begin{array}{l}\text { Failure results in a subsystem or partial mal- } \\
\text { function of the product. }\end{array}$ \\
\hline 4 & Low & $\begin{array}{l}\text { Failure creates enough of a performance loss to } \\
\text { cause the customer to complain. }\end{array}$ \\
\hline 3 & Minor & $\begin{array}{l}\text { Failure can be overcome with modifications to } \\
\text { the customer's process or product, but there is } \\
\text { minor performance loss. }\end{array}$ \\
\hline 2 & Very Minor & $\begin{array}{l}\text { Failure would create a minor nuisance to the } \\
\text { customer, but the customer can overcome it } \\
\text { without performance loss. }\end{array}$ \\
\hline 1 & $\begin{array}{l}\text { Failure may not be readily apparent to the cus- } \\
\text { tomer, but would have minor effects on the } \\
\text { customer's process or product. }\end{array}$ \\
\hline None & $\begin{array}{l}\text { Failure would not be noticeable to the customer } \\
\text { and would not affect the customer's process or } \\
\text { product. }\end{array}$ \\
\hline
\end{tabular}

(a)

\section{Deteetion Rating Seals}

\begin{tabular}{|c|c|l|}
\hline Rating & Description & \multicolumn{1}{|c|}{ Definition } \\
\hline 10 & $\begin{array}{l}\text { Absolute } \\
\text { Uncertainty }\end{array}$ & $\begin{array}{l}\text { The product is not inspected or the defect } \\
\text { caused by failure is not detectable. }\end{array}$ \\
\hline 9 & Very Remote & $\begin{array}{l}\text { Product is sampled, inspected, and released } \\
\text { based on Acceptable Quality Level (AQL) } \\
\text { sampling plans. }\end{array}$ \\
\hline 8 & Remote & $\begin{array}{l}\text { Product is accepted based on no defectives in a } \\
\text { sample. }\end{array}$ \\
\hline 7 & Very Low & $\begin{array}{l}\text { Product is 100\% manually inspected in the } \\
\text { process. }\end{array}$ \\
\hline 6 & Low & $\begin{array}{l}\text { Product is 100\% manually inspected using } \\
\text { go/no-go or other mistake-proofing gages. }\end{array}$ \\
\hline 5 & Moderate & $\begin{array}{l}\text { Some Statistical Process Control (SPC) is used } \\
\text { in process and product is final inspected off- } \\
\text { line. }\end{array}$ \\
\hline 3 & Moderately & $\begin{array}{l}\text { SPC is used and there is immediate reaction to } \\
\text { out-of-control conditions. }\end{array}$ \\
\hline 2 & High & $\begin{array}{l}\text { An effective SPC program is in place with pro- } \\
\text { cess capabilities (C } \text { pk) greater than 1.33. }\end{array}$ \\
\hline 1 & Almost & All product is $100 \%$ automatically inspected. \\
\hline Certain & $\begin{array}{l}\text { The defect is obvious or there is 100\% auto- } \\
\text { matic inspection with regular calibration and } \\
\text { preventive maintenance of the inspection } \\
\text { equipment. }\end{array}$ \\
\hline
\end{tabular}

(b)

\section{Operirrence Ration Sarle}

\begin{tabular}{|c|c|c|}
\hline Rating & Description & Potential Failure Rate \\
\hline 10 & $\begin{array}{l}\text { Very High: } \\
\text { Failure is al- } \\
\text { most inevitable. }\end{array}$ & $\begin{array}{l}\text { More than one occurrence per day or a } \\
\text { probability of more than three occurrences } \\
\text { in } 10 \text { events }\left(\mathrm{C}_{\mathrm{pk}}<0.33\right) \text {. }\end{array}$ \\
\hline 9 & $\begin{array}{l}\text { High: Failures } \\
\text { occur almost } \\
\text { as often as not. }\end{array}$ & $\begin{array}{l}\text { One occurrence every three to four days or } \\
\text { a probability of three occurrences in } 10 \\
\text { events (Cpk } \approx 0.33) \text {. }\end{array}$ \\
\hline 8 & $\begin{array}{l}\text { High: Re- } \\
\text { peated failures. }\end{array}$ & $\begin{array}{l}\text { One occurrence per week or a probability } \\
\text { of } 5 \text { occurrences in } 100 \text { events }\left(\mathrm{C}_{\mathrm{pk}} \approx\right. \\
0.67) \text {. }\end{array}$ \\
\hline 7 & $\begin{array}{l}\text { High: Failures } \\
\text { occur often. }\end{array}$ & $\begin{array}{l}\text { One occurrence every month or one occur- } \\
\text { rence in } 100 \text { events }\left(\mathrm{C}_{\mathrm{pk}} \approx 0.83\right) \text {. }\end{array}$ \\
\hline 6 & $\begin{array}{l}\text { Moderately } \\
\text { High: Frequent } \\
\text { failures. }\end{array}$ & $\begin{array}{l}\text { One occurrence every three months or three } \\
\text { occurrences in } 1,000 \text { events }\left(C_{p k} \approx 1.00\right) \text {. }\end{array}$ \\
\hline 5 & $\begin{array}{l}\text { Moderate: Oc- } \\
\text { casional fail- } \\
\text { ures. }\end{array}$ & $\begin{array}{l}\text { One occurrence every six months to one } \\
\text { year or five occurrences in } 10,000 \text { events } \\
\left(\mathrm{C}_{\mathrm{pk}} \approx 1.17\right) \text {. }\end{array}$ \\
\hline 4 & $\begin{array}{l}\text { Moderately } \\
\text { Low: Infre- } \\
\text { quent failures. }\end{array}$ & $\begin{array}{l}\text { One occurrence per year or six occurrences } \\
\text { in } 100,000 \text { everts }\left(\mathrm{C}_{\mathrm{pk}} \approx 1.33\right) \text {. }\end{array}$ \\
\hline 3 & $\begin{array}{l}\text { Low: Relatively } \\
\text { few failures. }\end{array}$ & $\begin{array}{l}\text { One occurrence every one to three years or } \\
\text { six occurrences in ten million events ( } \mathrm{C}_{\mathrm{pk}} \\
\approx 1.67) \text {. }\end{array}$ \\
\hline 2 & $\begin{array}{l}\text { Low: Failures } \\
\text { are few and far } \\
\text { between. }\end{array}$ & $\begin{array}{l}\text { One occurrence every three to five years or } \\
2 \text { occurrences in one billion events ( } \mathrm{C}_{\mathrm{pk}} \approx \\
2.00) \text {. }\end{array}$ \\
\hline 1 & $\begin{array}{l}\text { Remote: Fail- } \\
\text { ure is unlikely. }\end{array}$ & $\begin{array}{l}\text { One occurrence in greater than five years or } \\
\text { less than two occurences in one billion } \\
\text { events }\left(\mathrm{C}_{\mathrm{pk}}>2.00\right) \text {. }\end{array}$ \\
\hline
\end{tabular}

(c)

Figure 7-1 (a,b,c) - Risk Priority Number Rating Scales [27] 
Table 7-2 is the most recent FMEA done on the SuPER system. The areas with the highest RPNs show where effort is needed in mitigating risk to the entire system. Using this as a guideline will help in determining which areas of the system need to be focused on during design to ensure the risk of failure is kept low. The Recommendations section will include more information on this FMEA.

Table 7-2 - Failure Modes and Effects Analysis (FMEA)

\begin{tabular}{|c|c|c|c|c|c|c|c|c|}
\hline Failure Mode & $\begin{array}{c}\text { Potential Effects of } \\
\text { Failure }\end{array}$ & $\begin{array}{l}\mathbf{S} \\
\mathbf{E} \\
\mathbf{V}\end{array}$ & $\begin{array}{c}\text { Potential Causes of } \\
\text { Failure }\end{array}$ & $\begin{array}{l}\mathbf{P} \\
\mathbf{R} \\
\mathbf{O} \\
\mathbf{B}\end{array}$ & $\begin{array}{c}\text { Current Design } \\
\text { Controls }\end{array}$ & $\begin{array}{l}\mathbf{D} \\
\mathbf{E} \\
\mathbf{T}\end{array}$ & $\begin{array}{l}\mathbf{R} \\
\mathbf{P} \\
\mathbf{N}\end{array}$ & $\begin{array}{c}\text { Action based on } \\
\text { RPN }\end{array}$ \\
\hline \multirow[t]{3}{*}{$\begin{array}{l}\text { PV panel } \\
\text { fails }\end{array}$} & \multirow[t]{3}{*}{$\begin{array}{l}\text { Power will } \\
\text { eventually run out } \\
\text { and the system will } \\
\text { be rendered useless }\end{array}$} & 8 & water damage [29] & 1 & Manual inspection & 7 & 56 & $\begin{array}{l}\text { Ensure PV panel is } \\
\text { tilted and electrical } \\
\text { connections have } \\
\text { environmental } \\
\text { protection }\end{array}$ \\
\hline & & 8 & $\begin{array}{l}\text { improper installation } \\
\text { or maintenance [29] }\end{array}$ & 1 & $\begin{array}{l}\text { adherence to } \\
\text { installation } \\
\text { guidelines }\end{array}$ & 3 & 24 & \\
\hline & & 8 & $\begin{array}{l}\text { under-rated } \\
\text { electronic } \\
\text { components }\end{array}$ & 2 & $\begin{array}{l}\text { preliminary test } \\
\text { results and } \\
\text { theoretical values } \\
\text { used to determine } \\
\text { component ratings }\end{array}$ & 7 & 112 & $\begin{array}{l}\text { Simulate and verify } \\
\text { what min/max } \\
\text { voltage, current, and } \\
\text { temperatures are and } \\
\text { get components that } \\
\text { are rated higher than } \\
\text { necessary }\end{array}$ \\
\hline
\end{tabular}


Table 7-2 (continued)

\begin{tabular}{|c|c|c|c|c|c|c|c|c|}
\hline \multirow[t]{3}{*}{$\begin{array}{l}\text { Wind turbine } \\
\text { fails [28] }\end{array}$} & \multirow[t]{3}{*}{$\begin{array}{l}\text { A backup system for } \\
\text { energy generation } \\
\text { will be unusable }\end{array}$} & 7 & $\begin{array}{l}\text { Cyclic stresses and } \\
\text { vibration }\end{array}$ & 1 & $\begin{array}{l}\text { Purchasing a reliable } \\
\text { product that has } \\
\text { shown high } \\
\text { performance in the } \\
\text { past }\end{array}$ & 7 & 49 & \\
\hline & & 7 & $\begin{array}{l}\text { The turbine mast } \\
\text { falling over or } \\
\text { breaking }\end{array}$ & 1 & $\begin{array}{l}\text { Proper installation } \\
\text { procedures and } \\
\text { analysis of the forces } \\
\text { seen by the turbine }\end{array}$ & 7 & 49 & \\
\hline & & 7 & $\begin{array}{l}\text { A foreign object } \\
\text { hitting the blades of } \\
\text { the turbine }\end{array}$ & 5 & $\begin{array}{l}\text { Analyzing the } \\
\text { surrounding area } \\
\text { where the turbine } \\
\text { will be installed }\end{array}$ & 7 & 245 & $\begin{array}{l}\text { Ensure the } \\
\text { surrounding area is } \\
\text { free of material that } \\
\text { could fly into the } \\
\text { turbine. Mount high } \\
\text { enough to avoid } \\
\text { human interaction. }\end{array}$ \\
\hline
\end{tabular}


Table 7-2 (continued)

\begin{tabular}{|c|c|c|c|c|c|c|c|c|}
\hline \multirow{2}{*}{$\begin{array}{l}\text { Battery loses large } \\
\text { percentage of } \\
\text { charge capacity } \\
\text { during expected } \\
\text { useful lifetime } \\
\text { (<10 years) }\end{array}$} & \multirow{2}{*}{$\begin{array}{l}\text { Electric power will } \\
\text { not be available for } \\
\text { long periods of time. } \\
\text { Large loads won't be } \\
\text { supported by battery. }\end{array}$} & \multirow[t]{2}{*}{5} & $\begin{array}{l}\text { Incorrect charge } \\
\text { mode }\end{array}$ & 3 & $\begin{array}{l}\text { Charge mode control } \\
\text { software }\end{array}$ & 3 & 45 & $\begin{array}{l}\text { Field testing should } \\
\text { be done to ensure that } \\
\text { the charge modes } \\
\text { operate as intended. }\end{array}$ \\
\hline & & & Aging & 1 & $\begin{array}{l}\text { Measure what the } \\
\text { maximum voltage is } \\
\text { on the battery when } \\
\text { charged }\end{array}$ & 4 & 20 & $\begin{array}{l}\text { Can field operator } \\
\text { use any of this } \\
\text { information to extend } \\
\text { battery life? New } \\
\text { charge modes when } \\
\text { in older age? }\end{array}$ \\
\hline $\begin{array}{l}\text { Power transmission } \\
\text { bus fails }\end{array}$ & $\begin{array}{l}\text { System loses } \\
\text { functionality and } \\
\text { could pose danger to } \\
\text { users }\end{array}$ & 10 & $\begin{array}{l}\text { PCB traces or wire } \\
\text { gauge too thin for } \\
\text { the amount of } \\
\text { current }\end{array}$ & 5 & $\begin{array}{l}\text { A theoretical } \\
\text { analysis of } \\
\text { maximum current in } \\
\text { different sub- } \\
\text { systems }\end{array}$ & 3 & 150 & $\begin{array}{l}\text { Control software } \\
\text { needs update to } \\
\text { account for a scenario } \\
\text { like this. Use good } \\
\text { PCB design } \\
\text { techniques and }\end{array}$ \\
\hline
\end{tabular}


Table 7-2 (continued)

\begin{tabular}{|c|c|c|c|c|c|c|c|c|}
\hline & & & & & & & & $\begin{array}{l}\text { proper wire gauges } \\
\text { for power flow. }\end{array}$ \\
\hline $\begin{array}{l}\text { Appliances that } \\
\text { aren't } 12 \mathrm{~V} \text { DC can } \\
\text { be plugged in }\end{array}$ & $\begin{array}{l}\text { User devices can be } \\
\text { permanently } \\
\text { damaged }\end{array}$ & 5 & $\begin{array}{l}\text { Using standard } \\
\text { appliance sockets } \\
\text { that allow a } \\
\text { 120VAC appliance } \\
\text { to be attached }\end{array}$ & 3 & $\begin{array}{l}\text { Power sockets have } \\
\text { a label indicating } \\
12 \mathrm{~V} \text { bus }\end{array}$ & 8 & 120 & $\begin{array}{l}\text { Users should be } \\
\text { aware of the } 12 \mathrm{~V} \text { bus } \\
\text { or sockets should be } \\
\text { changed to only work } \\
\text { with special } \\
\text { connectors }\end{array}$ \\
\hline $\begin{array}{l}\text { User is allowed } \\
\text { physical interaction } \\
\text { with high voltage, } \\
\text { current, or } \\
\text { temperatures }\end{array}$ & $\begin{array}{l}\text { Physical hard to } \\
\text { users }\end{array}$ & 10 & $\begin{array}{l}\text { Not having high- } \\
\text { power system } \\
\text { components } \\
\text { properly isolated } \\
\text { from the user }\end{array}$ & 2 & $\begin{array}{l}\text { Industry standard } \\
\text { enclosures used for } \\
\text { high power elements } \\
\text { of the system }\end{array}$ & 2 & 40 & $\begin{array}{l}\text { Ensure that all } \\
\text { components are } \\
\text { packaged in the } \\
\text { proper containers or } \\
\text { enclosures. Look at } \\
\text { NEMA standards. }\end{array}$ \\
\hline $\begin{array}{l}\text { Sun damage, water } \\
\text { leakage, dirt } \\
\text { contamination, etc. }\end{array}$ & $\begin{array}{l}\text { Could degrade } \\
\text { performance over } \\
\text { time or cause major } \\
\text { malfunction }\end{array}$ & 8 & $\begin{array}{l}\text { Enclosures don't } \\
\text { meet standards, } \\
\text { careless installation }\end{array}$ & 2 & $\begin{array}{l}\text { Packaging standards } \\
\text { must be followed for } \\
\text { electrical } \\
\text { components and } \\
\text { connections }\end{array}$ & 5 & 80 & $\begin{array}{l}\text { All electronics must } \\
\text { be enclosed properly }\end{array}$ \\
\hline
\end{tabular}


Table 7-2 (continued)

\begin{tabular}{|c|c|c|c|c|c|c|c|c|}
\hline $\begin{array}{l}\text { SD memory card } \\
\text { fails }\end{array}$ & $\begin{array}{l}\text { User will be unable } \\
\text { to store and retrieve } \\
\text { system usage } \\
\text { statistics }\end{array}$ & 5 & $\begin{array}{l}\text { Maximum } \\
\text { read/write cycles } \\
\text { exceeded }\end{array}$ & 1 & $\begin{array}{l}\text { Observation of } \\
\text { number of years in } \\
\text { use }\end{array}$ & 8 & 40 & $\begin{array}{l}\text { Use a high grade } \\
\text { standard capacity } \\
\text { card from a reputable } \\
\text { manufacturer. }\end{array}$ \\
\hline & & & Overheating & 4 & $\begin{array}{l}\text { PACK_0105 req. for } \\
\text { ventilating the PCB } \\
\text { enclosures }\end{array}$ & 4 & 80 & \\
\hline $\begin{array}{l}\text { Component failure } \\
\text { on PCB }\end{array}$ & $\begin{array}{l}\text { Ranges from } \\
\text { incorrect data } \\
\text { readings to entire } \\
\text { system failure }\end{array}$ & 8 & Overheating & 2 & $\begin{array}{l}\text { PACK_0105 req. for } \\
\text { ventilating the PCB } \\
\text { enclosures }\end{array}$ & 4 & 64 & \\
\hline EMI & $\begin{array}{l}\text { Incorrect data or } \\
\text { commands sent } \\
\text { through the system }\end{array}$ & 8 & $\begin{array}{l}\text { Crossed wires, bad } \\
\text { ground planes, poor } \\
\text { shielding }\end{array}$ & 3 & $\begin{array}{l}\text { PCB_0150 req. for } \\
\text { using robust } \mathrm{PCB} \\
\text { design techniques }\end{array}$ & 3 & 72 & $\begin{array}{l}\text { Use test setup to } \\
\text { ensure the correct } \\
\text { data is sent across the } \\
\text { I2C bus }\end{array}$ \\
\hline $\begin{array}{l}\text { Ultra-capacitor } \\
\text { fails }\end{array}$ & $\begin{array}{l}\text { If large loads (like } \\
\text { the motor) are turned } \\
\text { on the battery could } \\
\text { experience a large } \\
\text { charge drop }\end{array}$ & 4 & $\begin{array}{l}\text { Degradation due to } \\
\text { age. Worsened when } \\
\text { voltages are over } \\
\text { specified limits for } \\
\text { the cells. }\end{array}$ & 1 & $\begin{array}{l}\text { Have an ultra-cap } \\
\text { that has a higher } \\
\text { rated voltage than } \\
\text { what the battery can } \\
\text { provide }\end{array}$ & 2 & 8 & $\begin{array}{l}\text { Voltage that charges } \\
\text { the ultra-capacitor } \\
\text { must not exceed its } \\
\text { limits }\end{array}$ \\
\hline
\end{tabular}




\section{Recommendations}

This section will outline my recommendations for the next students who begin work on the SuPER system. These recommendations are geared more towards a systems engineering perspective which include scaling the system, modifying the reliability analysis, and updating subsystems to reduce cost and increase lifetime.

One major factor in the sizing for the system is the types of loads that will be serviced. Using a large DC motor requires the addition of an ultra-capacitor to prevent battery levels from drooping too low during the DC motor start up. If a large load like this was not going to be attached, the system could do without ultra-capacitor and its associated control software. This would then leave the $98 \mathrm{Ah}$ battery which could be downgraded to a smaller size or kept in the hopes that it would experience even smaller discharging, thereby increasing its life expectancy. More system modeling should be able to determine the right course of action. Similar sizing issues may arise as solar PV panels become more efficient. The SuPER systems in the future could either take advantage of this in a few ways. Either, by increasing the amount of power available to the user for the same price, or buying a smaller panel that will output the same amount of power the system currently does. Of course, with different component sizings and efficiencies individual subsystems may need to be tweaked to take full advantage.

Some immediate changes that could be made which didn't take effect in phase 2 are the addition of an environmental chamber for the battery, and a wind turbine. Some requirements were developed for these two subsystems, but they aren't quite ready to implement yet. The environmental chamber could be used to regulate the temperature around the battery, keeping it at a lower temperature to extend its lifetime. The wind turbine would be a great source of

additional energy generation, but needs to be added to the system in a smart way. First off, there 
will need to be another DC-DC converter designed to have the voltage stepped down for compliance with a $12 \mathrm{~V}$ system battery. Second, one system battery can only be charged by one device at a time, so there would need to be a switch that chose wind or solar power based on some external factors such as solar insolation or wind speeds.

The addition of a microgrid could benefit a more widespread group of people in a remote village. It is mentioned throughout this thesis, but many details still need to be worked out before its implementation is complete. DC-DC converters need to be designed for stepping the voltage up to $160 \mathrm{~V}$ for transmission and another for stepping it down where the external loads are to be serviced. This concept would fit very well with an upgraded SuPER system of the future which takes advantage of more abundant energy, such as with increased PV panel efficiency or the addition of a wind turbine. Users across a village would be able to plug into a power outlet without having to physically go to the central power generating SuPER cart.

Modifications could be made to the way the printed circuit assemblies are produced in order to save costs. The cost breakdown for phase 2, section 3.12 , showed that these boards end up costing a lot of money when fully populated with all components. The goal was to have one PCB design in order to reduce part count, make repair easier, and hopefully reduce failures. By populating every board with all of the current sensors, temperature sensors, and MOSFETs the price rises dramatically. Purchased in bulk, these boards would be much cheaper to produce, but it is worth looking at the tradeoffs for populating boards separately in order to lower costs. This is especially true for the digitizer board which is located at the PV panel. It only has a few measurements to make and fully populating that PCB would not be worth the costs.

The selection of the $\mathrm{I} 2 \mathrm{C}$ bus was made because it is easy to implement and available on most microcontrollers. A more advanced and robust option would be using a CAN bus. It would 
introduce a lot more complexity, but also increase the reliability. Not very many microcontrollers have a CAN controller and can provide the functionality needed at the date of this writing. If an upgraded microcontroller is chosen in the future it may be worth the extra effort of having a CAN controller on board for a more reliable communication bus.

The current design for the user interface only allows it to retrieve data and control the ultra-capacitor. Future revisions of the software could allow the user on the portable device to actually reprogram the SuPER controller to upgrade it. This would allow upgrades in the field without having to swap out hardware or make other major changes to the communications bus. Also, the user interface could be expanded to allow the user to connect to the system and actually control it from the portable device. This would mean that some additions to the user interface could be made allowing the user to manually send commands to the controller for controlling portions of the system from something like a laptop.

The reliability analysis presented here is a very general model that uses some MTBF metrics for determining system reliability and availability. Having the target life of 20 years in mind, a more complex model could be developed which would impact system design and operation decisions. A newer model may find that incorporating redundancy into certain areas greatly improves the lifespan. Determining which parts are most likely to fail identifies areas where spares would be needed. Items like the battery obviously won't last for 20 years, so having these on-site will allow the system to last for 20 years with minimum down time and a target mean-time to repair of 1 hour. The FMEA section of the reliability analysis should also be used for designing the various subsystems, especially the areas which have a high risk priority number. This will ensure that major failure modes are accounted for when designing and integrating the subsystems. 


\section{Conclusion}

My main goal for pushing the SuPER project closer to a field testable version has been achieved in this thesis. I have also learned many valuable systems engineering processes along the way. My wish is that future SuPER team members will use my thesis as a guide for implementing the phase 2 design and ultimately provide affordable power to the 2 billion people on Earth lacking it.

My personal goals were also fulfilled while working on SuPER. I gained much knowledge in the systems engineering field by making systems level decisions that could only happen after I understood what all the sub systems would be in detail. This began with me analyzing the previous work completed by Cal Poly students and comparing it to the future needs of the system. Their work was indeed the foundation for developing the phase 2 design presented here. Many of the sub systems that are presented here contain technologies that were foreign to me before I started this project. However, after learning what these new systems could do it allowed me to modify their design in attempts of extending the lifetime to 20 years. Once this new, robust design is integrated and tested it will be ready for real world testing at the Cal Poly Organic Farm.

Many of the improvements I made to the system were through the use of systems engineering tools. The sub systems that are developed here needed to be well defined for future implementers. I created interfaces for each of the sub systems that allow them to be modular in their design and integration. This includes the physical, hardware, and software interfaces between system components. However, many areas of my paper may seem foreign and not as technical to the average electrical engineer. These include system lifecycle issues such as reparability, maintainability, part count, price, MTBF, failure analysis, reliability, and safety. For 
a large scale project that expects a long lifetime, these issues needed to be analyzed during the phase 2 design. Not only did these areas increase my awareness of what systems engineers do, but they also lead toward a safer, more reliable system that will endure the technological changes coming in the next 20 years and beyond.

My major improvements to the system also include the addition of a digital

communications bus. This bus will give more accurate readings for the status software and allow for subsystem control. Although it would be desirable to have a team of 15-20 students complete my phase 2 design together, that is out of my control. The general structure and content of this thesis is laid out in a way that each subsystem can be built and tested separately before total system integration. This phase 2 design is pushing the SuPER system to meet the end user's requirements of being safe, affordable, and reliable. 


\section{Bibliography}

[1] Harris, James G. White Paper for Sustainable Power for Electrical Resources. Tech. 15 July 2005. Web. 12 May 2010.

$<$ http://courseware.ee.calpoly.edu/ jharris/research/super_project/white_paper_susper. pdf $>$.

[2] SunPower Corporation. Levelized Cost of Electricity for Utility-Scale Photovoltaics. Rep. 14 Aug. 2008. Web. 11 Apr. 2010.

<http://us.sunpowercorp.com/downloads/SunPower_levelized_cost_of_electricity.pdf>.

[3] Hande, H. H. "Does Solar PV Still Make Sense for the Developing World?" Renewable Energy World. 16 Feb. 2006. Web. 12 Mar. 2010.

<http://www.renewableenergyworld.com/rea/news/article/2006/02/does-solar-pv-stillmake-sense-for-the-developing-world-43569>.

[4] Minnesota State University - Mankato. "Design of a Small Scale Solar Chimney for Sustainable Power." U.S. EPA ColdFusion Server. 28 Oct. 2008. Web. 12 Mar. 2010. $<$ http://cfpub.epa.gov/ncer_abstracts/index.cfm/fuseaction/display.abstractDetail/abstra ct/8805/report/0>.

[5] Massachusetts Institute of Technology. "A Novel Solar Thermal Combined Cycle with Bio-Methane Carbon Capture for Distributed Power Generation." U.S. EPA ColdFusion Server. 28 Oct. 2008. Web. 12 Mar. 2010.

<http://cfpub.epa.gov/ncer_abstracts/index.cfm/fuseaction/display.abstractDetail/abstra $\mathrm{ct} / 8823>$.

[6] Rochester Institute of Technology. "Self-Contained Human and Solar Powered LED Lighting System for Use in the Developing World." U.S. EPA ColdFusion Server. 28 Oct. 2008. Web. 12 Mar. 2010.

<http://cfpub.epa.gov/ncer_abstracts/index.cfm/fuseaction/display.abstractDetail/abstra ct/8828>.

[7] The Cooper Union for the Advancement of Science and Art. "Final Report | Solar Lighting for Remote Rural Communities." U.S. EPA ColdFusion Server. 5 Sept. 2008. Web. 12 Mar. 2010.

<http://cfpub.epa.gov/ncer_abstracts/index.cfm/fuseaction/display.abstractDetail/abstra $\mathrm{ct} / 8637 /$ report/F>.

[8] Promethean Power Systems. Promethean Power Systems | Solar Powered Refrigeration. Web. 12 Mar. 2010.

<http://www.coolectrica.com/content_solarpower.php?products>.

[9] KYOCERA. "KYOCERA Donates Solar Power Generating Systems to Schools in Uganda; 600-watt Systems with Educational Equipment to Be Installed in 15 
Schools." KYOCERA GLOBAL SITE. 8 Oct. 2009. Web. 12 Mar. 2010.

<http://global.kyocera.com/news/2009/1003_jfsu.html>.

[10] Tal, Eran. "SuPER System Prototype Design and Implementation." Thesis. Cal Poly San Luis Obispo, 2006. Print.

[11] "Gate Turn-off Thyristor." Wikipedia, the Free Encyclopedia. 21 Apr. 2010. Web. 12 Mar. 2010. <http://en.wikipedia.org/wiki/Gate_turn-off_thyristor>.

[12] "The Silicon-Controlled Rectifier (SCR) : THYRISTORS." All About Circuits. Web. 12 Mar. 2010. <http://www.allaboutcircuits.com/vol_3/chpt_7/5.html>.

[13] Witts, Joseph. SuPER Cart DC Motor Model and Ultra-Capacitor Addition. Cal Poly Sustainable Power for Electrical Resources (SuPER) Project. 18 Mar. 2008. Web. Fall 2009.

$<$ http://courseware.ee.calpoly.edu/ jharris/research/super_project/jw_spring08_report.p df $>$.

[14] McFarland, Matthew. "Enhanced Cal Poly SuPER System Simulink Model." Thesis. Cal Poly San Luis Obispo, 2010. Print.

[15] Baskin, Gavin. SuPER System Safety. Cal Poly Sustainable Power for Electrical Resources (SuPER) Project. Winter 2008. Web. 12 Mar. 2010. <http://courseware.ee.calpoly.edu/ jharris/research/super_project/gb_sp.pdf>.

[16] Tecate Group. PowerBurst Ultra Capacitors. Tech. 1 Apr. 2010. Web. 20 Apr. 2010. <http://www.tecategroup.com/capacitors/datasheets/powerburst/PBD.pdf>.

[17] Harris, James G. Cal Poly Sustainable Power for Electrical Resources (SuPER) Project. Tech. May 2008. Web. 26 Apr. 2010.

$<$ http://courseware.ee.calpoly.edu/ jharris/research/super_project/calpoly_solar_2008_f inal.pdf $>$.

[18] Neubeck, Ken. "Opinion: MIL-HDBK-217 and the Real World." RAC Journal 2.2 (1994). Web. 5 May 2010.

[19] Ebeling, Charles E. "Reliability of Systems." An Introduction to Reliability and Maintainability Engineering. New York: McGraw Hill Co, 1997. 83-87. Print.

[20] "Universal Serial Bus." Wikipedia, the Free Encyclopedia. Web. 11 Apr. 2010. <http://en.wikipedia.org/wiki/Universal_Serial_Bus>.

[21] Kalinsky, David, and Roee Kalinsky. "Embedded.com - Introduction to I2C." Embedded Systems Design - Embedded.com. 31 July 2001. Web. 12 May 2010. <http://www.embedded.com/story/OEG20010718S0073>. 
[22] Patrick, John. "Embedded.com - Serial Protocols Compared." Embedded Systems Design - Embedded.com. 31 May 2002. Web. Fall 2009. <http://www.embedded.com/story/OEG20020528S0057>.

[23] National Instruments. "Controller Area Network (CAN) Overview." NI Developer Zone. 7 Nov. 2009. Web. Fall 2009. <http://zone.ni.com/devzone/cda/tut/p/id/2732>.

[24] "Secure Digital Card Pinout, SD Flash Card Memory Module Pin Out." Interfacebus.com. 17 Dec. 2009. Web. Fall 2009. <http://www.interfacebus.com/Secure_Digital_Card_Pinout.html>.

[25] Berik, Cem. "Secure Digital (SD) Card Pinout and Wiring @ Pinouts.ru." Handbook of Hardware Pinouts, Cables Schemes and Connectors Layouts @ Pinouts.ru. 6 Jan. 2010. Web. 12 Mar. 2010. <http://pinouts.ru/Memory/sdcard_pinout.shtml>.

[26] DRM Associates. "FAILURE MODES AND EFFECTS ANALYSIS (FMEA)." New Product Development Solutions. 2002. Web. 12 Jan. 2010. <http://www.npdsolutions.com/fmea.html>.

[27] McDermott, Robin. "What You Need to Know about Failure Modes and Effects Analysis (FMEA)." Failure Mode and Effects Analysis (FMEA) Resource Center. 2009. Web. 12 Mar. 2010. <http://www.qualitytrainingportal.com/resources/fmea/index.htm>.

[28] Sagrillo, Mick. "Advice from an Expert - Wind System Operation and Maintenance Costs."American Wind Energy Association. Dec. 2002. Web. 12 Mar. 2010. <http://www.awea.org/faq/sagrillo/ms_oandm_0212.html>.

[29] Energy Unlimited, LLC. "Energy Unlimited - FAQs." Energy Unlimited - The Northwest Leader in Energy Conservation \& Alternative Energy Production. 2009. Web. 12 Mar. 2010. 〈http://www.energyunlimitedoregon.com/faqs.htm>.

[30] Acra, Aftim, Zeina Raffoul, and Yester Karahagopian. "Solar Energy: World Distribution."Al Mashriq - the Levant - Lebanon and the Middle East. 1984. Web. 12 Mar. 2010. <http://almashriq.hiof.no/lebanon/600/610/614/solar-water/unesco/2426.html .

[31] Solar Energy Map. Digital image. Web. Winter 2009. <http://www.is.njit.edu/competition/2009/Cat2_2_Winner_Group142/img/image003.jp g>.

[32] Ionela. "Precision Temperature Sensing with RTD Circuits." Dev.emcelettronica.com. 23 Feb. 2009. Web. Winter 2009. <http://dev.emcelettronica.com/precisiontemperature-sensing-rtd-circuits $>$. 
[33] King, Dave. "Temperature Sensors, Thermocouples, Thermowells, Sensors, Heat Treatment." Temperature Sensors. 1997. Web. 12 May 2010. <http://www.thermometricscorp.com/temsensel.html>.

[34] "MOSFETs and MOSFET Drivers." PWS Tutorial - Default. 30 Jan. 2002. Web. 12 Mar. 2010. <http://homepages. which.net/ paul.hills/SpeedControl/MosfetBody.html〉.

[35] Summary of Levelized Energy Costs. Digital image. Web. 15 Apr. 2010. <http://nwbioregion.files.wordpress.com/2008/07/cost_power_ca.jpg>.

[36] Cook, David. "Robot Room: Atmel AVR TWI I2C Multimaster Issue." Robot Room: Robotics, Electronics, and Schematics. Web. 12 Mar. 2010. <http://www.robotroom.com/Atmel-AVR-TWI-I2C-Multi-Master-Problem.html〉.

[37] I2C Timing Diagram. Digital image. Web. Winter 2010. $<$ http://dev.emcelettronica.com/files/u7/i2c_400x150.jpg>.

[38] SPI Timing Diagram. Digital image. Web. Winter 2010. <http://book.opensourceproject.org.cn/embedded/oreillyedsignbed/opensource/0596003 625/images/0596003625/figs/deh_0904.gif>.

[39] "Serial Peripheral Interface Bus." Wikipedia, the Free Encyclopedia. Web. Mar. 2010. <http://en.wikipedia.org/wiki/Serial_Peripheral_Interface_Bus>.

[40] Datasheet Image for PIC24FJ256GB110. Digital image. Web. Winter 2010. <http://ww1.microchip.com/downloads/en/DeviceDoc/39897c.pdf>.

[41] EventHelix.com Inc. "Reliability and Availability Basics." Sequence Diagram Based Systems Engineering Tools. 2009. Web. Winter 2010. <http://www.eventhelix.com/RealtimeMantra/FaultHandling/reliability_avavailabili_ba sics.htm>

[42] Kazmerski, Lawrence. PVeff. Digital image. Wikipedia, the Free Encyclopedia. 21 Apr. 2010. Web. May 2010. <http://en.wikipedia.org/wiki/File:PVeff(rev100414).png>.

[43] Analog Devices. LC2MOS 8-/16-Channel High Performance Analog Multiplexers. Datasheet. Apr. 1994. Web. Apr. 2010. <http://www.analog.com/static/importedfiles/data_sheets/adg406_407_426.pdf>.

[44] EventHelix.com Inc. "System Reliability and Availability Calculation." Sequence Diagram Based Systems Engineering Tools. 2009. Web. Mar. 2010. <http://www.eventhelix.com/RealtimeMantra/FaultHandling/system_reliability_availab ility.htm>. 
[45] ALD. "Free MTBF Calculator." Free MTBF Calculator for Reliability Prediction ALD Service. Web. Apr. 2010. <http://www.aldservice.com/en/reliability-software/freemtbf-calculator.html>. 


\section{Appendix A - I2C Protocol}

The inter-integrated circuit (I2C) bus is made up of two signal lines, the data line (SDA) and clock line (SCL). A master device normally controls the clock line and slave devices respond to requests sent to their unique 7-bit address. The communication starts when the master device drops the SCL line low to signal a START condition. The 7-bit address along with the read/write bit ( 0 tells the slave to read, 1 tells it to write) is then sent out along the SDA line. When a slave device sees its address it will ACK. The master then sends data bytes starting with the MSB and waits for the receiver to ACK. These data bytes can be continuously transmitted until all the data transfer session is over. When the slave is receiving data it will ACK the last data byte, this tells the master transmitter the session is over and it raises the SCL line high to signal a STOP condition. When the slave is transmitting, the master device receiving the data does not ACK after the last data byte. This tells the slave it is done transmitting and the master device will issue the STOP condition. Note there is a repeated start condition for transmission where start and stop bits do not have to be sent for every data byte; this may prove useful for sending multiple data bytes consecutively.

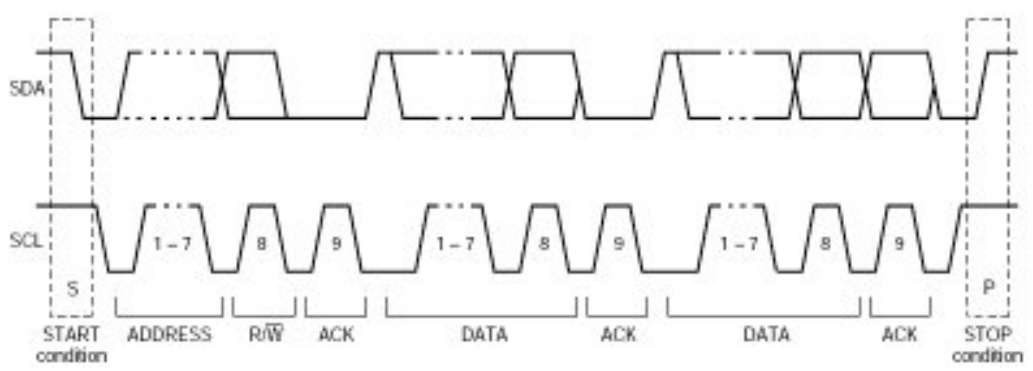

Figure A-1 - I2C Timing Diagram [37] 


\section{Appendix B - SPI Protocol}

The serial peripheral interface (SPI) is a 4-wire interface that operates in synchronous full-duplex mode [39]. The four wires are SCLK, MOSI, MISO, and /SS as seen in the timing diagram below. SCLK is the clock generated by the master device and sent to the slave. MOSI stands for master-out slave-in and is a serial data interface where data is written to. MISO stands for master-in slave-out and represents the reading interface. Each device thinks it is master. The /SS is active low and stands for slave-select. The master brings /SS low to initiate data transfers. If each device had a 1-byte shift register, then the data would be transferred byte by byte in this serial manner. Slave-select is brought high when the master is done transmitting. Note that for many devices the master must write to initiate a read function. This activates SCLK and prepares the slave device for data transfer. In this case, the data written by master is meaningless if all you want to do is read from the slave.

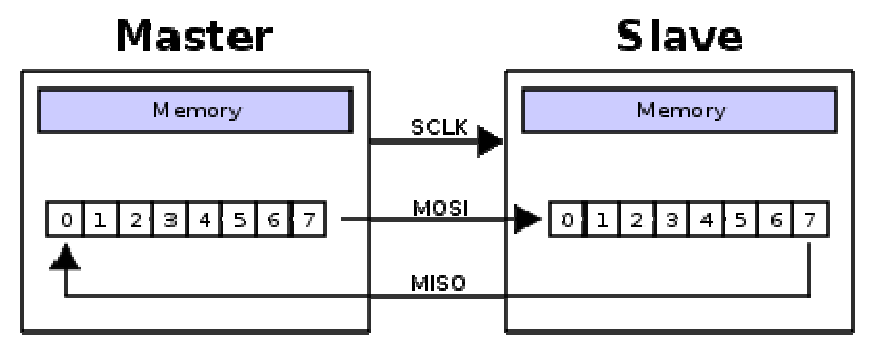

Figure B-1 - SPI Serial Data Flow [39]

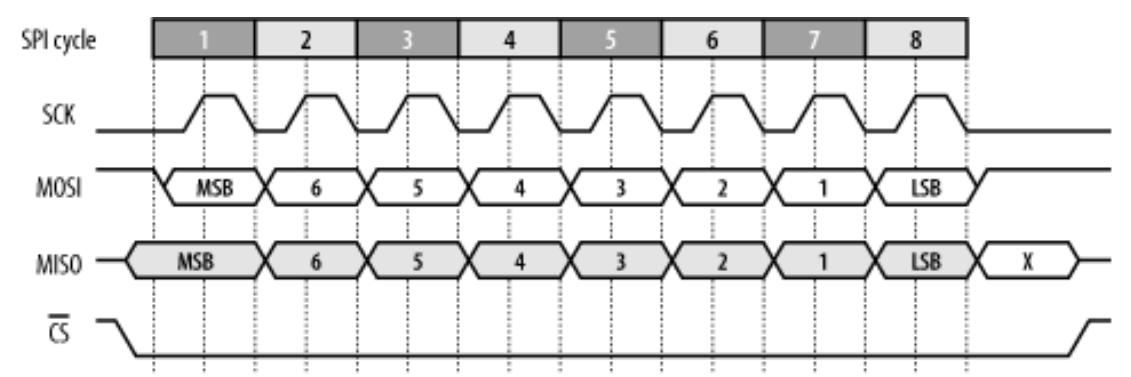

Figure B-2 - SPI Timing Diagram [38] 


\section{Appendix C - USB 2.0 OTG Protocol}

The USB 2.0 On-the-go (OTG) protocol was developed for connecting USB enabled devices together, instead of just having them be peripherals to a PC. The USB 2.0 standard is defined as "hi-speed" at $480 \mathrm{Mbits} / \mathrm{second}$ (or $57 \mathrm{MB} / \mathrm{s}$ ). It is a much more robust communication platform than I2C or SPI and has more overhead in its data transfer. This limits its actual data throughput to about 2/3 its maximum [20], but this is still useful for the SuPER project. The USB 2.0 data is transferred on the D+ and D- lines of a twisted-pair data cable for half-duplex communication. The data lines are toggled using the NRZI encoding scheme. USB packets begin with an 8-bit synchronization of "00000001" and end with an end of packet (EOP) encoding. There are many examples of using this protocol in Microchip's documentation and they should be referenced for more information. 


\section{Appendix D - SuPER Data Rate Analysis}

This analysis will be used to determine the best methods for passing information through the digital communications bus of the SuPER system. There are three different communication protocols that will be used: SPI, I2C, and USB. Here, we will look at the speeds and data formats for communication between these busses.

\section{$\underline{\text { I2C Throughput Analysis [36] }}$}

I2C transfers begin with 1 start bit and end with 1 stop bit. After the start bit comes the address byte which is a 7-bit address and 1 bit for read/write. Then the data packet transferred is 8 data bits followed with 1 ack/nak bit. This comes out to $1+7+1+1+8+1+1=20$ bits that must be transferred on the $\mathrm{I} 2 \mathrm{C}$ bus for the actual read or write of 1 data byte ( 8 bits). The start and stop bits are the overhead for I2C transfers between the same device and only occur during communication initialization and termination between two I2C devices.

For communication between the controller and the digitizer boards, there are three different data rates that occur for the three digitizer boards. Together, these will give the actual data rate transfer speed of all the A/D measurements to the controller.

Digitizer at Loads: 10 A/D measurements

$$
\begin{aligned}
\text { Start }+ \text { Addr }+\mathrm{Rd} / \mathrm{Wr}+\mathrm{Ack} / \mathrm{Nak}+10^{*}(\text { Data byte }+ \text { Ack/Nak })+\text { Stop } \\
1+7+1+10^{*}\left(\begin{array}{c}
8+1 \\
1+1
\end{array}\right)+1=101 \text { bits }
\end{aligned}
$$

Digitizer at Battery/DC-DC Converter: 6 A/D measurements

$$
\begin{aligned}
& \text { Start }+ \text { Addr }+\mathrm{Rd} / \mathrm{Wr}+\text { Ack/Nak }+10^{*}(\text { Data byte }+ \text { Ack } / \text { Nak })+\text { Stop } \\
& 1+7+1+1+6^{*}(8+1)+1=65 \text { bits }
\end{aligned}
$$

Digitizer at PV Panel: 3 A/D measurements

Start + Addr + Rd/Wr + Ack/Nak $+10^{*}($ Data byte + Ack/Nak $)+$ Stop

$1+7+1+1+3 *(8+1)+1=38$ bits

Total bits transferred for all A/D measurements $=204$ bits 
To determine the actual data throughput we need to look at the speed of the $\mathrm{I} 2 \mathrm{C}$ bus. Using the speed of $100 \mathrm{KHz}$ and 204 bits transferred for 19 data bytes we can calculate the data throughput as:

$100,000 \mathrm{~Hz} / 204$ bits $=490$ messages $* 19$ data bytes $=9310$ bytes $/$ second

It is recommended to just use the 8 most significant bits from the 10-bit resolution A/D converters of the microcontroller. It would simplify coding and not take too much away from the accuracy of the measurements, but all 10 bits are preferred if it is not too much extra work. If the upper 2 bits were to be included it would require another 19 data byte transmissions to get the readings. This would normally increase the throughput, but because each of the 19 extra transfers is only contributing 2 bits of useful data it results in 54\% degradation in throughput of:

$100,000 \mathrm{~Hz} /(204+171$ bits $)=266$ messages $* 19$ data bytes $=5054$ bytes $/$ second These values could be scaled if the chosen I2C interface does not operate at $100 \mathrm{KHz}$. If $100 \mathrm{KHz}$ is used however, the theoretical minimum time it would take for each A/D measurement transfer is:

(1 second / 9310 bytes $) *(9$ bits $/ 1$ A/D reading $)=0.121$ milliseconds $*$

*excluding start and stop bits

If continuous sampling occurred for all $19 \mathrm{~A} / \mathrm{D}$ measurements, the fastest that any one measurement could occur when cycling through all 19 is:

(0.121 milliseconds / A/D reading) $* 19 \mathrm{~A} / \mathrm{D}$ readings $=2.300$ milliseconds 


\section{$\underline{\text { SPI Throughput Analysis }}$}

The SPI protocol can transfer data at the speed which its clock runs at. Therefore, if a $10 \mathrm{MHz}$ clock is used it would be able to transfer 10Mbits / second over the SPI interface. If a standard capacity SD memory card is used, it can be addressed by byte. The real time clock and calendar (RTCC) function of the microcontroller is provided when an external $32.768 \mathrm{KHz}$ crystal is supplied. It has four 8-bit registers (YEAR, MTHDY, WKDYHR, MINSEC) for timestamping the A/D data in the SD memory card.

Each $\mathrm{A} / \mathrm{D}$ reading that gets stored in the SD memory card will require 6 bytes. This is true whether or not the 8 most significant bits are used from the A/D measurement, or all 10, as described in the $\mathrm{I} 2 \mathrm{C}$ throughput section above. The table below shows this 6 byte configuration if 8 bits from the A/D measurement are used. The LOCATION byte will need to be used for tracking which voltage, current, or temperature measurement is contained within byte 6 (which is the actual A/D reading).

Table D-1 - 6-Byte Digitizer Data Format

\begin{tabular}{|l|l|l|l|l|l|}
\hline Byte 1 & Byte 2 & Byte 3 & Byte 4 & Byte 5 & Byte 6 \\
\hline YEAR & MTHDY & WKDYHR & MINSEC & LOCATION & A/D \\
\hline
\end{tabular}

Using this 6 byte scheme for all 19 A/D measurements would result in 114 bytes stored in the SD memory card every sampling cycle. Theoretically, storing these measurements in 5 minute intervals on a $1 \mathrm{~GB}$ standard capacity SD memory card would allow measurements to be taken for:

(1 x 10E9 bytes $) *(5$ mins / 114 bytes $) *(1 \mathrm{hr} / 60 \mathrm{mins}) *(1$ day / $24 \mathrm{hrs}) *(1 \mathrm{yr} / 365$ days $)$ $=83.4$ years 
That is a lot of data! This analysis is only theoretical though and does not follow SD memory card reading/writing specifications which could bring the actual amount of stored data down to a lower amount. If we assume the SuPER system will be serviced annually, then we want to find out how long it will take to download a year's worth of data to the operator's laptop. Running SPI at $10 \mathrm{MHz}$, theoretically this will take:

$$
\begin{aligned}
& 1 \text { Year of data }=(114 \text { bytes } / 5 \text { mins }) *(60 \text { mins } / 1 \mathrm{hr}) *(24 \mathrm{hrs} / \text { day }) *(365 \text { days } / 1 \mathrm{yr}) \\
& =11,983,680 \text { bytes } \\
& (1 \text { second / 1x10E7 bits }) *(11,983,680 \text { bytes }) *(8 \text { bits } / \text { byte })=9.59 \text { seconds }
\end{aligned}
$$
will have to be sent through the USB 2.0 OTG microcontroller connection to the user's laptop. The actual time will be slower, but hopefully on this same order of magnitude since 1 year's worth of data comes out to just over $10 \mathrm{MB}$, which is not too much for a high-speed interface.

\section{USB 2.0 OTG Throughput Analysis}

The USB 2.0 On-the-go (OTG) protocol was developed for connecting USB enabled devices together, instead of just having them be peripherals to a PC. The USB 2.0 standard is defined as "hi-speed" at 480Mbits/second (or 57MB/s). Actual throughput varies based on application, but many devices can get up to $2 / 3$ their maximum rated throughput [20]. Other tests have shown that around $25-27 \mathrm{MB} / \mathrm{s}$ data rate transfers are possible. Either way, these speeds should be able to keep up with a $10 \mathrm{MHz}$ SPI bus $(1.25 \mathrm{MB} / \mathrm{s})$ when transferring stored data from the SD memory card. 


\section{Appendix E - Charge Controller ' $C$ ' Code}

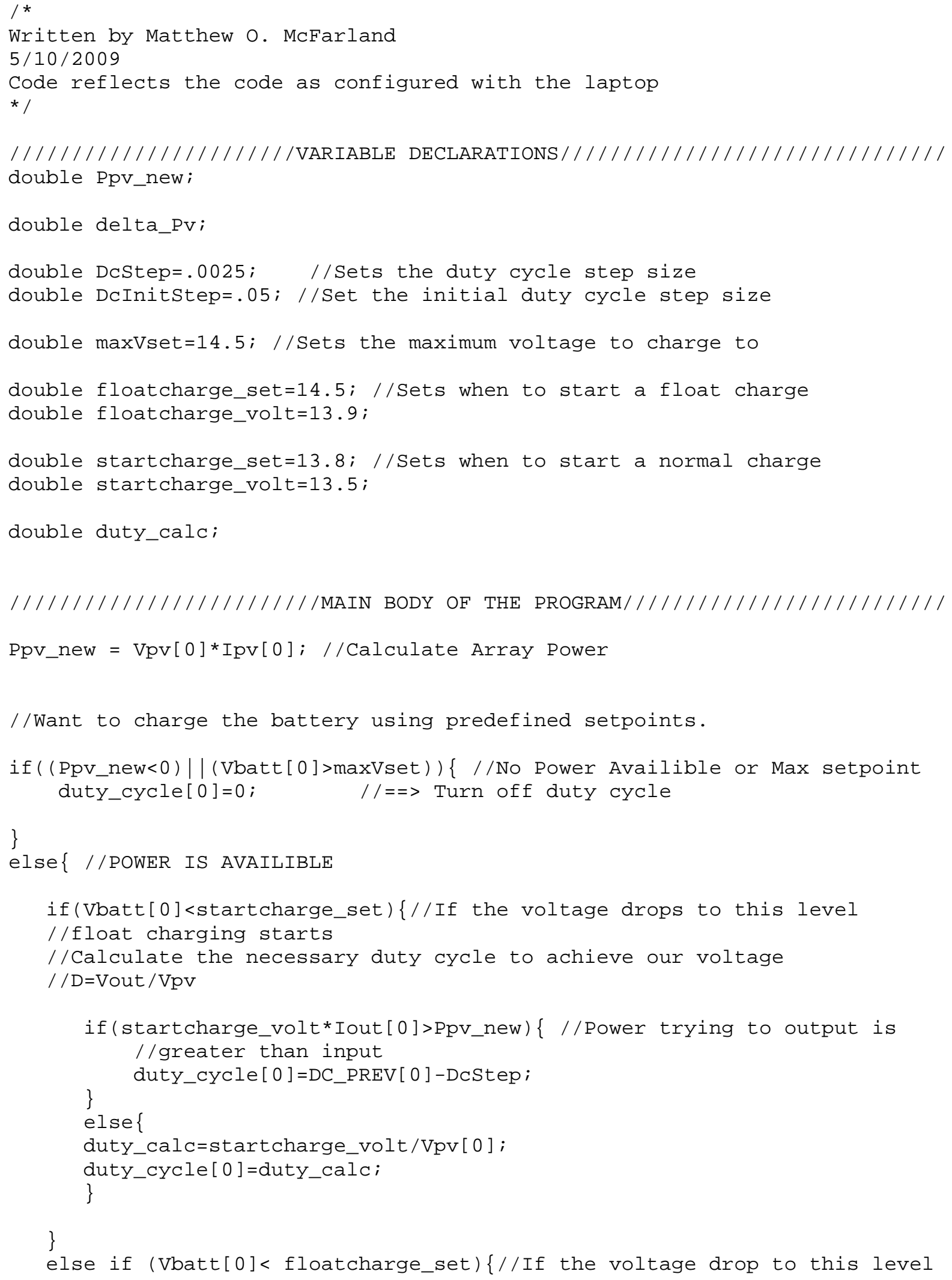




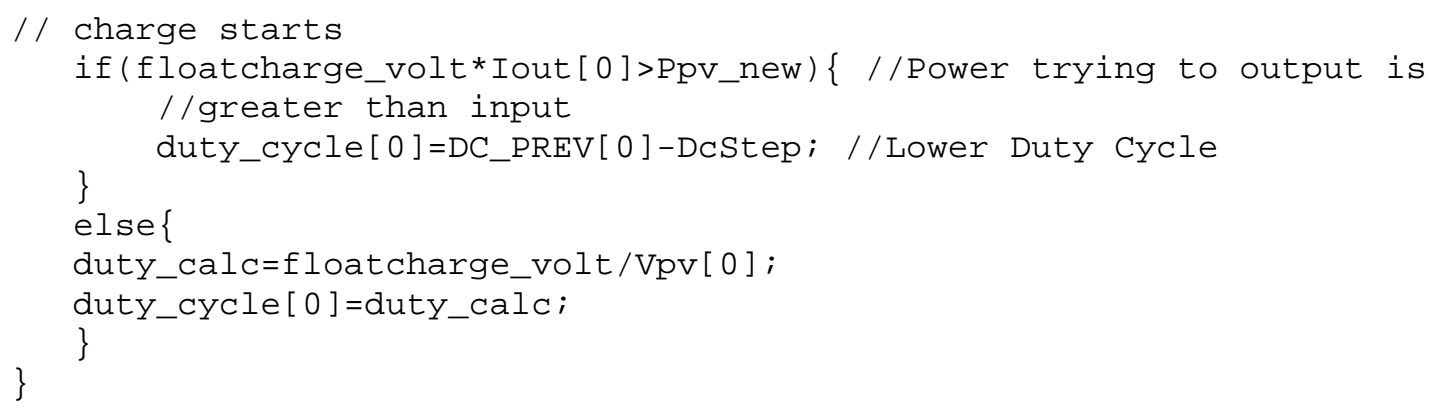




\section{Appendix F - Student Project Descriptions}

\section{1) White light LED load system}

White LEDs offer an efficient way to bring lighting into an area that now has some sort of battery supply, like on the SuPER cart. This project will require somebody to continue the work completed by Joseph Zukowki on a white LED load for the SuPER cart. Maximum efficiency requires that an LED maintains a certain constant current, so this system needs to account for even the smallest voltage drops in a length of wire. The student may investigate different possible methods, but a series implementation may be best. The LEDs should have proper thermal management and be modeled to allow for a more accurate system simulation.

\section{2) SuPER Controller (2 student project)}

The SuPER Controller will be developed on a microcontroller and keep the system in a healthy operating state. This will entail writing embedded $\mathrm{C}$ code to port over previously working software from a Linux system. All the supplies and development tools will be available to begin work on this. This controller will have to interface to other student projects, so it will be good real world experience for working on a team-oriented embedded system project. Some of the features to be implemented include pulse width modulation

(PWM), $\mathrm{I}^{2} \mathrm{C}$ communication, and controlling MOSFET switches. This board and the digitizer board will be laid out on one PCB. Therefore, this group will need to work with the printed circuit board and digitizer groups. Development could be done on the 100-pin Explorer 16 Development Board with MA240014 microcontroller PIM and USB PICtail Plus Daughter Board for USB programming. 


\section{3) SuPER Digitizer}

The digitizer board will be responsible for turning analog data (voltage, temperature, and current) values into digital data to transmit over the $\mathrm{I}^{2} \mathrm{C}$ bus. This will allow the system to gather measurements from further away without running into noise problems that corrupt the values. Development will be done on the same microcontroller as the controller board, so initial work may be as a team to get things started. The technical challenge here will be to receive commands from the controller, use up to 19 analog to digital (A/D) converters, and send the data back to the controller over $\mathrm{I}^{2} \mathrm{C}$. This board and the controller board will be laid out on one PCB. Therefore, this group will need to work with the printed circuit board and controller groups. Development could be done on the 100-pin Explorer 16 Development Board with MA240014 microcontroller PIM.

\section{4) Modularized PCB for Controller and Digitizer Boards}

Printed circuit boards (PCBs) will need to be designed for the controller and digitizer boards. The controller and digitizer functionality will be designed onto one PCB. This will make the PCB larger, but having the union of their functionality reduces part count. This project will need to work closely with the students working on the controller and digitizers to ensure that the hardware is laid out appropriately. To make sure that the microcontrollers A/D converters receive voltages that have a full swing, external voltage scaling components will need to be added to the digitizer PCB. The controller will need connections for an SD memory card and a USB port. Custom connectors will be designed to make the board as easy 
to repair in the field as possible. There will be resources needed to design these PCBs, test them, and then send them back to be reworked if needed.

\section{5) Data logging on SD memory card}

The voltage, temperature, and current measurements will need to be stored in the system for an extended period of time to allow the user to view past performance. This will be accomplished by interfacing an SD memory card to the controller board. A serial peripheral interface (SPI) will be used. It will be ideal to create a read/write interface between the microcontroller and SD card. The measurements will need to be time-stamped and stored to allow future retrieval.

\section{6) User interface on laptop with connection to microcontroller USB port}

To allow a user to view the system performance, a graphical user interface (GUI) will be developed to interact with the system. With this GUI running on a laptop, it can be taken out to the field and plugged into the SuPER system to allow the user to view real-time data or past performance. The GUI can be written in any language ( $\mathrm{C}$ or a close derivative preferred) as long as it allows communication over USB. This project will also work with the controller group to develop a way of allowing the GUI to connect to the system.

\section{7) Model battery performance in an environmental chamber}

This project will be an investigation into how an environmental chamber can extend a battery's life and how that sort of system can be controlled. When batteries get too hot their life expectancy and performance degrades, so placing it inside a thermally controlled 
chamber may extend its useful life. It will need to be determined how the battery can be placed inside an environmental chamber, how the chamber can be controlled by software, and which measurements will be needed to achieve this. A model will also be developed to integrate into the SuPER simulation to better understand how this will change system performance.

\section{8) Enclosures and packaging for the SuPER system}

The SuPER system will be exposed to the elements year-round, so to ensure the expected 20 year lifespan, all of the components need the appropriate packaging. A heavy focus of this project will be enclosures for the electronic systems to protect them from water, heat, and dirt. The entire system layout will need to be redesigned because the next generation SuPER cart will be a different shape and much smaller. There will also be safety issues involved here, as the entire system will need to be safe for operators in the field.

\section{9) Integration and control of wind turbine}

The SuPER system currently relies on solar insolation as the means of energy generation, but there are multiple times during the course of a day when it isn't available. Nighttime and cloudy days make the PV panel nearly useless, but in many locations there is wind blowing all day. This project is to integrate a wind turbine into the SuPER system. It will need its own control software and a new DC-DC converter to be designed. 


\section{0) System reliability model}

The current system reliability model will need to be updated to help extend the system's lifetime to 20 years. The current reliability model is very general and uses information gathered from various sources. It would be more beneficial to have field testing data or higher order models used in fine-tuning the system reliability parameters. With this new information, a maintenance plan could be developed including how to deal with spare parts once the system is deployed. A new model could also prove useful during phase 2 design and manufacture by increasing various subsystem reliabilities.

\section{1) Microgrid and DC-DC converter design (Masters)}

The SuPER system generates and stores a good amount of energy, but it would be more ideal to have a way of distributing that power throughout a small village. The idea of a microgrid can be used to have a $160 \mathrm{~V}$ transmission system within the village. The higher voltage will reduce transmission losses, but this also requires the design of DC-DC converters to step up the voltage on one end and down on the other. The converters will need to be designed, modeled, and then tested with the SuPER system. Safety issues will also need to be investigated with this high voltage transmission line.

\section{2) System Test and Integration (Masters)}

Once all of the subsystems for SuPER have been built they will need to be put together. To ensure that each subsystem performs up to its expectations it will need to be tested and integrated with the other subsystems. Depending on when other Cal Poly students complete 
work on SuPER for the previously listed projects, this Masters level thesis would focus on integration into a complete and field testable model. The recommendations from this thesis would need to be reviewed and surely other system level design decisions would need to be made. 
Appendix G - MTBF Parameters

Table G-1 - System Reliability Parameters and Sources

\begin{tabular}{|c|c|c|c|c|c|c|}
\hline Part & Quantity & $\begin{array}{l}\text { Component } \\
\text { MTBF (hrs) }\end{array}$ & $\begin{array}{l}\text { Component } \lambda \\
\text { (failures / } \\
1000000 \mathrm{hrs} \text { ) }\end{array}$ & $\begin{array}{l}\text { Subsystem } \\
\text { MTBF } \\
\text { (hrs) }\end{array}$ & $\begin{array}{l}\text { Subsystem } \lambda \\
\text { (failures / } \\
1000000 \mathrm{hrs} \text { ) }\end{array}$ & \\
\hline \multicolumn{6}{|c|}{ PV Panel } & \\
\hline \multicolumn{7}{|c|}{ Ultra-Capacitor } \\
\hline 58F Ultra-capacitor & 1 & 87600 & 11.415525 & 87600 & 11.415525 & $\begin{array}{l}10 \text { years based on Tecate Group } \\
\text { PBD- } 58 / 16.2 \mathrm{M} \text { ultra-capacitor } \\
\text { datasheet }\end{array}$ \\
\hline $\begin{array}{r}\text { FR-4 PCB with } \\
\text { through-hole } \\
\text { soldering }\end{array}$ & 1 & 105042018 & 0.009520 & & & $\begin{array}{r}\text { PWB/Tech:PrintedWiringAssembli } \\
\text { es/\#ckt } \\
\text { Planes=2/Qual=Lower/WAVE=0/H } \\
\text { AND=20/EquipType:Automotive/S } \\
\text { ubstrate:SR-4 } \\
\text { Laminate/SolderJointHeight=5mils/ } \\
\text { DesignLifeCycle=20 years }\end{array}$ \\
\hline
\end{tabular}


Table G-1 (continued)

\begin{tabular}{|c|c|c|c|c|c|c|}
\hline $\begin{array}{r}\text { IRF3205ZPBF } \\
\text { Mosfet } \\
\end{array}$ & 2 & 2266001 & 0.441306 & & & $\begin{array}{r}\text { LFtransistor/Style:FET_SI_MOSF/ } \\
\text { PowerRating: 50W/App: } \\
\text { PowerFET/Quality: LOWER/ } \\
\text { JC=0.75 Pd=1/Lead: Non } \\
\text { SMT/Dist: } 10 \mathrm{mil}\end{array}$ \\
\hline $\begin{array}{r}\text { MBR2045CTPBF } \\
\text { Diode }\end{array}$ & 2 & 24180984 & 0.041355 & & & $\begin{array}{l}\text { LFDiode/Style:Diode_SI/App:Scho } \\
\text { ttkyPower/Constr:Bonded/Qual:LO } \\
\text { WER/DeltaTj=150/VSR=.2/Vappl= } \\
.2 / \text { Vrate=1/Lead:NonSMT/Dist=1m }\end{array}$ \\
\hline SBR2060CT Diode & 1 & 157059350 & 0.006367 & & & $\begin{array}{l}\text { LFDiode/Style:Diode_SI/App:Swit } \\
\text { ching/Constr:Bonded/Qual:LOWE } \\
\text { R/DeltaTj=100/VSR=.2/Vappl=.2/ } \\
\text { Vrate=1/Lead:NonSMT/Dist=1mil }\end{array}$ \\
\hline $\begin{array}{r}\text { IHV15BJ500 } \\
\text { Inductor }\end{array}$ & 1 & 7464951474 & 0.000134 & 1019012 & 0.981343 & $\begin{array}{r}\text { Inductive/Type:Coil,Fixed } \\
\text { Inductor/COILS:Lower/T.raise=5/L } \\
\text { ead:NonSMT/Dist=20mils }\end{array}$ \\
\hline
\end{tabular}


Table G-1 (continued)

\begin{tabular}{|c|c|c|c|c|}
\hline \multicolumn{5}{|c|}{ Printed Circuit Assembly } \\
\hline $\begin{array}{r}\text { FR-4 PCB with } \\
\text { through-hole and } \\
\text { SMT soldering } \\
\end{array}$ & 1 & 9010957 & 0.110976 & $\begin{array}{l}\text { PWB/Tech:PrintedWiringAssembli } \\
\text { es/\#ckt } \\
\text { Planes=2/Qual=Lower/WAVE=44/ } \\
\text { HAND=230/EquipType:Automotiv } \\
\text { e/Substrate:SR-4 } \\
\text { Laminate/SolderJointHeight=5mils/ } \\
\text { DesignLifeCycle=20 years }\end{array}$ \\
\hline Microprocessor & 1 & 23091360 & 0.043306 & $\begin{array}{l}\text { From 4th Quarter } 2009 \text { PIC24 } \\
\text { Reliability Report }\end{array}$ \\
\hline $\begin{array}{r}\text { HUF75645S3ST } \\
\text { MOSFET Switch } \\
\end{array}$ & 10 & 887204 & 1.127136 & $\begin{array}{l}\text { LFTransistor/Style:FET_SI_MOSF/ } \\
\text { PowerRating:310W/App:PowerFE } \\
\text { T/Qual:LOWER/ThetaJC=0.48/Pd= } \\
\text { 4/Lead:NonSMT/Dist=10mil }\end{array}$ \\
\hline SD Memory Card & 1 & 1000000 & 1.000000 & $\begin{array}{l}\text { From SanDisk SD memory card } \\
\text { specifications }\end{array}$ \\
\hline $\begin{array}{r}\text { LM324 Quad Op } \\
\text { Amp } \\
\end{array}$ & 5 & 759000000 & 0.001318 & $\begin{array}{l}\text { From Texas Instruments LM324D } \\
\text { Quad Op-Amp Reliability Data }\end{array}$ \\
\hline Assorted Resistors & 40 & 337287569 & 0.002965 & $\begin{array}{l}\text { Resistor/Style:RC/Qual:Commercia } \\
\text { 1/Poper=0.01/Prat=0.5/Lead:NonS } \\
\text { MT/Dist=1mil }\end{array}$ \\
\hline $\begin{array}{l}\text { 5V Voltage } \\
\text { Regulator }\end{array}$ & 1 & 759000000 & 0.001318 & $\begin{array}{l}\text { From Texas Instruments UA7805 } \\
\text { 5V Regulator Reliability Data }\end{array}$ \\
\hline
\end{tabular}


Table G-1 (continued)

\begin{tabular}{|r|r|r|r|l|l|l|}
\hline $\begin{array}{r}\text { 3.3V Voltage } \\
\text { Regulator }\end{array}$ & & & & & & $\begin{array}{l}\text { From Texas Instruments } \\
\text { TPPM0110 3.3V Regulator } \\
\text { Reliability Data }\end{array}$ \\
\hline $\begin{array}{r}\text { ACS758LCB-050 } \\
\text { Current Sensor }\end{array}$ & 8 & 8000000000 & 0.000250 & & $\begin{array}{l}\text { From Texas Instruments } \\
\text { DRV401AIDWP Current Sensor } \\
\text { Reliability Data }\end{array}$ \\
\hline $\begin{array}{r}\text { RTD Temperature } \\
\text { Sensor }\end{array}$ & & & & & & \\
\hline
\end{tabular}




\section{Appendix H - Getting Started with the SuPER Project}

The information given in this thesis is a guideline for implementation of the SuPER system, but it is not a cookbook for completing the subsystems. Students that start working on one of these subsystems should use this paper as a guide for helping them complete their senior

project or thesis. Before any work is done, the student should understand what the SuPER system is and have a general idea of its subsystems. Next, they should know how the particular subsystem they decide to work on is integrated into the entire system. This includes the hardware and software interfaces between it and its adjoining subsystems. Once this information is understood, the student should begin work on their own subsystem. It is not a project meant to be worked on in isolation either. They should work closely with their advisor and other SuPER team members to understand how it fits in to the entire system architecture. Any modifications to the subsystem that affect how it interacts with other subsystems should be documented for future project members. The information given throughout this paper is a guideline and the actual hardware or software solution is up to the student to decide.

Reading the section "SuPER Phase 2 Design" in this paper will give a good overview of how the subsystems of SuPER are laid out. The section Sub-System Interfacing will contain the main information needed for designing the solution to each subsystem project. Most of the subsystems will require a software implementation which can be found in the section "SuPER Software". The chosen solution should be tested to ensure that it meets the requirements laid out for it and will integrate with the system as a whole when all projects are completed. The FMEA in the reliability analysis section should also be briefly reviewed to ensure that major failure modes are avoided during design. 


\title{
Appendix I - Analysis of Senior Project Design
}

Project Title: Systems Engineering Analysis and Digital Communication Bus Design for the Cal Poly SuPER Project

\author{
Student's Name: Matt Camack Student's Signature: \\ Advisor's Name: Dr. James Harris Advisor's Initials: Date:
}

\section{Summary of Functional Requirements:}

My project is a new system design for the Cal Poly SuPER project. This phase 2 design looks at how the system can be modified to reach its goal of a 20 year lifespan for $\$ 500$ total system cost. This project lays out the sub system designs that will be needed for building a more reliable system. Systems engineering analyses were performed to help mitigate risk and reduce failures.

\section{Primary Constraints:}

The major constraints for doing this phase 2 design were cost and reliability. A complex system like SuPER has many parts, so they need to be chosen carefully to ensure it reaches its 20 year lifetime. Reducing the part count was another way of driving down costs while increasing reliability because buying in bulk is cheaper and similar components are easier to replace and repair.

\section{Economic:}

The cost of the SuPER system before my design is estimated at $\$ 3008.21$ and after my redesign it is down to $\$ 2746.47$. My design does not have a schedule for manufacturing, but I estimate that with a team of about 15 students it could be completed within a single school year. I have no basis for the actual development time besides the number of subsystems to complete and their complexity.

\section{If manufactured on a commercial basis:}

The market for the SuPER system is outside the United States and demand in numbers is not known. The goal for the system is to have a price of $\$ 500$ that will make it affordable for underdeveloped areas in remote regions of the world. Right now the prototype costs $\$ 2746.47$ to manufacture, but that price would go down significantly with my phase 2 design and if multiple units were built. There is no profit margin for the SuPER system. Costs to operate the device are also unknown at this time until a system maintenance plan is developed in the future.

\section{Environmental:}

There are no known environmental impacts.

\section{Manufacturability:}

The major manufacturing challenge will be to produce enough units in bulk to drive down the overall system cost. Most of the components are commercial off the shelf devices which are 
readily available. In house developed components will require more effort to manufacture in bulk.

\section{Sustainability:}

This project contains sustainable in its title and its goal is to provide clean sustainable energy to remote areas of the world. One concern is that the system battery will need to be replaced at least a few times throughout the life cycle of the project. Proper disposal will be needed to ensure that this does not harm the environment. As solar panel efficiency increases the system will take better advantage of the solar radiation coming to Earth. The system may need upgraded components if it is to handle this greater energy distribution. Lighting will be a major use of power in remote areas and with increases in the efficiency of white LEDs the system could become more sustainable in its energy usage.

\section{Ethical:}

It is ethically responsible to have developed nations like ours commit some time and energy to helping those areas of the world that need it most. The SuPER project was created for this reason, not for profit, and will be of tremendous use to developing nations.

\section{Health and Safety:}

This project has the potential to bring human beings into contact with high voltage electronics. Proper packaging needs to be developed to ensure that humans are not harmed by the power distribution throughout the system.

\section{Social and Political:}

There are no planned social or political issues with the SuPER system. It would be ideal, however, for the system to eventually have widespread use in changing the lives of people within societies for the better.

\section{Development:}

I learned how to use a variety of systems engineering tools for analyzing the system. These include mean time between failure (MTBF) calculators for determining system reliability, failure modes and effects analyses (FMEA) for finding potential failures and preventing them, and requirements breakdown analysis that helped create well defined subsystems. 